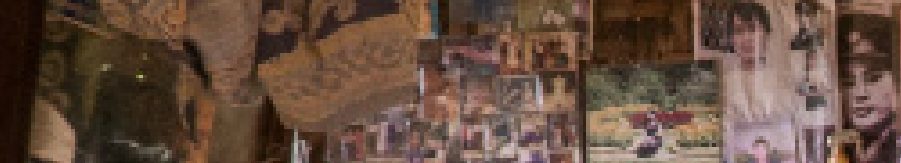
1.

3. 40 की

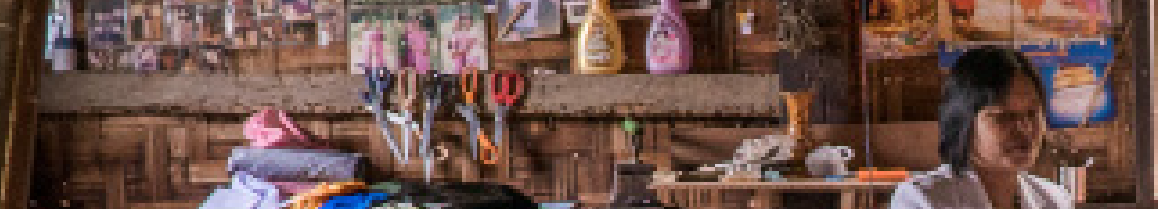

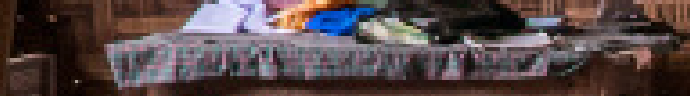

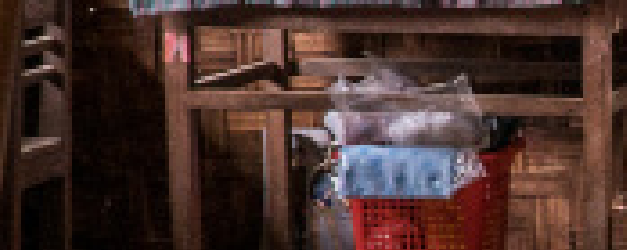

REGIONAL MALARIA AND OTHER COMMUNICABLE

DISEASE THREATS

TRUST FUND

FINAL REPORT

NOVEMBER 2018 


\section{REGIONAL MALARIA AND OTHER COMMUNICABLE DISEASE THREATS TRUST FUND}

FINAL REPORT

NOVEMBER 2018 


\section{REGIONAL MALARIA AND OTHER COMMUNICABLE DISEASE THREATS TRUST FUND}

KEY ACHIEVEMENTS

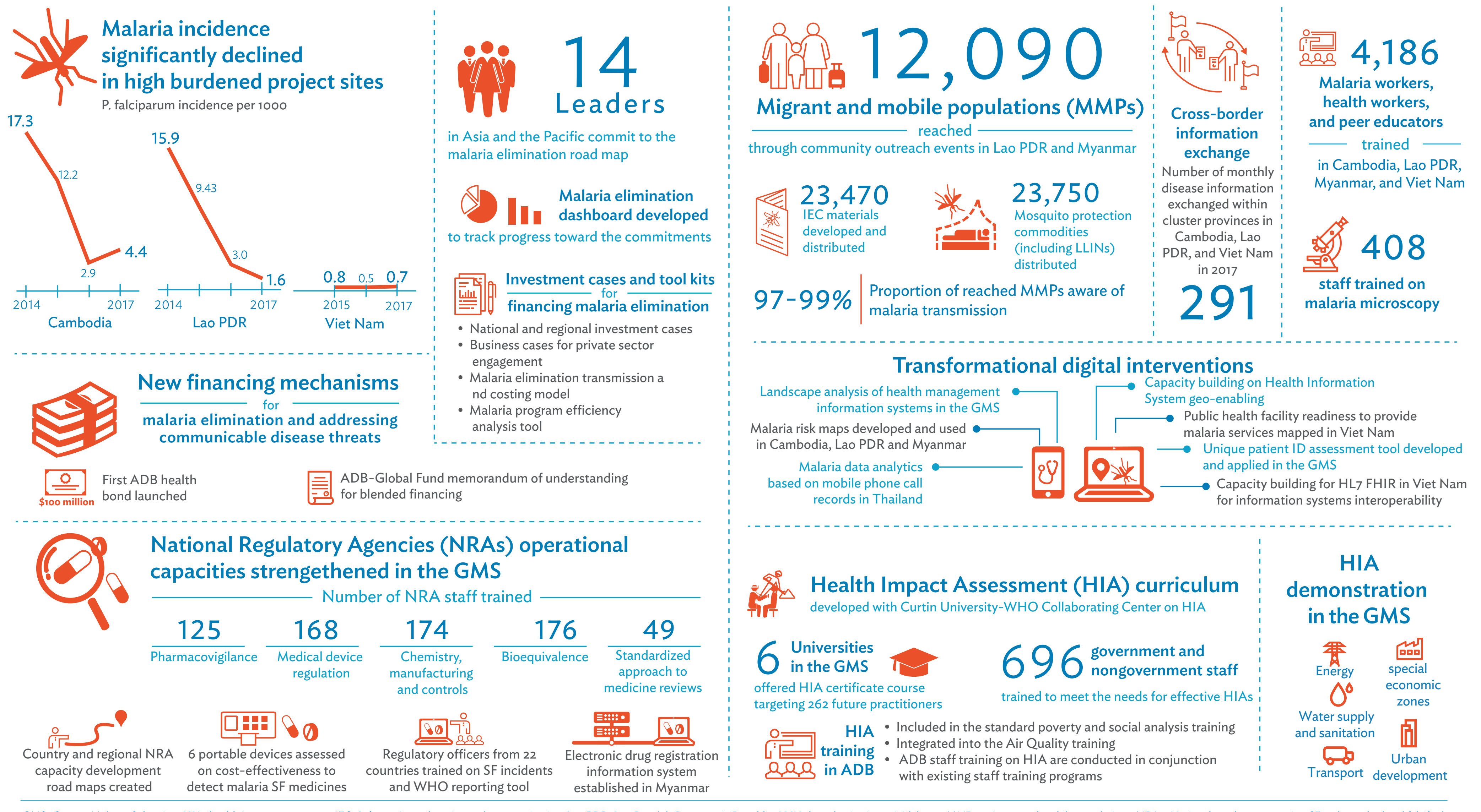

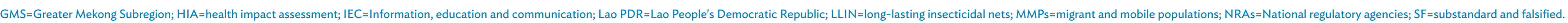


(C) 2018 Asian Development Bank

6 ADB Avenue, Mandaluyong City, 1550 Metro Manila, Philippines

Tel +632632 4444; Fax +6326362444

www.adb.org

Some rights reserved. Published in 2018.

ISBN 978-92-9261-364-8 (print), 978-92-9261-365-5 (electronic)

Publication Stock No. TCS189605-2

DOI: http://dx.doi.org/10.22617/TCS189605-2

The views expressed in this publication are those of the authors and do not necessarily reflect the views and policies of the Asian Development Bank (ADB) or its Board of Governors or the governments they represent.

ADB does not guarantee the accuracy of the data included in this publication and accepts no responsibility for any consequence of their use. The mention of specific companies or products of manufacturers does not imply that they are endorsed or recommended by ADB in preference to others of a similar nature that are not mentioned.

By making any designation of or reference to a particular territory or geographic area, or by using the term "country" in this document, $A D B$ does not intend to make any judgments as to the legal or other status of any territory or area.

This work is available under the Creative Commons Attribution 3.0 IGO license (CC BY 3.0 IGO)

https://creativecommons.org/licenses/by/3.o/igo/. By using the content of this publication, you agree to be bound by the terms of this license. For attribution, translations, adaptations, and permissions, please read the provisions and terms of use at https://www.adb.org/terms-use\#openaccess

This CC license does not apply to non-ADB copyright materials in this publication. If the material is attributed to another source, please contact the copyright owner or publisher of that source for permission to reproduce it. $\mathrm{ADB}$ cannot be held liable for any claims that arise as a result of your use of the material.

Please contact pubsmarketing@adb.org if you have questions or comments with respect to content, or if you wish to obtain copyright permission for your intended use that does not fall within these terms, or for permission to use the ADB logo.

Notes:

In this publication, "\$” refers to United States dollars.

ADB recognizes "China" as the People's Republic of China and "Hanoi" as Ha Noi.

Corrigenda to ADB publications may be found at http://www.adb.org/publications/corrigenda 


\section{CONTENTS}

Tables and Figures

vii

Acknowledgments

viii

Abbreviations

ix

Executive Summary

$\mathrm{xi}$

1. Introduction

From Control to Elimination

Asian Development Bank and Malaria Elimination

Leadership, Collaboration, Innovation

The Structure of the Regional Malaria and Other Communicable Disease Threats Trust Fund

2. Fund Utilization and Management

3. Results by Outcome $r$

$\begin{array}{lr}\text { Outcome 1: Leadership } & 9\end{array}$

Rationale

Asia Pacific Leaders Malaria Alliance Support 11

Investment Cases $\quad 11$

Enabling Factors $\quad 12$

Next Steps and Sustainability Pathway 12

Outcome 2: Financing $\quad 13$

Rationale $\quad 14$

Mobilizing Financing 14

Landmark Collaboration $\quad 14$

Enabling Factors $\quad 15$

Next Steps and Sustainability Pathway $\quad 15$

$\begin{array}{ll}\text { Outcome 3: Medicines } & 16\end{array}$

Rationale $\quad 17$

Regulatory Systems Strengthening 17

Medicines Safety 18

Malaria Medicines Field Testing 18

Myanmar Regulatory Reform 19

$\begin{array}{ll}\text { Enabling Factors } & 19\end{array}$

Next Steps and Sustainability Pathway 19 
Outcome 4: Information Systems

Rationale $\quad 22$

Landscape Analysis $\quad 23$

Malaria Surveillance $\quad 23$

Geospatial Technology $\quad 23$

Policy and Strategy $\quad 24$

Investment Guidance $\quad 24$

Viet Nam $\quad 25$

Enabling Factors $\quad 25$

Next Steps and Sustainability Pathway 26

Outcome 5: Laboratory Diagnostics and Surveillance 27

Rationale $\quad 28$

Communicable Disease Control 2 - Additional Financing 31

Laboratory Quality Assurance and Malaria Surveillance in Myanmar 31

Migrant and Mobile Populations $\quad 31$

Enabling Factors $\quad 32$

Next Steps and Sustainability Pathway $\quad 32$

Outcome 6: Promotion and Prevention 34

Rationale $\quad 35$

Malaria Prevention in Infrastructure Development 35

Case Study in Urban Development Project $\quad 35$

Case Studies in Special Economic Zones and Border Development 35

Curriculum Development and Training

Regulations and Guidelines $\quad 37$

Enabling Factors $\quad 38$

Next Steps and Sustainability Pathway 38

4. Knowledge Products and Publications 39

5. Gender Dimensions $\quad 41$

6. Annex $\quad 42$

Annex A. RMTF Results-Based Framework 42

Annex B. Glossary of Results-Based Framework Terms

Annex C. Gender Dimensions

Annex D: Finance $\quad 82$

Annex E. RMTF Recommendations for Management of Future Trust Funds 83 


\section{TABLES AND FIGURES}

\section{TABLES}

1 Results of Outcome 1.1

2 Results of Outcome 1.2

3 Results of Outcome 2

4 Results of Outcome 3.1

5 Results of Outcome 3.2

6 Results of Outcome 4

7 Results of Outcome 5.1

8 Results of Outcome 5.2

9 Results of Outcome 5.3

10 Results of Outcome 5.4

11 Results of Outcome 6.1

12 Results of Outcome 6.2

\section{FIGURES}

1 The RMTF Ecosystem 2

2 Cambodia - Malaria Incidence per 1,000 population 2

3 Lao PDR - Malaria Incidence per 1,000 population 3

4 Viet Nam - Malaria Incidence per 1,000 population 3

5 Projects of the Regional Malaria and Other Communicable Disease Threats Trust Fund 5 


\section{ACKNOWLEDGMENTS}

Report preparation led by Susann Roth and Jane Parry, supported by Rosebelle May Azcuna, Liza Tabora, Randolph Dacanay, and Editha Santos. Graphic design and layout led by Keisuke Taketani.

Financing partners: The Government of Australia (Department of Foreign Affairs and Trade); the Government of Canada (Department of Foreign Affairs, Trade and Development); and the Government of the United Kingdom (Department for International Development). 


\section{ABBREVIATIONS}

\begin{tabular}{|c|c|}
\hline ADB & Asian Development Bank \\
\hline ADF & Asian Development Fund \\
\hline AeHIN & Asia eHealth Information Network \\
\hline APLMA & Asia Pacific Leaders Malaria Alliance \\
\hline $\mathrm{AOP}$ & annual operational plan \\
\hline APMEN & Asia Pacific Malaria Elimination Network \\
\hline CDC & communicable disease control \\
\hline CoRE & Centre of Regulatory Excellence \\
\hline CSO & civil society organization \\
\hline DFAT & Department of Foreign Affairs and Trade, Australia \\
\hline DFID & Department for International Development \\
\hline DFTAD & The Department of Foreign Affairs, Trade and Development \\
\hline DMC & developing member country \\
\hline DMS & Data management system \\
\hline eCDS & electronic communicable disease surveillance \\
\hline eHealth & ICT in the health sector, also called "digital health" \\
\hline FDA & Department of Food and Drug Administration \\
\hline GAP & gender action plan \\
\hline GIS & geographic information system \\
\hline Global Fund/GFATM & The Global Fund to Fight AIDS, Tuberculosis and Malaria \\
\hline GMS & Greater Mekong Subregion \\
\hline HIA & health impact assessment \\
\hline $\mathrm{HIE}$ & health information exchange \\
\hline HIGAF & health ICT governance architecture framework \\
\hline HINARI & HINARI Access to Research in Health Programme \\
\hline HIS & health information system \\
\hline HISP & Health Information Systems Programme \\
\hline HL7-FHIR & HL7 Fast Healthcare Interoperability Resources \\
\hline ICT & information and communication technology \\
\hline IEC & information, education and communication \\
\hline IOM & International Organization for Migration \\
\hline IRIMS & integrated regulatory information management system \\
\hline LLIN & long lasting insecticidal nets \\
\hline LOMWRU & Lao-Oxford-Mahosot Hospital Wellcome Trust Research Unit \\
\hline$M \& E$ & monitoring and evaluation \\
\hline mDMS & Mobile data management system \\
\hline METCAP & Malaria Elimination Transmission and Costing in the Asia Pacific \\
\hline MMP & mobile and migrant populations \\
\hline $\mathrm{MOH}$ & Ministry of Health \\
\hline $\mathrm{MOHS}$ & Ministry of Health and Sports \\
\hline
\end{tabular}




\begin{tabular}{|c|c|}
\hline MORU & Mahidol Oxford Research Unit \\
\hline MOU & memorandum of understanding \\
\hline MPEAT & Malaria Program Efficiency Analysis Tool \\
\hline NMCP & National Malaria Control Programme \\
\hline NGO & nongovernment organization \\
\hline $\mathrm{NHL}$ & National Health Laboratory \\
\hline NRA & National Regulatory Agency \\
\hline $\mathrm{OCO}$ & Office of Cofinancing Operations \\
\hline Lao PDR & Lao People's Democratic Republic \\
\hline PHMP & Public Health Management Plan \\
\hline PMU & project management unit \\
\hline PNG & Papua New Guinea \\
\hline PPMU & provincial project management unit \\
\hline PRC & People's Republic of China \\
\hline RBF & results-based framework \\
\hline R-CDTA & regional capacity development technical assistance \\
\hline RECAP & $\begin{array}{l}\text { Results for Malaria Elimination and Control of Communicable Disease Threats in } \\
\text { Asia and the Pacific }\end{array}$ \\
\hline RMTF & Regional Malaria and Other Communicable Disease Threats Trust Fund \\
\hline RRP & Asia Pacific Regional Regulatory Partnership for Malaria Elimination \\
\hline RRT & Rapid response team \\
\hline SDG & Sustainable Development Goal \\
\hline SEARO & Regional Office for South-East Asia \\
\hline SERD & Southeast Asia Department \\
\hline SEZ & Special Economic Zone \\
\hline SF & substandard and falsified \\
\hline SOP & standard operating procedure \\
\hline TA & technical assistance \\
\hline TGA & Therapeutic Goods Administration, Australia \\
\hline UCSF/MEI & University of California, San Francisco Malaria Elimination Initiative \\
\hline $\mathrm{UHC}$ & universal health coverage \\
\hline URC & University Research Co. \\
\hline US & United States \\
\hline VMG & volunteer malaria group \\
\hline WHO & World Health Organization \\
\hline WPRO & Regional Office for the Western Pacific \\
\hline
\end{tabular}




\section{EXECUTIVE SUMMARY}

The Regional Malaria and Other Communicable Disease Threats Trust Fund (RMTF) was set up in December 2013. Its remit was to support multicountry, cross-border and multisector responses to urgent malaria and other communicable disease issues, with a focus on the countries of the Greater Mekong Subregion (GMS).

In 2015 the fund moved from supporting the control of malaria to eliminating the disease as a public health threat. This shift was in response to growing resistance to artemisinin-based combination therapy, which was emerging in four GMS countries: Cambodia, Myanmar, Thailand and Viet Nam. The rationale was that achieving elimination in Asia and the Pacific would prevent resistance reaching the African continent.

Over the next 5 years, the project funded projects under six broad domains: leadership, financing, medicines, information systems, laboratory diagnostics and surveillance, and promotion and prevention.

\section{Key achievements}

- Galvanized malaria elimination leadership at the highest level and provided decision support for accountability;

- Introduced innovative mechanisms for malaria elimination financing and donor collaboration;

- Supported regulatory and disease control bodies to work more effectively, strengthen post-market surveillance of anti-malarials, and to collaborate with regional counterparts;

- Convened partners within countries and across borders to work toward the common goal of eliminating malaria;

- Stimulated the appetite for transformational digital interventions and improved capacity, resulting in increased surveillance and automated reporting of malaria and communicable diseases;

- Strengthened the role of health impact assessment for malaria prevention in infrastructure projects and special economic zones in border areas.

The Department of Foreign Affairs and Trade (Australia) and Department for International Development (United Kingdom) contributions came to a close in June 2018, but in each of the six domains, a sustainability pathway was left in place to ensure that the results continue to resonate, that the governments of each country involved at different levels, together with donor agencies, nongovernment organizations and the private sector, can continue to build on what has been achieved. 


\section{GOVERNANCE STRUCTURE}

Regional Malaria and Other Communicable Disease Threats Trust Fund under the Health Financing Partnership Facility (HFPF)

HFPF Steering Committee Chair WooChong Um,

Director General, Sustainable Development and Climate Change Department (SDCC)

HFPF Steering Committee Members

Michael Barrow

Director General, Private Sector Operations Department

Hun Kim

Director General, South Asia Department

Amy Leung

Director General, East Asia Department

Ramesh Subramaniam

Director General, Southeast Asia Department (SERD)

Werner E. Liepach

Director General, Central and West Asia Department

Ma. Carmela D. Locsin

Director General, Pacific Department

Ayako Inagaki

Health Committee Chair, Director, Human and Social Development Division, SERD

FACILITY MANAGER

N.J. Ahmad

Deputy Director General, SDCC, concurrently Chief Compliance Officer

Robert Guild

Chief Sector Officer

Sustainable Development and Climate Change Department (SDCC)

\section{Health Sector Secretariat}

Patrick Osewe, Chief of Health Sector, Health Sector Group, Sector Advisory Service Cluster (SDSC-HEA)

Eduardo Banzon, Principal Health Specialist, SDSC-HEA

Susann Roth, Senior Social Development Specialist, SDSC-HEA

Sonalini Khetrapal, Health Specialist, SDSC-HEA

Kirthi Ramesh, Social Development Specialist, SDSC-HEA

Pura Angela Wee-Co, Associate Health Officer, SDSC-HEA

Honey May Manzano-Guerzon, Operations Analyst, SDSC-HEA

Wendy Nazal Montealto, Senior Operations Assistant, SDSC-HEA

OfFICE OF Cofinancing Operations (OCO)

Kai Preugschat, Head, OCO

Ilaria Caetani, Principal Financing Partnerships Specialist, OCO

Guenther Mate, Principal Financing Partnership Specialist, OCO

Marites Torres, Senior Financing Partnerships Officer, OCO

Katherine Barrameda, Financing Partnerships Officer, OCO

Trina Mari M. Raymundo-Samia, Financing Partnerships Analyst, OCO 


\section{INTRODUCTION}

\section{From Control to Elimination}

When the Regional Malaria and Other Communicable Disease Threats Trust Fund (RMTF) was set up in December 2013, its remit was to support, for a five-year period, the Asian Development Bank's (ADB) developing member countries (DMCs) to develop multicountry, crossborder, and multisector responses to urgent malaria and other communicable disease issues. In 2015 the fund moved from supporting the control of malaria to eliminating the disease through a process of strengthening health systems that would also have an impact on other communicable disease threats.

Two factors led to this decision: first, growing resistance to artemisinin-based combination therapy-the last line of simple-to-use and effective malaria drugs - had been detected in four countries of the Greater Mekong Subregion (GMS): Cambodia, Myanmar, Thailand, and Viet Nam.

Second, it became clear that with the right health systems' building blocks in place, eliminating malaria was technically feasible in Asia and the Pacific. Elimination, as defined by the World Health Organization (WHO), is "the interruption of local transmission (i.e., reduction to zero incidence of indigenous cases) of a specified malaria parasite species in a defined geographical area." Achieving this in Asia and the Pacific could prevent resistance reaching the African continent, where it would have devastating consequences and potentially reverse the gains in global malaria control made over the previous decade.
This shift in focus is aligned with the WHO Framework for Malaria Elimination, which calls on countries to put in place the tools and systems needed to reduce the disease burden of malaria and progress toward elimination as soon as possible. 'These interventions include enhancing and optimizing vector control and case management; increasing the sensitivity and specificity of surveillance; accelerating transmission reduction, and investigating and clearing individual cases. All of these were addressed under the RMTF.

In turn, the fund's activities tied in with the healthrelated Sustainable Development Goals (SDGs) and targets, in particular SDG Target 3.3: "by 2030, end the epidemics of AIDS, tuberculosis, malaria and neglected tropical diseases and combat hepatitis, water-borne diseases and other communicable diseases," and SDG target 3.8: "achieving UHC, including access to quality essential health-care services and safe, effective, quality and affordable essential medicines."

The GMS countries overall have made great progress in controlling malaria. Data from the ministries of health in the recent years show that the Lao People's Democratic Republic (Lao PDR) had an $85 \%$ decline in its malaria incidence from 7.2 in 2014 to 1.2 cases per 1,000 population in 2017. The malaria incidence in Viet Nam in 2014 was already low at 0.1 cases per 1,000 population but was further reduced by $40 \%$ in 2017. Cambodia had 3.1 malaria cases per 1,000 population in 2014 and was significantly reduced to 1.6 cases per 1,000 in 2016 . The country however experienced a surge in the number of malaria cases in 2017, which raised the incidence level back to 3.0 cases per 1,000.

WHO. 2017. A framework for malaria elimination. Geneva: WHO.

2 Sustainable Development Goal 3. https://sustainabledevelopment.un.org/sdg3 http://www.who.int/malaria/publications/atoz/9789241511988/en/ 


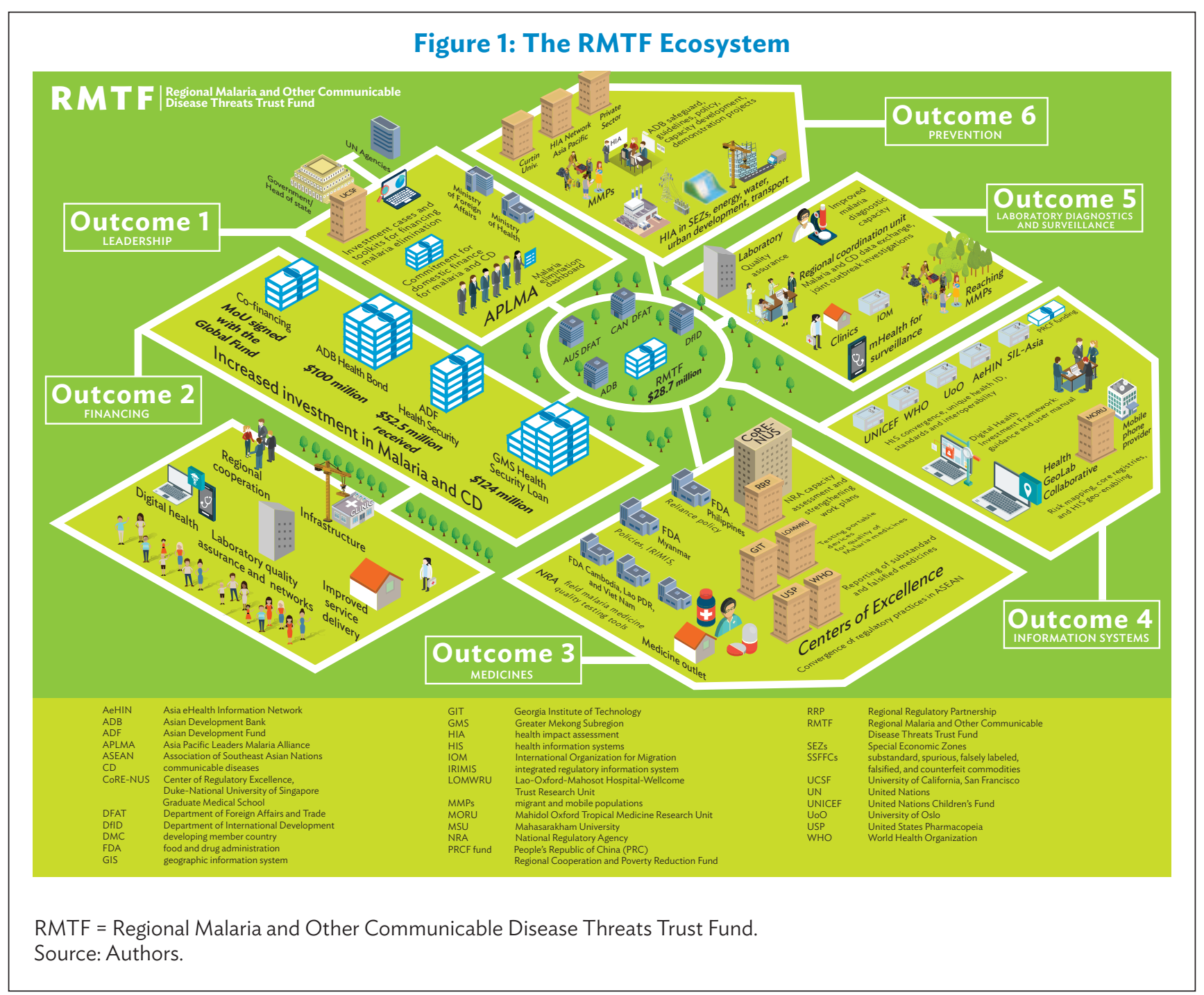

Malaria transmission in the GMS is mostly concentrated in hilly, forested areas, in border areas, and where forest goers and temporary migrants and seasonal workers reside. Such areas were targeted in the RMTF through the CDC2-AF. In the project sites of Cambodia, the malaria incidence of 31.3 cases per 1,000 in 2014, more than halved to 13.1 per 1,000 in 2017. In the Lao PDR project sites, malaria incidence was reduced by $86 \%$, from 31.1 in 2014 to 4.2 cases per 1,000 in 2017. The malaria incidence in the Viet Nam project sites was already low at 1.4 in 2015 but was further reduced to 1.0 cases per 1,000 in 2017.
Figure 2: Cambodia - Malaria Incidence per 1,000 population

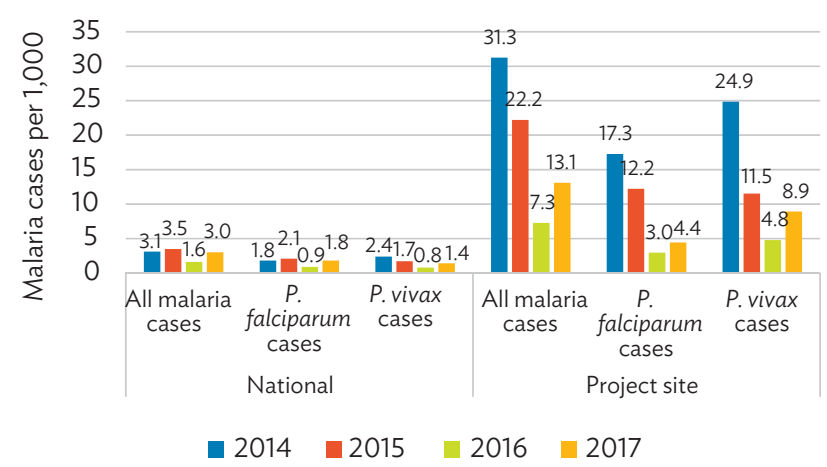

Source: Ministy of Health, Cambodia, provided August 2018. 
Figure 3: Lao PDR - Malaria Incidence per 1,000 population

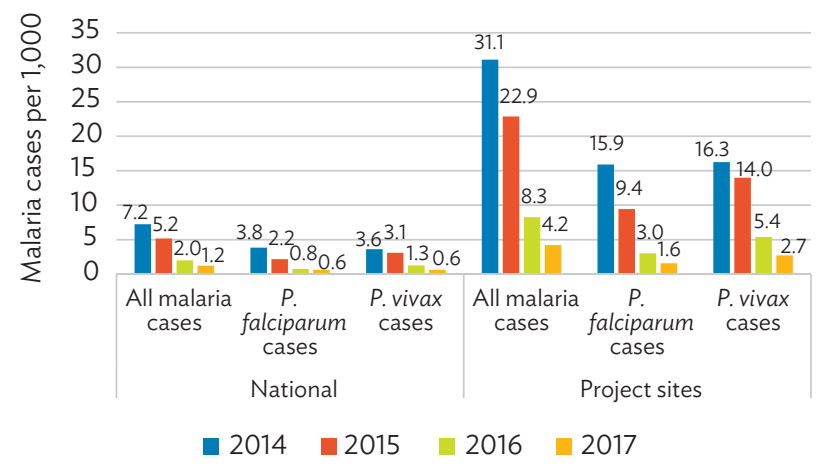

Lao PDR = Lao People's Democratic Republic

Source: Ministry of Health, Lao People's Democratic Republic, provided August 2018.

\section{Figure 4: Viet Nam - Malaria Incidence per 1,000 population}

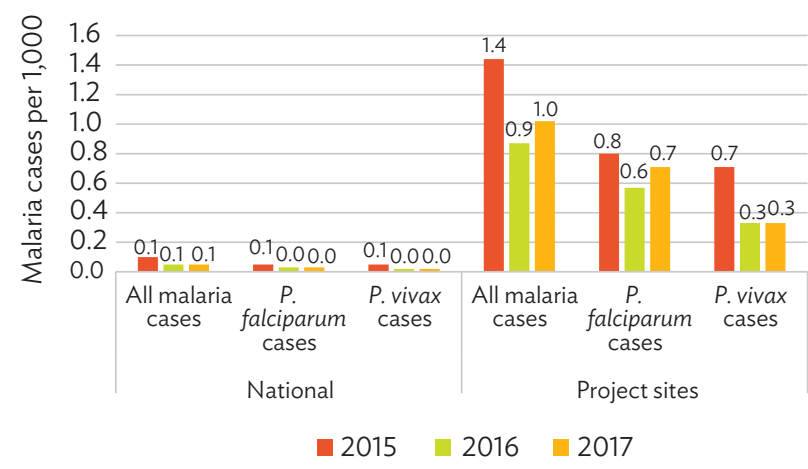

Source: Ministry of Health, Viet Nam, provided August 2018.

\section{Asian Development Bank and Malaria Elimination}

Health is an integral part of ADB's work, and under Strategy 2030, the bank's new strategy agenda, it is recognized as a key building block to achieve a prosperous, inclusive, resilient, and sustainable Asia and the Pacific, while sustaining its efforts to eradicate extreme poverty. ${ }^{3}$ With its background in supporting regional health security, coupled with its commitment to investing in health, ADB is in a good position to support malaria elimination by strengthening health systems in the region. ADB's established reputation and relationships with DMC governments, as well as its partnerships with other development agencies, the private sector, and civil society organizations (CSOs) have amplified the fund's impact.

Through engagement with $A D B, D M C$ s gain access to ADB's technical assistance (TA) and grant funding, as well as to loans and innovative ways for countries to finance health systems strengthening. The RMTF was useful in catalyzing impact for malaria, but entrusting funds to ADB for malaria elimination also led to a return on investment beyond this goal. Many governments and donors are looking at integrative health programs, and are reaching for ways to strengthen health systems, both nationally and regionally. ADB had identified an emerging trend in government demand for health financing, to leverage past successes in vertical disease programs and begin to focus on integrated health sector and systems development.

In response to increasing demand for new types of financing to support integrated health goals, including malaria elimination, ADB engaged with the Global Fund to Fight AIDS, Tuberculosis and Malaria and other development partners. Through this consultative process with partners, donors, and governments, it became clear that funding for programs like malaria elimination required a new approach. This new approach built upon the successes of the RMTF to target blended financing for health. Partners such as the Global Fund recognize their investments are much more impactful over the long term when paired with $A D B$ financing. This type of financing will also sustain results, such as strong health systems that prevent the reemergence of malaria.

\section{Leadership, Collaboration, Innovation}

The RMTF promoted political leadership on malaria elimination and related investments in health systems, including a higher level of sustainable domestic financing. It also mobilized more funds to tackle malaria and other communicable disease 
threats. Its projects contributed to the process of fostering more reliable supplies of quality medicines, improved data for evidence-based decision-making, and strengthened national malaria and other communicable disease threats programs.

Through its projects, RMTF advocated for a collaborative approach to malaria elimination that goes beyond the health sector and national governments to draw in the private sector, nongovernment agencies, and the donor community across multiple domains, with a focus on health systems strengthening, rather than on a single disease.

The fund's activities tackled malaria at multiple levels, from regional to national and subnational. For example, the fund boosted regional leadership on malaria elimination through its collaboration of the Asia Pacific Leaders Malaria Alliance (APLMA). RMTF projects also built regional learning networks for health impact assessment (HIA) of infrastructure projects, and in medicines regulation created a regional road map for regulatory systems strengthening. This in turn informed the work of a newly created Asia Pacific Regional Regulatory Partnership for Malaria Elimination (RRP). By providing additional financing to ADB's already well-established regional communicable disease control project, the fund was able to build on preexisting successes, especially related to financing activities and building capacity at the subnational level rather than starting from scratch to develop a regional health project.

At the national level, projects under the RMTF entailed widespread engagement with government ministries for policy dialog, advocacy, and planning, strengthening both capacity building and evidenceinformed decision-making. While national level action is key, many malaria elimination initiatives are most effective at the subnational level. The fund's projects include subnational level malaria and communicable disease reporting, laboratory systems strengthening, access to innovative information and communication tools, post-market medicines surveillance, outreach to underserved and marginalized populations, and local-level training. The fund also supported malaria-specific operational research.

\section{The Structure of the Regional Malaria and Other Communicable Disease Threats Trust Fund}

The RMTF funded a range of projects under six distinct outcomes: leadership, financing, medicines, information technology, laboratory diagnostics and surveillance, and promotion and prevention. It took as its starting point the theory of change structure of the Department for International Development (DFID) of the United Kingdom, which sought to address gaps in regional cooperation, sustainable financing for regional public goods in health, adequate incentives and institutions for the medicines supply chain, timely and reliable data, and effective program management.

Projects were then developed under each of the outcomes, deliberately tailored to the prevailing malaria and other communicable disease, and health system landscape in each country. This bespoke approach enabled the fund to best meet the needs of each country, rather than using an overly simplistic, one-size-fits-all approach. While development banks and donor agencies bring their own unique expertise to every project they fund, engaging implementing partners and coordinating within a crowded development partner landscape is crucial to the success of a project. ADB took a pragmatic approach to this, partnering with whatever agencies could best support each project, be they international nongovernment organizations (NGOs), CSOs, academic institutions, government agencies, or individual expert consultants. Taken together, these six pillars of the RMTF coalesced to form a health system strengthening approach, and the fund supported countries to reach for attainment of universal health coverage (UHC).

The RMTF financed regional capacity development technical assistance (R-CDTA), standalone projects, and grant components of investment to improve health outcomes and increase health security by reducing the risk of malaria and other communicable disease threats in Asia and the Pacific. 
The RMTF's financing partners were the

Government of Australia (Department of Foreign Affairs and Trade, \$15.8 million), the Government of Canada (Department of Foreign Affairs, Trade and Development, $\$ 0.5$ million), and the Government of the United Kingdom (DFID \$12.4m).
In total, the RMTF management has approved a total of $\$ 18.075$ million for five technical assistance projects, and $\$ 9.5$ million in additional financing for ADB's Second GMS Regional Communicable Diseases Project (CDC2) (Figure 5).

\section{Figure 5: Projects of the Regional Malaria and Other Communicable Disease Threats Trust Fund}

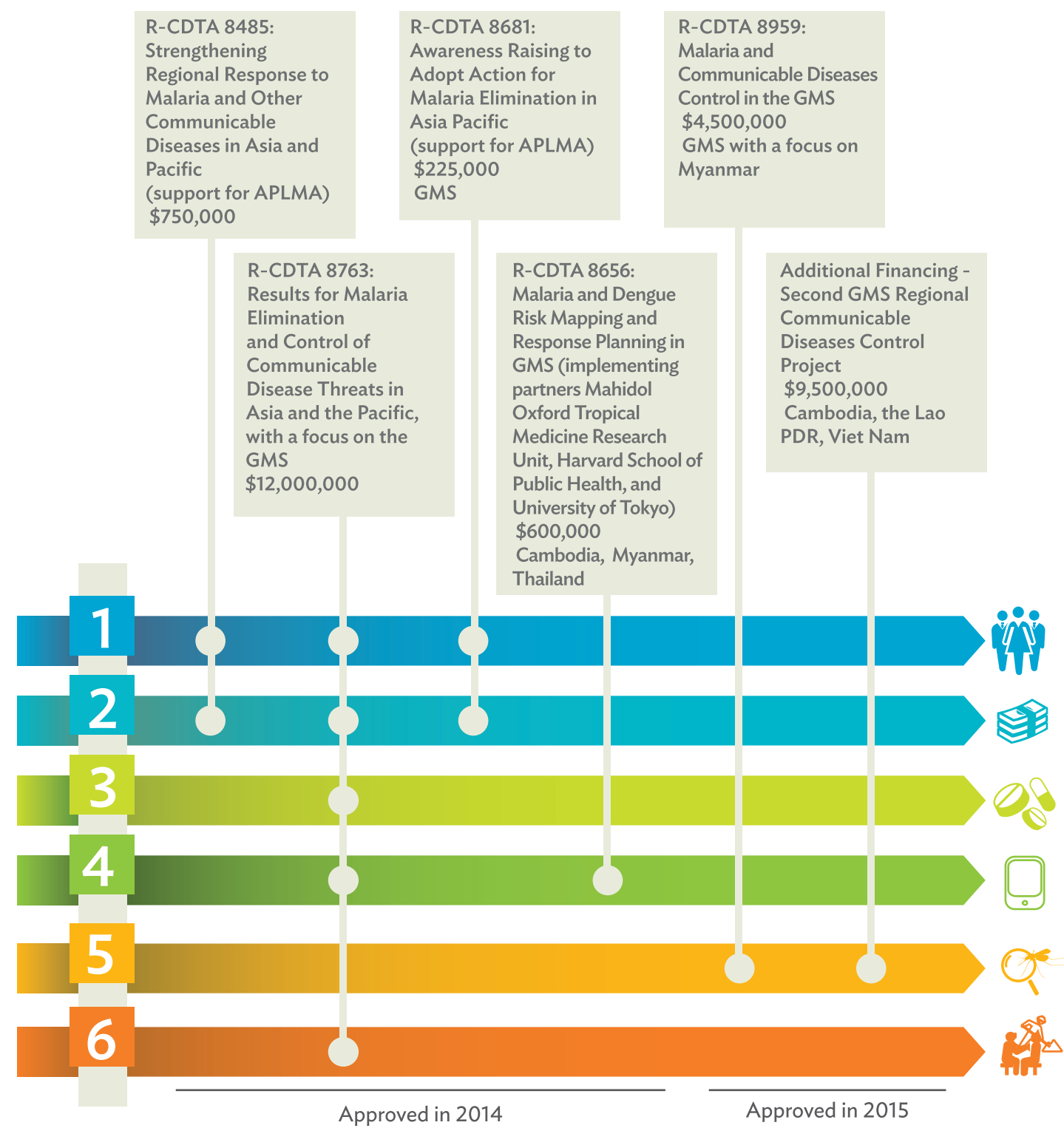

Source: Authors. 


\section{FUND UTILIZATION AND MANAGEMENT}

The donors' total investment of $\$ 28.70$ million and interest income of $\$ 316,764$ were used to mobilize consultants, procure equipment, provide malaria-specific health services, conduct workshops and training, and cover costs directly related to trust fund administration and management. Total support by the RMTF to specific activities of five technical assistance and three grant projects in the GMS countries amounted to $\$ 28.33$ million (Annex D). The bulk of the unspent balance of the RMTF, $\$ 685,703$, were savings from the planned activities of CDC2-Additional Financing which were not pursued based on the advice of the governments of Cambodia, the Lao PDR, and Viet Nam. It was agreed with The Department of Foreign Affairs, Trade and Development (DFATD) Canada that its contribution, amounting to $\$ 531,916$, can remain in the fund beyond 2018 and does not need to be returned. This leaves less than $\$ 150,000$ from the income earned from investments from the RMTF under the Department for International Development (DFID) of the United Kingdom and Department of Foreign Affairs and Trade, Australia (DFAT) contributions.

The ADB has reported quarterly to the donors on the status of RMTF utilization using a financial reporting system that is different from that used by the donors. Because the donors found ADB's reporting system complicated, a financial dashboard was designed for donors' easy understanding. The RMTF financial dashboard is an RMTF financial management tool that visually summarizes the quarterly comparative trends of RMTF disbursements from 2014 to 2018, and the results of Outcome 1 to Outcome 6 in the GMS countries. 


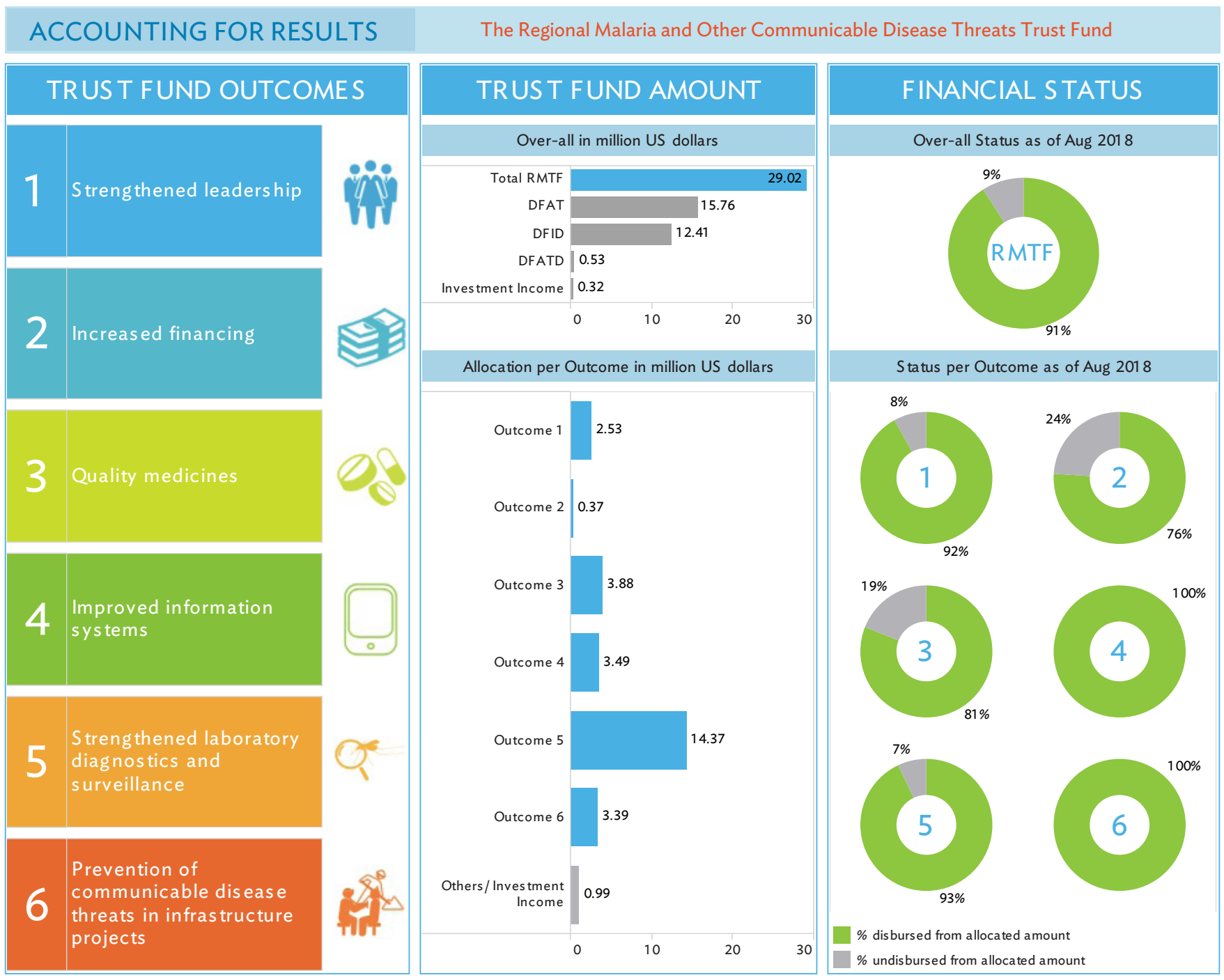




\section{RESULTS BY OUTCOME}

The following section presents the results and achievements for each of the RMTF six outcomes. These are presented through a financial dashboard, results-based framework indicator table, list of TA projects contributing to the outcome, and description of key achievements. Details of each RMTF output and activity are elaborated in the results-based framework (RBF) (Annex A) and project work plans. 

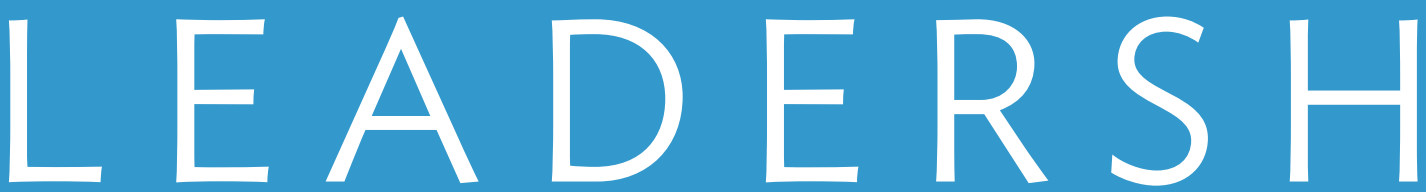

Strengthened leadership, decision-making and accountability for malaria elimination and addressing communicable disease threats.

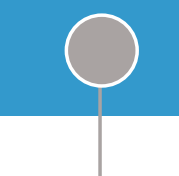

RCDTA 8485

Strengthening Regional Results for Malaria

Other Communicable Diseases in Asia and the Pacific

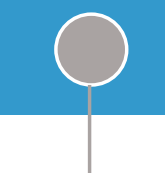

R-CDTA 8763 of Communicable Malaria Elimination in

Diseases Threats in Asia and the Pacific (RECAP)

$$
\text { - Output } 1
$$

OUTCOME 1: Strengthened leadership, decision-making and accountability for malaria elimination and addressing communicable disease threats

\begin{tabular}{|l|}
\hline KEY OUTCOMES \\
\hline $\begin{array}{l}\text { Increased commitment and collaboration for malaria } \\
\text { elimination and addressing communicable disease } \\
\text { threats }\end{array}$ \\
$\begin{array}{l}\text { Improved use of information for decision-making and } \\
\text { accountability to progress toward malaria elimination } \\
\text { and addressing communicable disease threats }\end{array}$ \\
\hline
\end{tabular}

OUTCOME RESULTS

Countries that have endorsed the malaria elimination roadmap
(As of Aug 2018)

\begin{tabular}{|c|c|c|c|}
\hline Afghanistan & Aus tralia & Bangladesh & Bhutan \\
\hline $\begin{array}{c}\text { Brunei } \\
\text { Darussalam }\end{array}$ & Cambodia & $\begin{array}{c}\text { People's Republic } \\
\text { of China }\end{array}$ & India \\
\hline Indonesia & Japan & Lao PDR & Malaysia \\
\hline Myanmar & $\begin{array}{c}\text { Democratic } \\
\text { People's Republic } \\
\text { of Korea }\end{array}$ & Nepal & New Zealand \\
\hline Pakistan & Philippines & PNG & Russia \\
\hline $\begin{array}{l}\text { Republic of } \\
\text { Korea }\end{array}$ & Singapore & $\begin{array}{l}\text { Solomon } \\
\text { Islands }\end{array}$ & Thailand \\
\hline Timor-Leste & US & Vanuatu & Viet Nam \\
\hline $\begin{array}{l}\text { ountries } \\
\text { Malaria-ender } \\
\text { Donor country }\end{array}$ & country & \multicolumn{2}{|c|}{$\begin{array}{l}\text { Endorsement status } \\
\text { Endorsed } \\
\text { Has not endorsed }\end{array}$} \\
\hline
\end{tabular}

Note: List of countries provided by Asia Pacific Leaders Malaria Alliance secretariat

\section{Other key achievements}

- Malaria Elimination Dashboard

- Investment cases for financing malaria elimination program and the Malaria Program Efficiency Analysis Tool developed

\begin{tabular}{|l|l|l|}
\hline \multicolumn{3}{|c|}{ TRUS T FUND ALLOCATION } \\
\hline $\begin{array}{l}\text { Total } \\
\text { allocation } \\
\text { in million US\$ }\end{array}$ & 2.53 & Share in RMTF \\
\hline
\end{tabular}

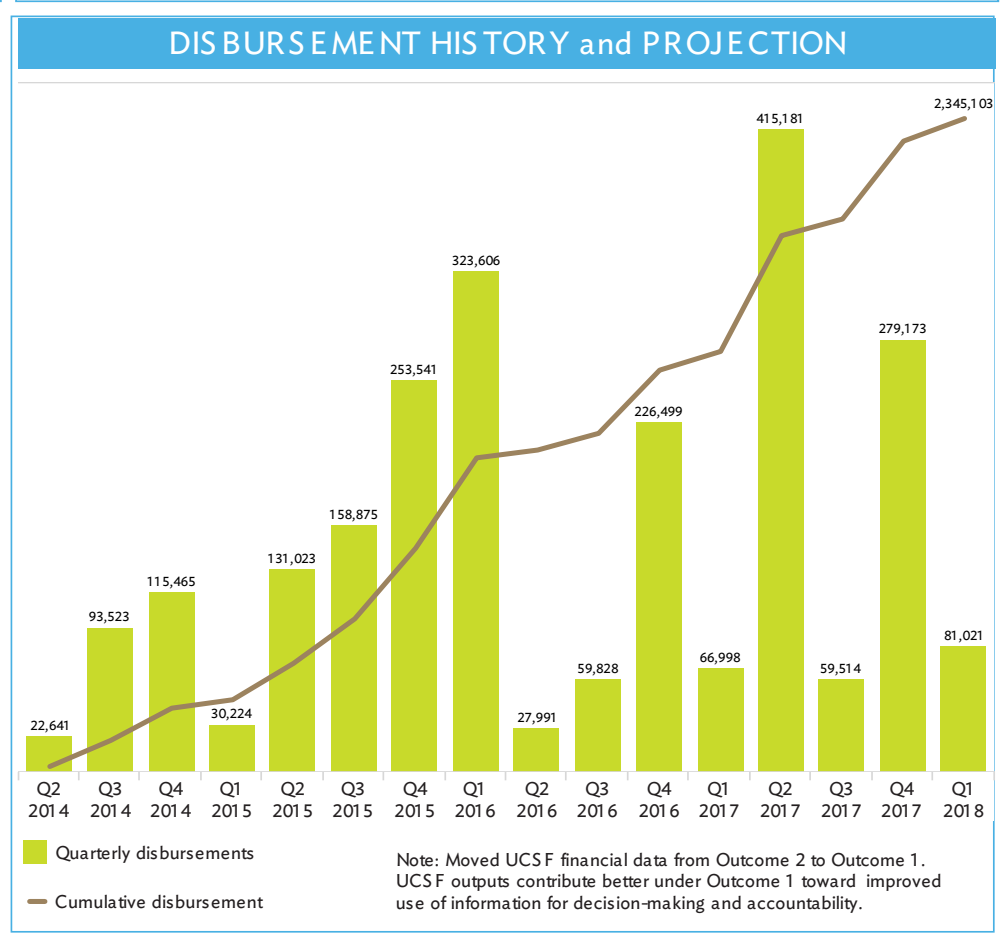




\section{Rationale}

Globally, malaria infected 216 million people in 91 countries in 2016, leading to 445,000 deaths. ${ }^{4}$ Progress toward malaria elimination has stalled in many countries, and the world is failing to keep pace with WHO's 2020 milestones that can bring about a $40 \%$ reduction in incidence and death rates by 2030 . More than 2.1 billion people in Asia and the Pacific are at risk of malaria, including 152.3 million in the GMS, making the disease a major regional public health concern. According to WHO estimates for Asia and the Pacific, there were 16.2 million malaria cases in 2016, and 30,300 deaths. With such a large-scale threat, eliminating malaria demands political and financial commitment at the highest level, for both national responses, and for regional partnerships and coordination of efforts.

Table 1: Results of Outcome 1.1

\begin{tabular}{|c|c|c|c|c|c|c|c|c|c|c|c|}
\hline \multirow{2}{*}{ Outcome Indicator } & \multirow{2}{*}{$\begin{array}{c}2014 \\
\text { Baseline }\end{array}$} & \multicolumn{2}{|c|}{ Status in } & \multirow{2}{*}{ Target } & \multirow{2}{*}{ Progress } & \multirow{2}{*}{ Output Indicator } & \multirow{2}{*}{$\begin{array}{c}2014 \\
\text { Baseline }\end{array}$} & \multicolumn{2}{|c|}{ Status in } & \multirow{2}{*}{ Target } & \multirow{2}{*}{ Progress } \\
\hline & & 2016 & 2017 & & & & & 2016 & 2017 & & \\
\hline $\begin{array}{l}\text { 1. Number of malaria- } \\
\text { endemic countries that } \\
\text { endorsed the malaria } \\
\text { elimination road map }\end{array}$ & 0 & 13 & $14^{*}$ & $21^{* *}$ & - & $\begin{array}{l}\text { 1. Malaria elimination road } \\
\text { map developed }\end{array}$ & No & Yes & Yes & Yes & - \\
\hline $\begin{array}{l}\text { 2. Number of donor } \\
\text { countries that endorsed } \\
\text { the malaria elimination } \\
\text { road map }\end{array}$ & 0 & 7 & $7^{* * *}$ & 7 & 0 & & & & & & \\
\hline
\end{tabular}

Progress: Achieved or on track

* Cambodia, India, Indonesia, Lao People's Democratic Republic Malaysia, Myanmar, Papua New Guinea, People's Republic of China, Philippines,

Republic of Korea, Solomon Islands, Thailand, Vanuatu, Viet Nam

** APLMA's 2020 target

** Australia, Brunei Darussalam, Japan, New Zealand, Russian Federation, Singapore, United States

Source: Authors.

\section{Asia Pacific Leaders Malaria Alliance Support}

Under the leadership component of the RMTF, APLMA - an affiliation of Asian and Pacific heads of government, housed within ADB from its establishment 2014 to 2016 -was supported with technical input. APLMA is now a full fledged independent entity that works to accelerate progress against malaria and to eliminate it in the region by 2030. APLMA has also been financed directly by DFAT and the Bill \& Melinda Gates Foundation in addition to the collaboration and specific technical support under the RMTF.

With support under the RMTF, APLMA has introduced the Leaders' Dashboard, a decision and accountability tool that provides visibility to national and regional progress toward malaria elimination targets, as well as fulfillment of priority actions and identification of areas requiring attention. Support was also provided to strengthen the investment case of malaria elimination.

\section{Investment Cases}

The RMTF competitively recruited the University of California San Francisco Malaria Elimination Initiative (UCSF/MEI) to develop a series of investment cases and a toolkit for financing malaria elimination programs. The investment cases aim to generate evidence around optimal ways to increase and expand the amount of sustainable financing in support of malaria elimination. National and regional policymakers can use this evidence to inform malaria program budgeting, strategic planning, and advocacy for domestic resource

4 WHO. 2018. World Malaria Day 2018: Ready to beat malaria. Geneva: WHO. http://www.who.int/malaria/media/world-malaria-day-2018/en/ 
Table 2: Results of Outcome 1.2

\begin{tabular}{|c|c|c|c|c|c|c|c|c|c|c|c|}
\hline Outcome Indicator & $\begin{array}{c}2014 \\
\text { Baseline }\end{array}$ & \multicolumn{2}{|c|}{ Status in } & Target & Progress & Output Indicator & $\begin{array}{c}2014 \\
\text { Baseline }\end{array}$ & \multicolumn{2}{|c|}{ Status in } & Target & Progress \\
\hline \multirow{3}{*}{$\begin{array}{l}\text { 1. Malaria Elimination } \\
\text { Dashboard used to } \\
\text { inform high-level regional } \\
\text { policy dialog on malaria } \\
\text { elimination }\end{array}$} & \multirow[t]{3}{*}{ No } & \multirow[t]{3}{*}{ No } & \multirow[t]{3}{*}{ Yes } & \multirow[t]{3}{*}{ Yes } & \multirow[t]{3}{*}{ - } & $\begin{array}{l}\text { 1. Malaria Elimination } \\
\text { Dashboard prototype }\end{array}$ & No & Yes & Yes & Yes & O \\
\hline & & & & & & $\begin{array}{l}\text { 2.Number of countries with } \\
\text { data compiled from the } \\
\text { World Health Organization } \\
\text { (WHO) for the technical } \\
\text { annex of the Malaria } \\
\text { Elimination Dashboard }\end{array}$ & 0 & 22 & 22 & 22 & 0 \\
\hline & & & & & & $\begin{array}{l}\text { 3. Number of countries with } \\
\text { data compiled for Malaria } \\
\text { Elimination Dashboard } \\
\text { indicators }\end{array}$ & 0 & 4 & 22 & 22 & - \\
\hline \multirow{5}{*}{$\begin{array}{l}\text { 2. Investment cases and } \\
\text { toolkit results used to } \\
\text { inform high-level regional } \\
\text { policy dialog on malaria } \\
\text { financing }\end{array}$} & \multirow[t]{5}{*}{ No } & \multirow[t]{5}{*}{ No } & \multirow[t]{5}{*}{ Yes } & \multirow[t]{5}{*}{ Yes } & \multirow[t]{5}{*}{ - } & $\begin{array}{l}\text { 1. Costing framework and } \\
\text { tools developed }\end{array}$ & No & Yes & Yes & Yes & O \\
\hline & & & & & & $\begin{array}{l}\text { 2. Number of countries/ } \\
\text { subregion with costing for } \\
\text { malaria elimination* } \\
\text { (BAN, IND, PNG, GMS) }\end{array}$ & 0 & 2 & 2 & 4 & O \\
\hline & & & & & & $\begin{array}{l}\text { 3. Number of country/ } \\
\text { subregional investment } \\
\text { cases developed* } \\
\text { (BAN, IND, PNG, GMS) }\end{array}$ & 0 & 0 & 4 & 4 & - \\
\hline & & & & & & $\begin{array}{l}\text { 4. Number of business } \\
\text { cases for private sector } \\
\text { investment in malaria } \\
\text { control and elimination* } \\
\text { (BAN/IND/PNG and } \\
\text { GMS) }\end{array}$ & 0 & 0 & 2 & 2 & O \\
\hline & & & & & & $\begin{array}{l}\text { 6. Recommendations } \\
\text { developed on financing } \\
\text { options for the Asia and } \\
\text { Pacific Region* }\end{array}$ & No & No & Yes & Yes & 0 \\
\hline
\end{tabular}

Progress: Achieved at least $95 \%$ of target

BAN = Bangladesh, GMS = Greater Mekong Subregion, IND = India.

* Upon review of the logical flow of outputs and outcomes, these outputs that were previously tracked under Outcome 2 (Financing) are moved here as these better contribute toward improved use of information for decision-making and accountability for malaria elimination and addressing communicable disease Source: Authors. 
mobilization. The investment cases have since been used by both APLMA and ADB in policy dialog with countries and have also informed other parts of the RMTF's work, including the financing component, to help malaria program managers collect, organize, and track data points related to the technical efficiency of a malaria program.

National investment cases were commissioned for Bangladesh, Indonesia, and Papua New Guinea (PNG); two regional investment cases, one for the Asia and Pacific region and another specifically for the GMS, with estimates on the cost and economic and financial returns of malaria elimination through 2030; and business cases for private sector engagement in malaria elimination and communicable disease control in Bangladesh, Indonesia, PNG, and the GMS.

The RMTF also supported the development of the Malaria Program Efficiency Analysis Tool (MPEAT), to help malaria program managers collect, organize, and track data points related to the technical efficiency of a malaria program. The MPEAT has been used in Bangladesh, Indonesia, and PNG. In Bangladesh and Indonesia MPEAT was used to identify areas that need strengthening, to maximize value, reduce waste, and ultimately save resources. In the Philippines, the costing tool was used to help navigate the country's transition from Global Fund grant support to domestic financing for malaria elimination.

The tool is designed to be used in conjunction with the Malaria Elimination Transmission and Costing in the Asia Pacific (METCAP), a transmission model that measures allocative efficiency, created by Mahidol Oxford Tropical Medicine Research Unit (MORU), in collaboration with the USCF and the University of Cape Town. The outputs of the METCAP have been transformed into an online interactive mobile application that generates reader-friendly graphs and charts showing changes in malaria morbidity and mortality and associated program costs under different intervention scenarios.

\section{Enabling Factors}

The Leaders' Dashboard was an effective accountability tool, and the investment cases gave much-needed tangible evidence of the potential beneficial impact of malaria elimination ADB's involvement brought each country's ministry of finance to the table, which gave APLMA a level of reach that it could not have otherwise attained.

\section{Next Steps and Sustainability Pathway}

APLMA is now accepted as a legitimate policy platform, and DFAT also continues to support it. The Malaria Elimination Dashboard will hold leaders accountable, as well as supporting advocacy and communication to keep the malaria agenda active.

The partnership with APLMA under the RMTF also supported the collaboration with the Global Fund, which led to the signing of a memorandum of understanding (MOU), between ADB and the Global Fund to Fight AIDS, Tuberculosis and Malaria for a proposed regional financing facility (see p. 14). 

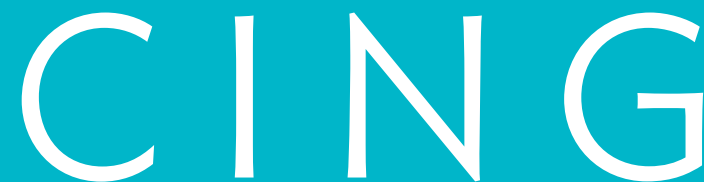

Increased financing for malaria elimination and addressing communicable disease threats
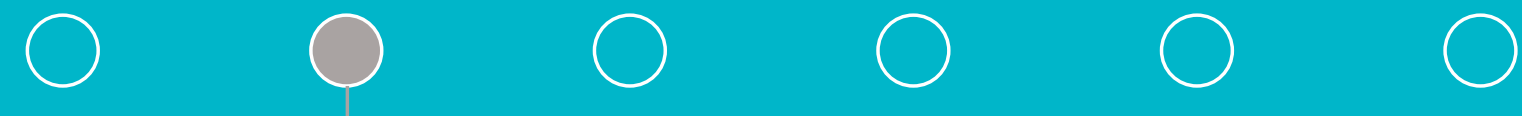

R-CDTA 8763:

Results for Malaria

Elimination and Control of

Communicable Diseases

Threats in Asia and the

Pacific (RECAP) - Output 2

OUTCOME 2: Increased funds for malaria elimination and addressing communicable disease threats

KEY OUTCOMES
Increased investments for malaria elimination and
addressing communicable disease threats
Increased domestic funds for malaria elimination

\begin{tabular}{|c|c|c|}
\hline & ALLOCATION & \\
\hline $\begin{array}{l}\text { Total } \\
\text { allocation } \\
\text { in million US\$ }\end{array}$ & Share in RMTF & $1 \%$ \\
\hline
\end{tabular}

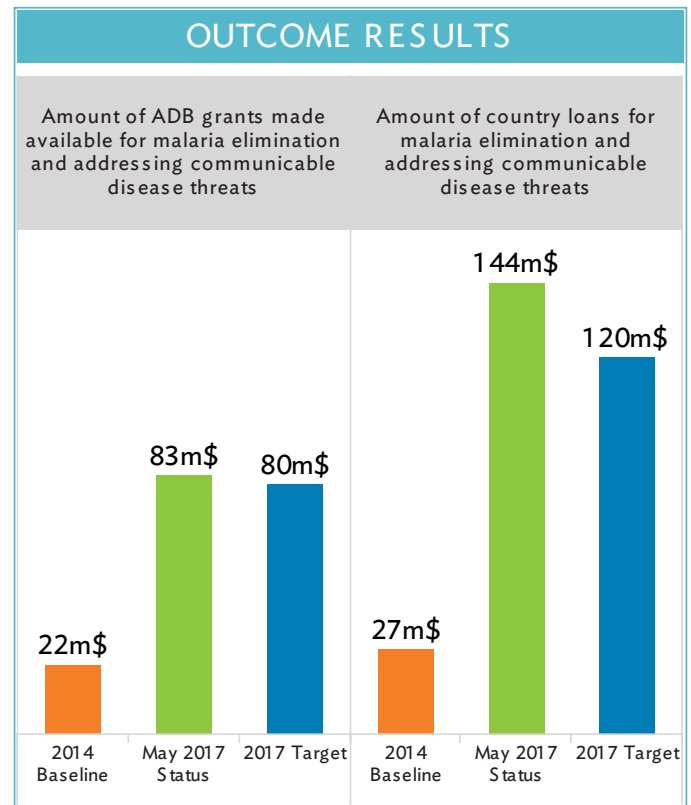

Other key achievements

- New innovative mechanisms that mobilized financing such as ADB's first Health Bond of \$100M and ADB-Global Fund MOU

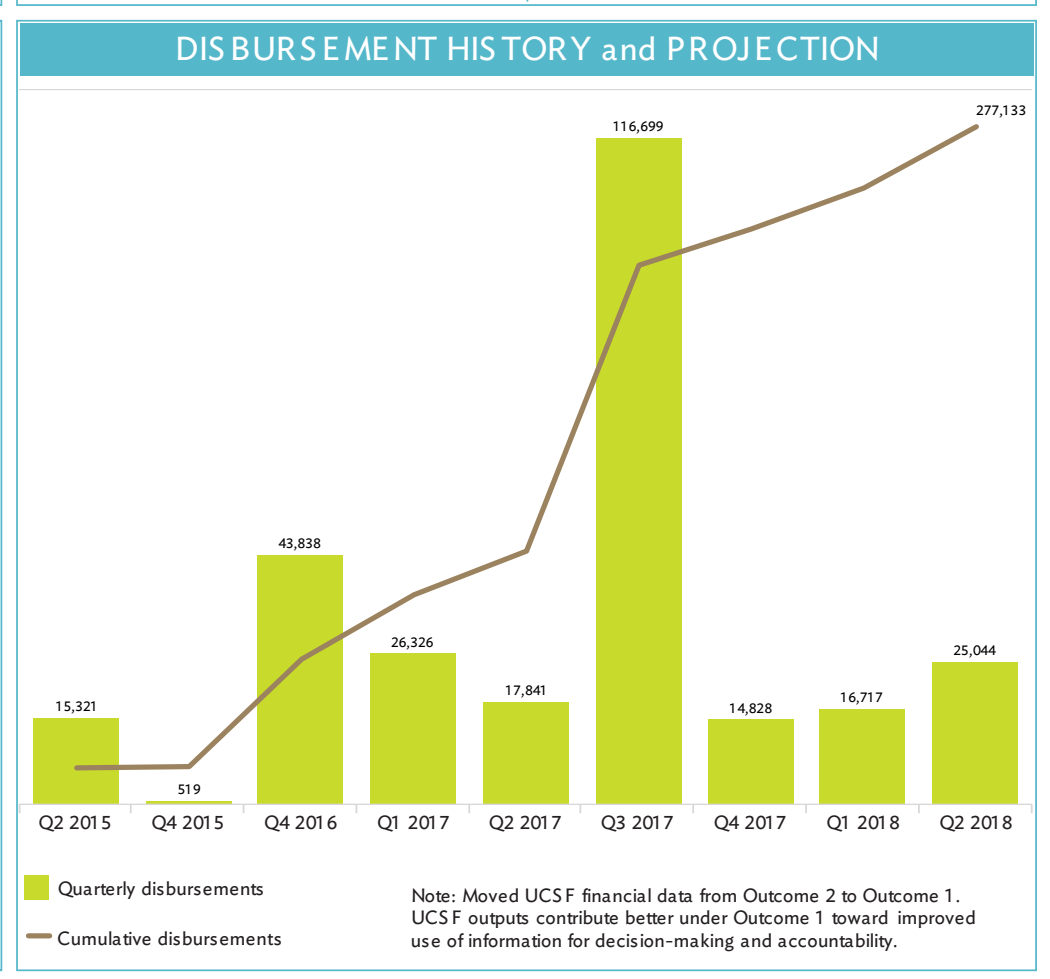




\section{Rationale}

Malaria elimination costs money, but the human and financial cost of underfunding is far higher. Securing funding entails both innovative approaches to sustainable health-care financing and ensuring that existing investments work smarter and are sustainable to achieve the most impact.

\section{Mobilizing Financing}

In 2015 the fund allocated $\$ 9.5$ million to an existing project in Cambodia, the Lao PDR, and Viet Nam. However, it was the use of RMTF funding as a catalyst that enabled the fund to both focus on malaria, and to greatly amplify its impact, by raising additional ADB resources through the development of new financing mechanisms to support efforts for malaria elimination and addressing communicable disease threats.

A total of $\$ 52.5$ million in grants was mobilized for health security measures from the Asian Development Fund (ADF), as well as an additional $\$ 125$ million worth of loans and grants for health security in GMS countries and, most notably, the issuance of ADB's first health bond. The private placement of $\$ 100$ million issued in March 2017 was purchased by the Dai-ichi Life Insurance Company, Limited, making it the world's first institutional investor to buy a bond that supports ADB's health program. The bond will support lending to countries on targeted health financing, including malaria and communicable disease programs, and ADB will continue to support the bond pipeline process for potential subsequent issues.

\section{Landmark Collaboration}

In late 2017, against a backdrop of Asia and the Pacific countries previously eligible for Global Fund grants transitioning to domestic responsibility for malaria and other communicable disease investments, the Global Fund and ADB signed a landmark MOU to find common ground and align malaria and other communicable disease funding opportunities. The MOU, signed in November 2017, was the first of its kind between the Global Fund and a development bank. The Global Fund/ADB MOU promotes ongoing coordination and future cofinancing between the two institutions, directly through projects and also through a new regional fund. There is already a project pipeline targeting health systems development and strengthening. Cofinancing opportunities for Bhutan, PNG, and Sri Lanka, as well as the GMS countries have already been mapped as a result of the MOU. The model is also proof of concept for ADB to collaborate with other donors on other health projects in future, beyond malaria, based on country needs and donor priorities.

Table 3: Results of Outcome 2

\begin{tabular}{|c|c|c|c|c|c|c|c|c|c|c|c|}
\hline \multirow{2}{*}{ Outcome Indicator } & \multirow{2}{*}{$\begin{array}{c}2014 \\
\text { Baseline }\end{array}$} & \multicolumn{2}{|c|}{ Status in } & \multirow{2}{*}{ Target } & \multirow{2}{*}{ Progress } & \multirow{2}{*}{ Output Indicator } & \multirow{2}{*}{$\begin{array}{c}2014 \\
\text { Baseline }\end{array}$} & \multicolumn{2}{|c|}{ Status in } & \multirow{2}{*}{ Target } & \multirow{2}{*}{ Progress } \\
\hline & & 2016 & Q2 2018 & & & & & 2016 & Q2 2018 & & \\
\hline $\begin{array}{l}\text { 1. Amount of ADB } \\
\text { grants made available } \\
\text { for malaria elimination } \\
\text { and addressing } \\
\text { communicable } \\
\text { disease threats }\end{array}$ & $\$ 22.0 \mathrm{~m}$ & $\$ 82.5 \mathrm{~m}^{*}$ & $\$ 82.5 \mathrm{~m}^{*}$ & $\$ 80.0 \mathrm{~m}$ & O & $\begin{array}{l}\text { 1. ADF health security } \\
\text { grants for group } A \text { and } \\
\text { B countries mobilized } \\
(\$ 52.5 \mathrm{~m})\end{array}$ & No & Yes & Yes & Yes & - \\
\hline \multirow[t]{2}{*}{$\begin{array}{l}\text { 2. Amount of country } \\
\text { loans for malaria } \\
\text { elimination } \\
\text { and addressing } \\
\text { communicable } \\
\text { disease threats }\end{array}$} & \multirow[t]{2}{*}{$\$ 27.0 \mathrm{~m}$} & \multirow[t]{2}{*}{$\$ 144.0 m^{*}$} & \multirow[t]{2}{*}{ *\$144.0m* } & \multirow[t]{2}{*}{$\$ 120.0 \mathrm{~m}$} & \multirow[t]{2}{*}{ - } & $\begin{array}{l}\text { 2. GMS health security } \\
\text { funds approved } \\
\text { ( } \$ 117 \mathrm{~m} \text { as loan and } \\
\$ 8 \mathrm{~m} \\
\text { as grant) }\end{array}$ & No & Yes & Yes & Yes & 0 \\
\hline & & & & & & $\begin{array}{l}\text { 3. ADB Health Bond } \\
\text { launched }(\$ 100 \mathrm{~m} \\
\text { OCR) }\end{array}$ & No & No & Yes & Yes & 0 \\
\hline
\end{tabular}

Progress: Achieved at least $95 \%$ of target ${ }^{*}$ Cumulative amount

$\mathrm{ADB}=$ Asian Development Bank, $\mathrm{ADF}=$ Asian Development Fund, GMS = Greater Mekong Subregion, $\mathrm{m}=$ million, OCR = ordinary capital resources. Source: Authors. 


\section{Enabling Factors}

Having a clear understanding of national government priorities and constraints, and establishing how public-private partnerships could appeal to both private and public sectors, paid off in terms of obtaining buy-in from both within ADB and with external partners. The success of the financing component is also a testament to the way in which the six outcomes worked together: the strong backdrop of projects that the RMTF had already developed, including the work done on what investments are needed to eliminate malaria, and the pipeline of upcoming projects gave muchneeded traction to leverage the broader health sector.

\section{Next Steps and Sustainability Pathway}

A legal agreement between ADB and the Global Fund has been drafted for the design of the new Regional Health Fund. This fund will potentially finance priority strategic regional activities, provide support to countries in the region with the highest malaria burden and least capacity to secure domestic funding, and scale up investments in national programs. It will meet demand for structured blended finance, allowing for integrated health sector development through concessional loans and innovative finance structures, including results-based grants, risk transfer mechanisms, and loan buy-downs. The vision is to provide a one-stop blended finance shop for governments to access finance that targets whole-system health programs. As a result, specific regional goals such as malaria elimination will also be expedited-with sustainable and long-term results - and health systems strengthened.

In addition, the health bond process was set up in a way that can be replicated, either for other health issuances or for related themes.

ADB has committed to health sector investment by increasing the health pipeline, providing substantial technical assistance, and integrating health in ADB country partnership strategies. The ADB Strategy 2030 also provides ample opportunity to leverage ADB's strong infrastructure footprint for the health sector. 

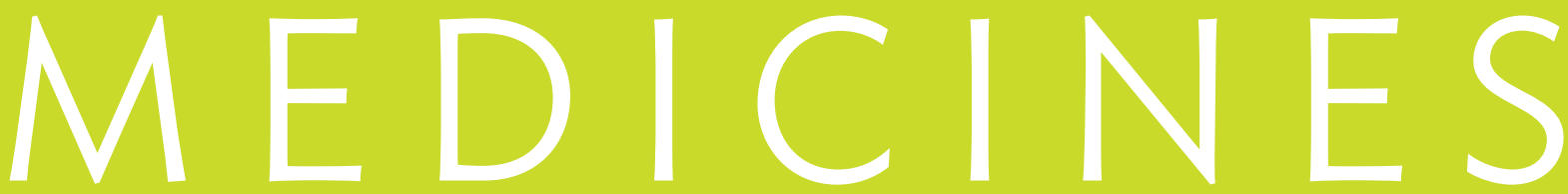

Improved regulatory capacity to support increased availability and use of quality assured medicines for malaria and other communicable diseases
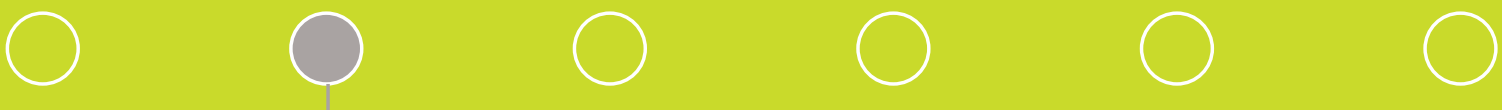

R-CDTA 8763:

Results for Malaria Elimination and Control of Communicable

Diseases Threats in Asia and the Pacific (RECAP)

Output 2 availability and use of quality assured commodities

OUTCOME 3: Improved quality assurance and post-market surveillance of medicines for malaria and other communicable diseases

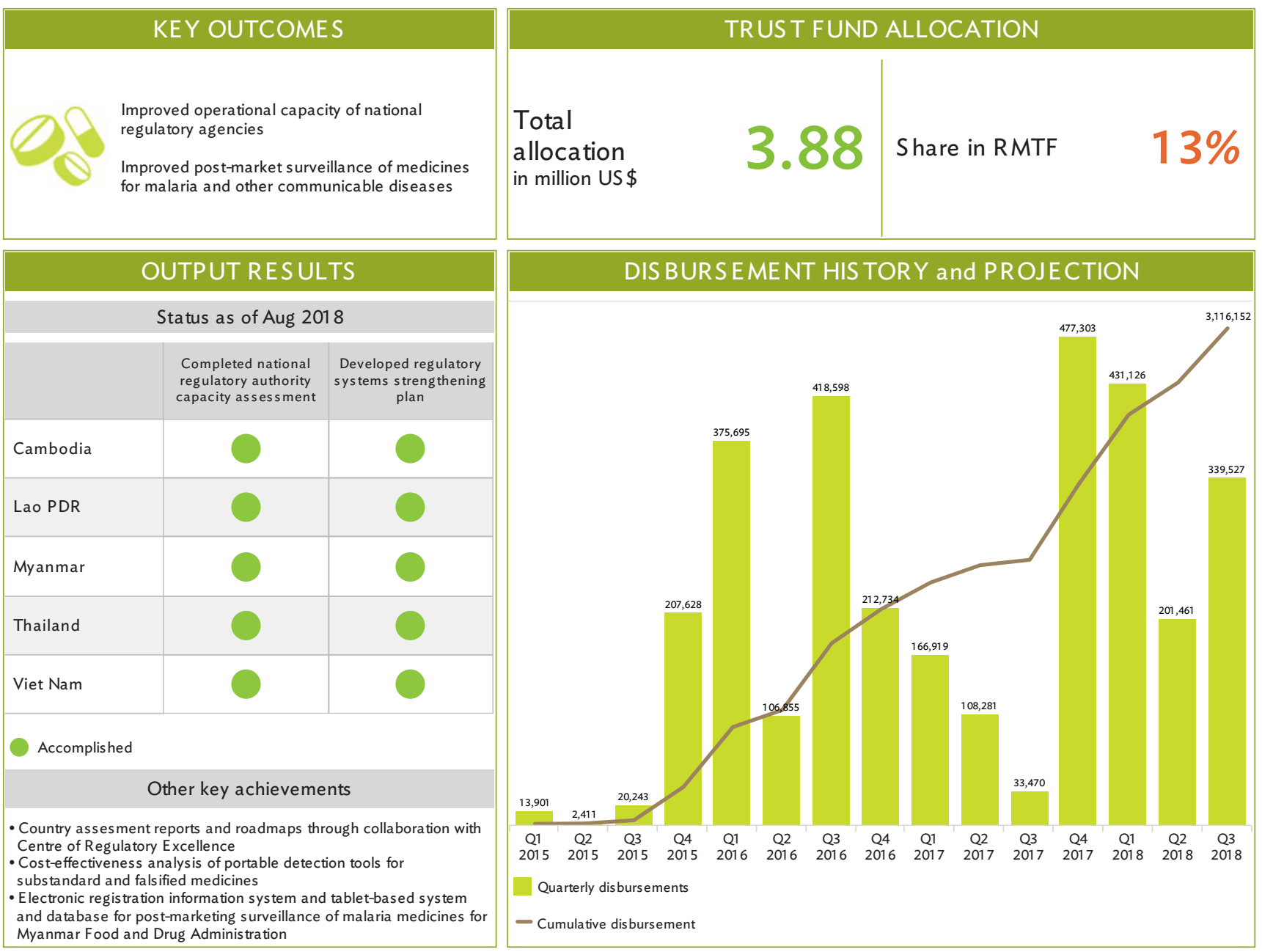




\section{Rationale}

Eliminating malaria requires reliable supplies of safe and efficacious treatments delivered to where they are needed, but the market is plagued by substandard and falsified (SF) medicines. This undermines the work of the Global Fund to Fight AIDS, Tuberculosis and Malaria, and other development agencies bringing malaria medicines to where they are needed. Better regulation and post-marketing surveillance of malaria medicines is key to addressing this issue. This in turn requires strong national regulatory agencies (NRAs) with effective tools for testing and post-market surveillance of malaria medicines, as well as collaboration with the global community of practice tackling the international trade in SF medical products.

\section{Regulatory Systems Strengthening}

Many NRAs in Asia and the Pacific struggle to cope with marketing approvals of new health products, inspections of manufacturing and distribution facilities, and ensuring the continued quality of medicines and medical devices throughout the supply chain. ${ }^{5}$ The RMTF supported regulatory systems strengthening through collaboration with the Centre of Regulatory Excellence (CoRE), a regional capacity-building center and partnercoordinating platform for regulatory systems strengthening and convergence for Southeast Asian DMCs.

CoRE developed individual country assessment reports and road maps, which were further analyzed to develop a regional capacity development road

Table 4: Results of Outcome 3.1

\begin{tabular}{|c|c|c|c|c|c|c|c|c|c|c|c|}
\hline \multirow{2}{*}{ Outcome Indicator } & \multirow{2}{*}{$\begin{array}{c}2014 \\
\text { Baseline }\end{array}$} & \multicolumn{2}{|c|}{ Status in } & \multirow{2}{*}{ Target } & \multirow{2}{*}{ Progress } & \multirow{2}{*}{ Output Indicator } & \multirow{2}{*}{$\begin{array}{c}2014 \\
\text { Baseline }\end{array}$} & \multicolumn{2}{|c|}{ Status in } & \multirow{2}{*}{ Target } & \multirow{2}{*}{ Progress } \\
\hline & & 2016 & Q2 2018 & & & & & 2016 & Q2 2018 & & \\
\hline \multirow[t]{3}{*}{$\begin{array}{l}\text { 1. Number of countries } \\
\text { with improved } \\
\text { operational regulatory } \\
\text { capacity }\end{array}$} & 0 & 0 & $3^{*}$ & 3 & 0 & $\begin{array}{l}\text { 1. Number of countries } \\
\text { with NRA capacity } \\
\text { profiles (CAM, LAO, } \\
\text { MYA, THA, VIE) }\end{array}$ & 0 & 3 & 5 & 5 & 0 \\
\hline & & & & & & $\begin{array}{l}\text { 2. Number of countries } \\
\text { with NRA capacity } \\
\text { strengthening road } \\
\text { maps (CAM, LAO, } \\
\text { MYA, THA, VIE) }\end{array}$ & 0 & 0 & 5 & 5 & 0 \\
\hline & & & & & & $\begin{array}{l}\text { 3. Training modules } \\
\text { developed }\end{array}$ & No & No & Yes & Yes & O \\
\hline & & & & & & $\begin{array}{l}\text { 4. Number of countries } \\
\text { with NRA staff trained } \\
\text { on priority regulatory } \\
\text { issues and gaps }\end{array}$ & 0 & 0 & 5 & 5 & 0 \\
\hline
\end{tabular}

Progress: Achieved at least $95 \%$ of target

CAM = Cambodia, LAO = Lao People's Democratic Republic, MYA = Myanmar, THA = Thailand, VIE = Viet Nam.

* Cambodia, the Lao PDR, and Myanmar built capacity based on the Centre of Regulatory Excellence (CoRE) needs assessment, which helped identify areas of focus and improve partner coordination. The trainings conducted for country representatives and the road map developed all encapsulate capacity building. Additionally, the targeted technical support and work in Myanmar had a direct impact on the operational capacity of its Food and Drug Administration and additional activities addressing targeted monitoring of the quality of medicines on the market, linking the quality control laboratory into the electronic information system and developing the basis of a national drug safety strategy and pharmacovigilance system.

Source: Authors. 
Table 5: Results of Outcome 3.2

\begin{tabular}{|c|c|c|c|c|c|c|c|c|c|c|c|}
\hline \multirow{2}{*}{ Outcome Indicator } & \multirow{2}{*}{$\begin{array}{c}2014 \\
\text { Baseline }\end{array}$} & \multicolumn{2}{|c|}{ Status in } & \multirow{2}{*}{ Target } & \multirow{2}{*}{ Progress } & \multirow{2}{*}{ Output Indicator } & \multirow{2}{*}{$\begin{array}{c}2014 \\
\text { Baseline }\end{array}$} & \multicolumn{2}{|c|}{ Status in } & \multirow{2}{*}{ Target } & \multirow{2}{*}{ Progress } \\
\hline & & 2016 & Q2 2018 & & & & & 2016 & Q2 2018 & & \\
\hline \multirow{5}{*}{$\begin{array}{l}\text { 1. Number of countries } \\
\text { piloting new field } \\
\text { detection tools }\end{array}$} & \multirow[t]{5}{*}{0} & \multirow[t]{5}{*}{0} & \multirow[t]{5}{*}{1} & \multirow[t]{5}{*}{1} & \multirow[t]{5}{*}{0} & \multicolumn{6}{|l|}{ SF field detection tools } \\
\hline & & & & & & $\begin{array}{l}\text { 1. Formal relationships } \\
\text { with global and local } \\
\text { research institutions } \\
\text { established }\end{array}$ & No & Yes & Yes & Yes & 0 \\
\hline & & & & & & $\begin{array}{l}\text { 2. Library of active } \\
\text { ingredients and finished } \\
\text { product profiles } \\
\text { developed }\end{array}$ & No & No & Yes & Yes & 0 \\
\hline & & & & & & $\begin{array}{l}\text { 3. Report on results } \\
\text { of testing and } \\
\text { cost-effectiveness } \\
\text { evaluation of field } \\
\text { detection tools }\end{array}$ & No & No & Yes & Yes & 0 \\
\hline & & & & & & $\begin{array}{l}\text { 4. Recommendations on } \\
\text { cost-effective post- } \\
\text { market surveillance } \\
\text { field tools for detecting } \\
\text { SF developed }\end{array}$ & No & No & Yes & Yes & 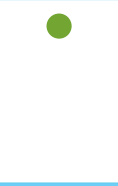 \\
\hline \multirow[b]{2}{*}{$\begin{array}{l}\text { 2. Number of WPRO } \\
\text { and SEARO } \\
\text { countries started to } \\
\text { report to the global } \\
\text { substandard and } \\
\text { falsified (SF) medical } \\
\text { products reporting } \\
\text { mechanism* }\end{array}$} & \multirow[t]{2}{*}{0} & \multirow[t]{2}{*}{6} & \multirow[t]{2}{*}{10} & \multirow[t]{2}{*}{5} & \multirow[t]{2}{*}{ - } & \multicolumn{6}{|l|}{ SF reporting } \\
\hline & & & & & & $\begin{array}{l}\text { 1. Number of countries } \\
\text { with staff trained on } \\
\text { the WHO global SF } \\
\text { reporting mechanism }\end{array}$ & 0 & 22 & 22 & 22 & 0 \\
\hline
\end{tabular}

Progress: Achieved at least $95 \%$ of target

$\mathrm{SEARO}=$ Regional Office for South-East Asia, WPRO = Regional Office for the Western Pacific, WHO = World Health Organization.

*WHO does not divulge information on reporting by individual countries due to confidentiality rules.

Source: Authors.

map, focusing on needs that are common among the five GMS countries. Further improvements in the operational capacity of NRAs in the GMS, while meeting their diverse needs, will require a coordinated effort by development partners, and with this in mind, the regional road map was shared with the RRP and the information was subsequently incorporated into the RRP workplan.

\section{Medicines Safety}

By sensitizing NRAs to the ways in which SF medical products contribute to artemisinin resistance and the danger this poses to malaria elimination efforts, the RMTF medicines component has supported countries to participate in the WHO monitoring mechanism for SF products. The training provided jointly with $\mathrm{WHO}$ led to improved reporting of SF products into the WHO Global SF medical product reporting mechanism. In addition, six countries in the WHO Western Pacific Region and South-East Region have since started to report SF products for the first time.

\section{Malaria Medicines Field Testing}

The RMTF also funded the Lao-OxfordMahosot Hospital-Wellcome Trust Research Unit (LOMWRU) to test portable devices for detecting anti-malaria medicine quality in both controlled and field conditions. This research led to advice and strategic recommendations both for DMCs looking to invest in such devices, and to device developers to make them more fit for purpose. The devices were piloted with the Lao PDR NRA, which provided invaluable insight into their usability in the 
field by resource-constrained NRA when testing antimalarial medications.

\section{Myanmar Regulatory Reform}

Myanmar's regulatory agency, Food and Drug Administration (FDA), Myanmar, relied on a paperbased medicines registration, and the agency's systems did not enable it to conduct effective post-marketing surveillance of malaria medicines, or efficiently bring new medicines to market. In late 2017, ADB worked with the regulatory agency, FDA, Myanmar, to move its paper-based registration system online to an integrated regulatory information management system (IRIMS), a digital platform that processes, stores, retrieves and shares information on regulatory activities. This is vital to ensuring the country can improve its supplies of safe, reliable, high-quality antimalarial medicines, a key facet of malaria elimination efforts.

By mid-2018, an online-only product registration application process was in place, including training of the private sector applicants, manufacturers, and agents. As part of establishing an IRIMS, the FDAs' online databases were linked to those for the management of facility inspections and of quality control (QC) laboratories.

National QC lab and inspectors can now use a tablet-based system to connect to the central registration database to know which products are registered, and to directly upload images and videos of the facility they inspect, along with the inspection report and follow-up action. The FDA also reviewed its existing list of approved products, to compare them with those used by reference authorities. After this review, the online medicines registration system was set up to automatically trigger an alert on any products submitted for registration that contain banned or obsolete active ingredients. Product information documents, which describe a medicine's indications, contraindications, dosages, and warnings, will also rely on reference texts obtained from the Therapeutic Goods Administration, Australia (TGA).

\section{Enabling Factors}

Recognizing NRAs as partners and key stakeholders in public health, and working with them together with technical agencies, especially WHO, was key to the success of this component. Coordinating efforts with other development partners ensured messaging to NRAs and training were aligned. CoRE was well placed to gain the trust and attention of NRAs, and to ensure that this newly established entity's work was aligned with the needs of NRAs. Similarly, LOMWRU has key expert researchers in the field and is based in one of the GMS countries with close links to the regulatory agency there, which was helpful.

In Myanmar, one of the key enablers was the fact that there was little in place already, making it relatively easy to introduce a new system. There was also an alignment of interests in the new online product registration system, as registrants also find the online system and standardized terminology it easier and cheaper to use. Inspectors in the field are now able to check which antimalarial are registered, and what the packaging should look like, which makes it easier for them to identify SF products.

\section{Next Steps and Sustainability Pathway}

Implementation of recommendations for using portable testing devices still requires GMS countries to develop better policies on postmarket surveillance and build the capacity of field inspectors who can act when suspected falsified and substandard medicines are identified. More understanding of the root causes of substandard medicines is needed to ascertain whether it is due to, for example, low-quality medicines entering the market, or subsequent incorrect storage along the supply chain.

While the portable devices that were assessed showed high sensitivity to falsified medicines, these devices were not optimal for detecting substandard medicines, yet in the Lao PDR, substandard malaria drugs are more prevalent than falsified ones in 
registered drug outlets. Currently, there are no agreements on who will be responsible for building a reference library, and whether it is possible to have one at regional level.

Although there are regional bodies for capacity development, and plans are ongoing for development partner alignment and harmonization, more support is required for the Association of Southeast Asian Nations pharmaceutical working group and for building subregional (GMS) consensus on reliance policy and sharing of information on SF medicines.

In SF reporting, each country now has a designated, trained contact person on reporting SF medical products. Reporting from the region to $\mathrm{WHO}$ has increased as a direct result, and is expected to continue. Myanmar has had additional training of inspectors and developed a national task force and action plan for addressing SF antimalarial medicines and other medical products. Also in Myanmar, DFAT is planning to continue funding the IRIMS work.

The capacity development plans that were developed for each NRA have been incorporated into the work of the RRP, which is helping to coordinate the actions of funding agencies and technical partners working to strengthen regulatory systems. At the national level, seven countries now have specific malaria elimination plans in place. WHO and TGA, the regulatory body for therapeutic goods in Australia, continue to be involved in supporting these efforts, and $\$ 20$ million has been secured from DFAT to continue this work. The NRAs themselves have also taken up the task of regulatory system strengthening, and some have their own funding to commit to this task. 


\section{INFORMATION SYSTEMS}

Increased use of quality data, information tools and technologies

to improve malaria and other communicable disease information systems
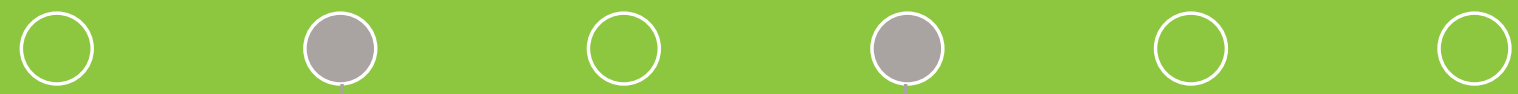

R-CDTA 8763:

Results for Malaria Elimination and

Control of Communicable Diseases Threats in Asia and the Pacific (RECAP)

Output 3

\section{R-CDTA 8656}

Malaria and Dengue Risk Mapping and Response Planning in GMS in Cambodia, Myanmar and Thailand

OUTCOME 4: Increased use of quality data, information tools and technologies

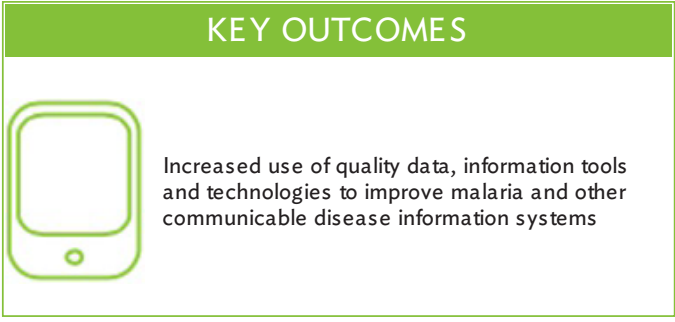

eHEALTH SOLUTIONS TES TED IN GMS COUNTRIES

\begin{tabular}{|l|l|l|}
\hline & Cambodia & Myanmar \\
\hline Unique Health IDs & \\
\hline GIS platform
\end{tabular}

TRUS T FUND ALLOCATION

Total allocation in million US\$

3. $49 *$ share in RMTF

* Increased from 2.93

\section{DIS BURSEMENT HISTORY and PROJECTION}

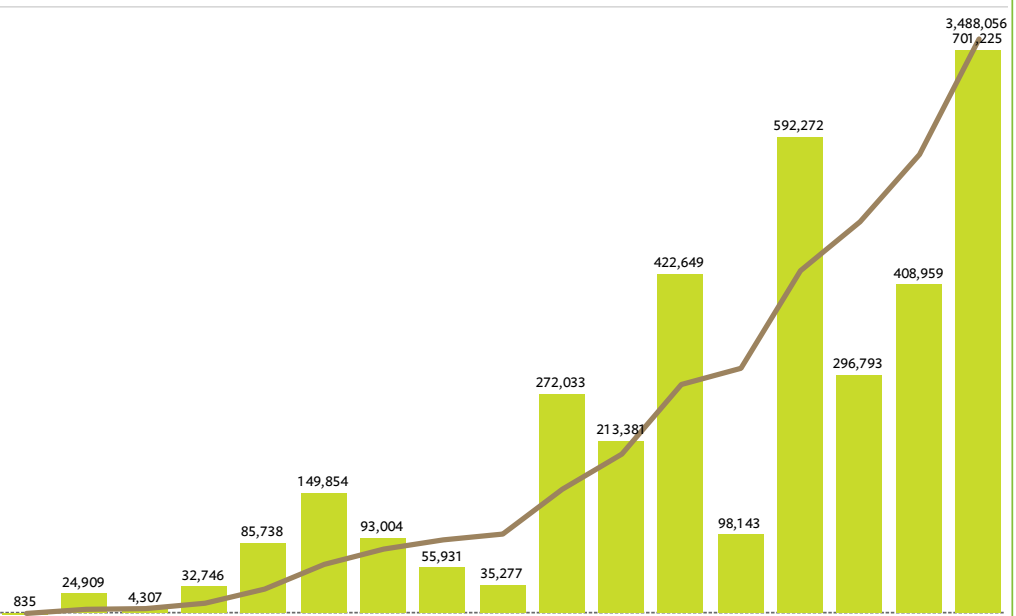

$\begin{array}{llllllllllllllllllll}\text { Q2 } & \text { Q3 } & \text { Q4 } & \text { Q2 } & \text { Q3 } & \text { Q4 } & \text { Q1 } & \text { Q2 } & \text { Q3 } & \text { Q4 } & \text { Q1 } & \text { Q2 } & \text { Q3 } & \text { Q4 } & \text { Q1 } & \text { Q2 } & \text { Q3 }\end{array}$

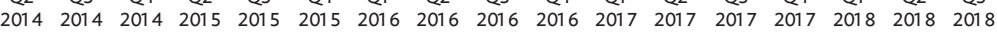
Quarterly disbursements 


\section{Rationale}

A strong information and communication technology (ICT) backbone is crucial for countries to transition from malaria control surveillance to elimination. Strengthening health information systems through better use of ICT can help countries to unlock the data they already collect, and use it more effectively for eliminating malaria and controlling communicable diseases. In countries with numerous disparate disease and patient-level systems and a complex ecosystem, tackling health information exchange, interoperability, and standardization directly improves the access to communicable disease data, both at the aggregate and patient levels. Interoperability efforts aimed at reducing the burden of health workers and providing seamless integration and transparency of information are needed to ensure use of the system.

Table 6: Results of Outcome 4

\begin{tabular}{|c|c|c|c|c|c|c|c|c|c|c|c|}
\hline \multirow{2}{*}{ Outcome Indicator } & \multirow{2}{*}{$\begin{array}{c}2014 \\
\text { Baseline }\end{array}$} & \multicolumn{2}{|c|}{ Status in } & \multirow{2}{*}{ Target } & \multirow{2}{*}{ Progress } & \multirow{2}{*}{ Output Indicator } & \multirow{2}{*}{$\begin{array}{c}2014 \\
\text { Baseline }\end{array}$} & \multicolumn{2}{|c|}{ Status in } & \multirow{2}{*}{ Target } & \multirow{2}{*}{ Progress } \\
\hline & & 2016 & Q1 2018 & & & & & 2016 & Q1 2018 & & \\
\hline \multirow{3}{*}{$\begin{array}{l}\text { 1. Number of ICT } \\
\text { solutions in use in } \\
\text { malaria and other } \\
\text { communicable } \\
\text { disease information } \\
\text { systems to improve } \\
\text { and harmonize } \\
\text { information } \\
\text { management in GMS } \\
\text { countries }\end{array}$} & \multirow[t]{3}{*}{0} & \multirow[t]{3}{*}{0} & \multirow[t]{3}{*}{$3^{* *}$} & \multirow[t]{3}{*}{2} & \multirow[t]{3}{*}{0} & $\begin{array}{l}\text { 1. Surveillance } \\
\text { mechanisms for malaria } \\
\text { and communicable } \\
\text { diseases mapped for } \\
\text { GMS countries }\end{array}$ & No & Yes & Yes & Yes & 0 \\
\hline & & & & & & $\begin{array}{l}\text { 2. Recommendations on } \\
\text { two ICT solutions to be } \\
\text { used in the region }\end{array}$ & No & Yes & Yes & Yes & 0 \\
\hline & & & & & & $\begin{array}{l}\text { 3. Number of ICT } \\
\text { solutions tested in } \\
\text { GMS countries }\end{array}$ & 0 & 0 & $5^{*}$ & 2 & 0 \\
\hline \multirow[t]{4}{*}{$\begin{array}{l}\text { 2. Number of countries } \\
\text { utilizing harmonized } \\
\text { geo-enabled } \\
\text { malaria and dengue } \\
\text { information systems }\end{array}$} & \multirow[t]{4}{*}{0} & \multirow[t]{4}{*}{0} & \multirow[t]{4}{*}{3} & \multirow[t]{4}{*}{3} & \multirow[t]{4}{*}{0} & $\begin{array}{l}\text { 1. Number of countries } \\
\text { with prevalence and } \\
\text { incidence data for } \\
\text { malaria and dengue } \\
\text { analyzed }\end{array}$ & 0 & 1 & 3 & 3 & 0 \\
\hline & & & & & & $\begin{array}{l}\text { 2. Number of countries } \\
\text { with developed } \\
\text { capacity of government } \\
\text { public health experts } \\
\text { for application of GIS- } \\
\text { based visualization }\end{array}$ & 0 & 1 & 3 & 3 & 0 \\
\hline & & & & & & $\begin{array}{l}\text { 3. Number of countries } \\
\text { with GIS-based } \\
\text { visualization system } \\
\text { of malaria and dengue } \\
\text { incidence and risk } \\
\text { established and } \\
\text { methodology evaluated }\end{array}$ & 0 & 0 & 3 & 3 & 0 \\
\hline & & & & & & $\begin{array}{l}\text { 4. Number of } \\
\text { countries with policy } \\
\text { recommendations } \\
\text { for targeting mobile } \\
\text { populations in } \\
\text { malaria and dengue } \\
\text { surveillance and } \\
\text { control programs } \\
\text { communicated to } \\
\text { Ministries of Health }\end{array}$ & 0 & 0 & 0 & 3 & 0 \\
\hline
\end{tabular}

Progress: Achieved at least 95\% of target Continued until Q4 2018 through additional funding for the work

GMS = Greater Mekong Subregion, GIS = geographic information system, ICT = information and communication technology.

* Unique Health ID in Cambodia; GIS platform in Cambodia, Myanmar, and Viet Nam; common geo-registry in Cambodia and Myanmar; Disease surveillance system (eCDS v2) in Viet Nam; HL7 and Fast Healthcare Interoperability Resources (FHIR) in Viet Nam.

${ }^{* *}$ GIS platform, common geo-registry and eCDS v2.

***Policy recommendations are being developed currently and will be finalized as population movement results are shared and discussed with ministry of health $(\mathrm{MOH})$ staff. Additional funding support has been secured by MORU to complete this work.

Source: Authors. 


\section{Landscape Analysis}

An RMTF-funded analysis of the landscape of health management information systems and malaria information systems in GMS countries found that most tools are used to manage malaria programs separately, without a common backbone or standards. A key finding was that support was needed so that a standards-based information system to benefit malaria and other communicable disease information system management could be built. To eliminate malaria, foundational components of surveillance are unique patient identification, the ability to track cases over the treatment course, and access to continuous timely surveillance data for both subnational and national stakeholders.

The analysis recommended several interventions, which informed subsequent projects under this outcome: implementation of good data management practices and digital health governance structure, agreement on digital health information standards and technical interoperability solutions, geo-enabling of the health information system, and implementation of unique health identifiers to link vertical disease information systems. ${ }^{6}$ The analysis showed that the gaps were not only technological, but also include the governance and enterprise architecture needed for the tools of ICT to be useful. Human resources for health information systems (HIS) were another key area for development under the project.

\section{Malaria Surveillance}

A low-cost software solution for hospital-based reporting of dengue cases in Myanmar was developed by MORU for piloting by the Myanmar Ministry of Health and Sports. MORU also trained local healthcare workers in high malaria risk areas in Cambodia and northeast Thailand to collect GPS data for village-level malaria risk mapping, a key step to local targeting of elimination activities. This uses a low-cost, high precision method developed by
MORU and the Asia eHealth Information Network (AeHIN) geographic information systems (GIS) Lab/Health GeoLab Collaborative with support from ADB. MORU mapped malaria and dengue surveillance data in Cambodia, Myanmar, and Thailand.

The project used data analytics based on call records, climate data, and travel surveys, to better understand the patterns of malaria infection and other communicable diseases (such as dengue) with regard to internal and cross-border migration. A consortium of research groups together with MORU analyzed mobile phone call records in Thailand to model the impact of population movement patterns on malaria and dengue distribution, and also analyzed travel survey data from patients with malaria in Cambodia, the Lao PDR, Myanmar, Thailand, and Viet Nam.

In Myanmar, data management systems for malaria surveillance were strengthened, including the use of mobile data management system (mDMS) for case reporting, and analytical tools for decisionmaking (see Outcome 5, pp.27). ${ }^{7}$ The project worked with grassroots volunteer malaria workers to improve routine, real-time case reporting through a mobile data management system piloted in the three townships. The mDMS, a smartphone-based app, was developed by Save the Children with the National Malaria Control Programme (NMCP), but RMTF funding enabled widespread piloting of the app for volunteer malaria workers and the initial results helped improve the app to make it more efficient and more user-friendly.

\section{Geospatial Technology}

The geographic dimension of malaria is key to enhancing disease surveillance and elimination through improved situational intelligence. ${ }^{8}$ In turn, ICT is key to geo-enabling a country HIS through geospatial technologies including GIS and the availability of a common registry of the geographic

\footnotetext{
6 Digital Health Infrastructure: The Backbone of Surveillance for Malaria Elimination - https:/www.adb.org/sites/default/files/publication/210856/ digital.

Funded under Outcome 5.

8 ADB. 2016. The Geography of Universal Health Coverage. ADB Briefs No. 55. April. Manila.
} 
objects core to public health (e.g., health facilities, administrative and reporting divisions, villages). RMTF funding supplied computer hardware and GIS software to Cambodia, Myanmar, Thailand, and Viet Nam, and also ran spatial data management and GIS training for national disease control program staff from the same countries, with the addition of Bangladesh and the Lao PDR. ${ }^{9}$ This initiative has now grown into the Health GeoLab Collaborative to bring more partners into the effort to geo-enable health systems in Asia and the Pacific and develop common geo-registries. RMTF funding also supported Cambodia, Myanmar, and Thailand to map and analyze national surveillance data for malaria and dengue. ${ }^{10}$

In Viet Nam, geospatial technology was applied to map the availability of malaria services in public health facilities and the readiness of these facilities to provide these services. This was done in nine districts with high malaria transmission rates. Results highlighted resource gaps in facilities to provide preventive, diagnostics, and treatment services. The same technology and assessment methodology have also been further applied by the malaria program.

\section{Policy and Strategy}

As governance was identified as a key gap in the malaria information systems landscape analysis, ADB developed a health ICT governance architecture framework (HIGAF), required for successful implementation and sustainability of digital health solutions. After consultation and close collaboration with health sector ICT experts in the region, the framework was further refined, leading to the creation of HIGAF 2.0, designed specifically to meet the evolving needs of DMCs in the region. ${ }^{11}$
Key to continuity of care is the ability to track malaria-infected subjects wherever they connect with service delivery through a unique health identifier, and the RMTF supported the development of a tool for unique patient ID assessment, which was then applied in Cambodia, the Lao PDR, Myanmar, and Viet Nam. ${ }^{12}$ At the same time, policy recommendations from a brief on unique patient health IDs informed Cambodia's strategy on national patient ID management, and the respective implementation plan. Mapping the country's existing setup brought together different stakeholders at country level to decide on the country's digital health vision and mission and develop potential next steps.

\section{Investment Guidance}

A working paper, Guidance for Investing in Digital Health, was published in May 2018, together with an accompanying website. ${ }^{13,14}$ The outcome of this work will inform decisions on developing digital health investments. This includes the strengthening of health systems as a whole, as well as the solutions required to address specific health challenges, such as malaria. The guidance demonstrates that investing simply in digitalizing the malaria surveillance and care system is not a value-for-money investment, and that there must first be a digital health foundation in place. Moreover, only a phased and well-planned investment in digital health can add significant value to malaria surveillance and at the same time remain sustainable. This is especially important to consider for development partners who tend to support the digitalization of vertical disease programs. The practicalities of delivering these outcomes while providing socioeconomic benefits have been addressed by developing an accompanying Digital

\footnotetext{
ADB. 2018. Building Capacity for Geo-Enabling Health Information Systems: Supporting Equitable Health Services and Well-Being for All. ADB Briefs No. 88. February. Manila.

10 https://healthgeolab.net/.

11 Transforming Health Systems Through Good Digital Health Governance. https://www.adb.org/sites/default/files/publication/401976/sdwp051-transforming-health-systems.pdf.

12 ADB. 2018. Unique Health Identifier Assessment Tool Kit. Manila.

13 ADB. 2018. Guidance for Investing in Digital Health. Manila. https://www.adb.org/sites/default/files/publication/424311/sdwp-052-guidanceinvesting-digital-health.pdf.

14 Digital Health: Strategy and investment. https://sites.google.com/view/digitalhealthasia/home.
} 
Health Impact Framework (DHIF). ${ }^{15}$ The DHIF helps DMCs to understand how to invest in digital health for vertical disease programs while taking a health sector enterprise approach. Developed from over 60 digital health case studies from many countries, the framework helps decision makers make better informed decisions about planned socioeconomic and financial impacts. It can be applied to several projects simultaneously so decision makers can find an optimal fit of projects.

\section{Viet Nam}

Viet Nam was a focus country under the RMTF information systems component, and the projects there illustrate the importance of digital health improvements to support malaria elimination and communicable disease control. There were a number of interrelated RMTF-funded initiatives in digital health to improve the country's generation and use of health data for malaria elimination. These initiatives helped the government establish a health ICT policy and develop an action plan to standardize national systems. The RMTF was also used to fund engagement for buy-in and training of health workers in the new policy and enhanced disease surveillance systems that are cased-based and include malaria and other communicable diseases.

With support under the RMTF, Viet Nam has adopted a digital health governance framework and decided to use the health-care standard HL7 FHIR as a practical solution to health data exchange and information systems interoperability. HL7 FHIR is a draft standard describing data formats and elements and an application programming interface for exchanging electronic health records especially in complex information systems so that patient data can be shared at all levels. Such data sharing is essential for countries to test, track, and treat and all malaria cases.

Before the involvement of the RMTF, in 2014 Viet Nam's Ministry of Health $(\mathrm{MOH})$, the US Center for Disease Control and Prevention, and private sector international partners had already begun collaborating to build a data warehouse using the electronic health disease surveillance system (eCDS). The government recognized that an enhanced eCDS system could reduce the time needed to generate disease surveillance reports, improve access to data on vaccine coverage rates, enhance early outbreak detection on a case-level basis, and allow for real-time malaria surveillance.

One important goal was to implement digital health solutions to ensure timely reporting for all notifiable diseases, including malaria, as mandated by Viet Nam's health policy. To bring all this work together, in February 2017, the MOH and the ADB met to identify a strategy and develop a workplan of activities and action for collaboration between the country's health agencies. Further strengthening of disease surveillance at local health facility levels, including for malaria, was identified as a priority with system interoperability and provincial training as a next step.

\section{Enabling Factors}

For most of the ICT projects under the RMTF, once local champions were identified, either within government or in partner organizations with a strong local presence, projects gained traction. Countries also benefited from guidance in establishing or enhancing their vision for digital health in disease surveillance, and policy design, rather than implementation of small-scale technical pilots, which can lead to even more fragmentation, as seen in malaria programs. Making the most of ADB's convening power, the RMTF projects brought together partners in ways they had not collaborated before, including separate ministries and departments within the same country, as well as uniting development partners to work more collaboratively toward a common goal. Another key enabler was deployment of both short-term international consultant experts and day-to-day engagement with local consultants.

15 Standards and Interoperability Lab for Asia. http://www.sil-asia.org/lab-assets/ 
The Viet Nam project succeeded because ADB brought key government decision makers together to get the foundations in place-standards, governance, and enterprise architecture-before launching in with new information systems. ADB was able to rally stakeholders and capitalize on the country leadership's commitment to malaria and communicable disease surveillance as a health priority. The introduction of geo-enabling tools for surveillance, health information standardization, interoperability for vertical disease programs, community level information systems such as the Digital Health Frame were wholeheartedly embraced by the $\mathrm{MOH}$. The decision to work with countries on their health-related ICT needs for malaria elimination existed at the start of the RMTF, but the project took off in Viet Nam in the latter part due to its right timing and commitment by all key stakeholders.

\section{Next Steps and Sustainability Pathway}

ADB helped establish both the Health GeoLab Collaborative, a collective of both institutions and individuals involved in geospatial technologies for health. Funding from the Bill \& Melinda Gates Foundation is supporting continued geo-enabling work in Viet Nam, MORU's risk mapping work in five GMS countries, and digital solutions to develop tools to support malaria elimination in Cambodia, the Lao PDR, and Viet Nam. Analysis of call data records to determine the impact of human mobility on malaria and dengue is ongoing.
ADB loans are in the pipeline for Viet Nam with an ICT component funded with an ADF grant to support the rollout of electronic health records with automated reporting of communicable diseases and malaria cases into vertical disease reporting systems. The Clinton Health Access Initiative and the National Institute of Malariology, Parasitology and Entomology, and Viettel Telecom and the Health Information Systems Programme Viet Nam continue to collaborate on developing the country's malaria management system aligned to new standard operating procedures and reporting forms for malaria case and foci reporting and investigation. Viet Nam is making its own investments in patient portals and cloud-based health information systems to support national information systems.

To further ensure the timely subnational patientlevel disease information, ADB supported the local health report automation by providing technical resources specific to District Health Information System (DHIS 2) that provides standardized health reporting from the 12,000 local health communes. This countrywide grassroots system will be connected with the district hospitals and national data center and is crucial in the timely access to patient-level communicable disease reporting and generation of the national health statistics. To help ensure standardization and disease reporting interoperability, ADB supported provincial-level $\mathrm{MOH}$ training of trainers and the drafting of standard operating procedures for reporting, which will also contribute to the sustainability of this project's achievements. 


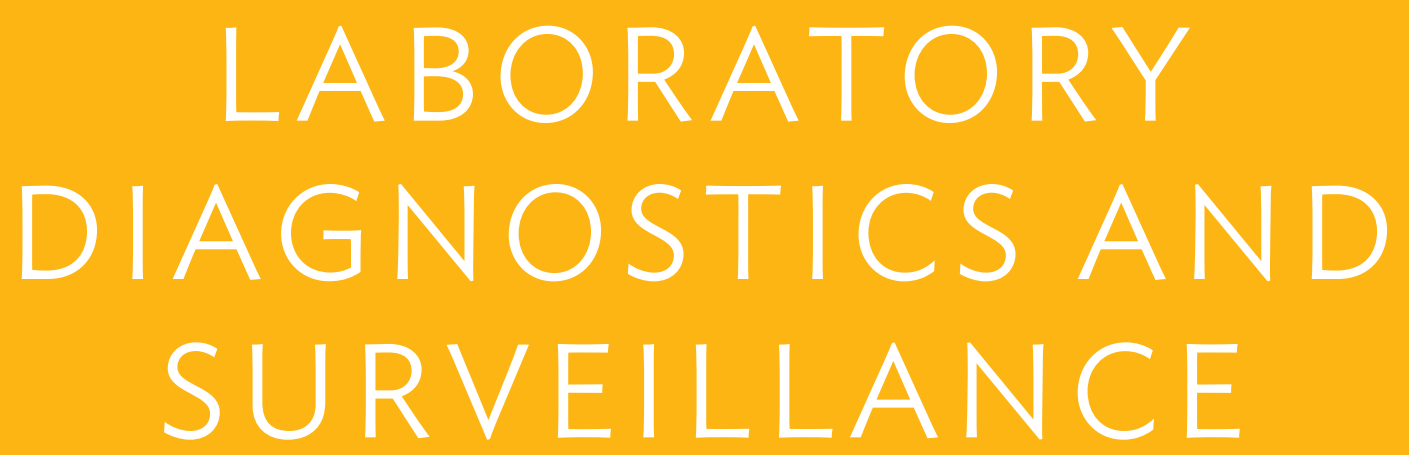

Improved capacity of laboratory diagnostics and surveillance systems

for malaria and other communicable diseases, including cross-border coordination
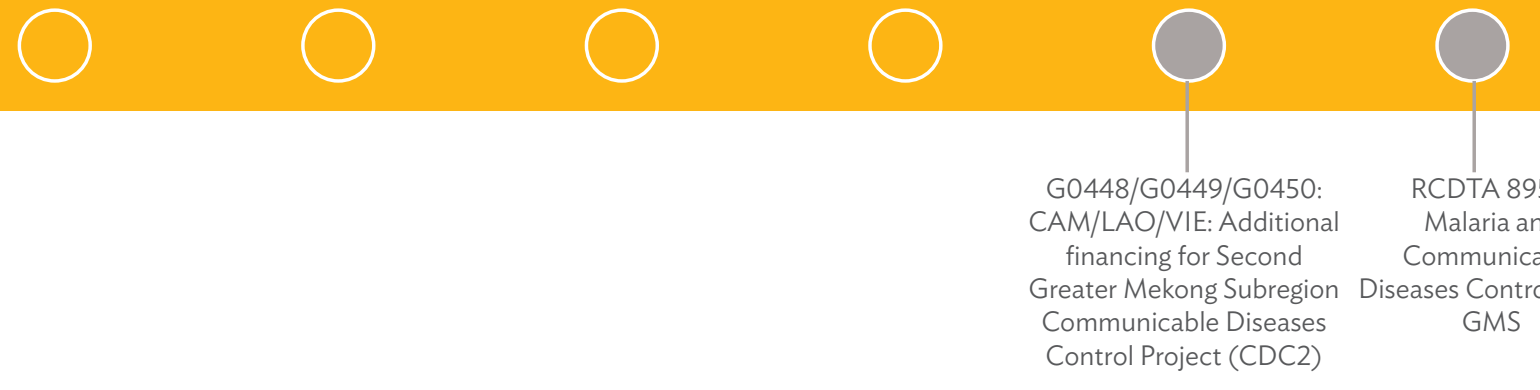

OUTCOME 5: Improved capacity of laboratory diagnostics and surveillance system for malaria, including cross border coordination

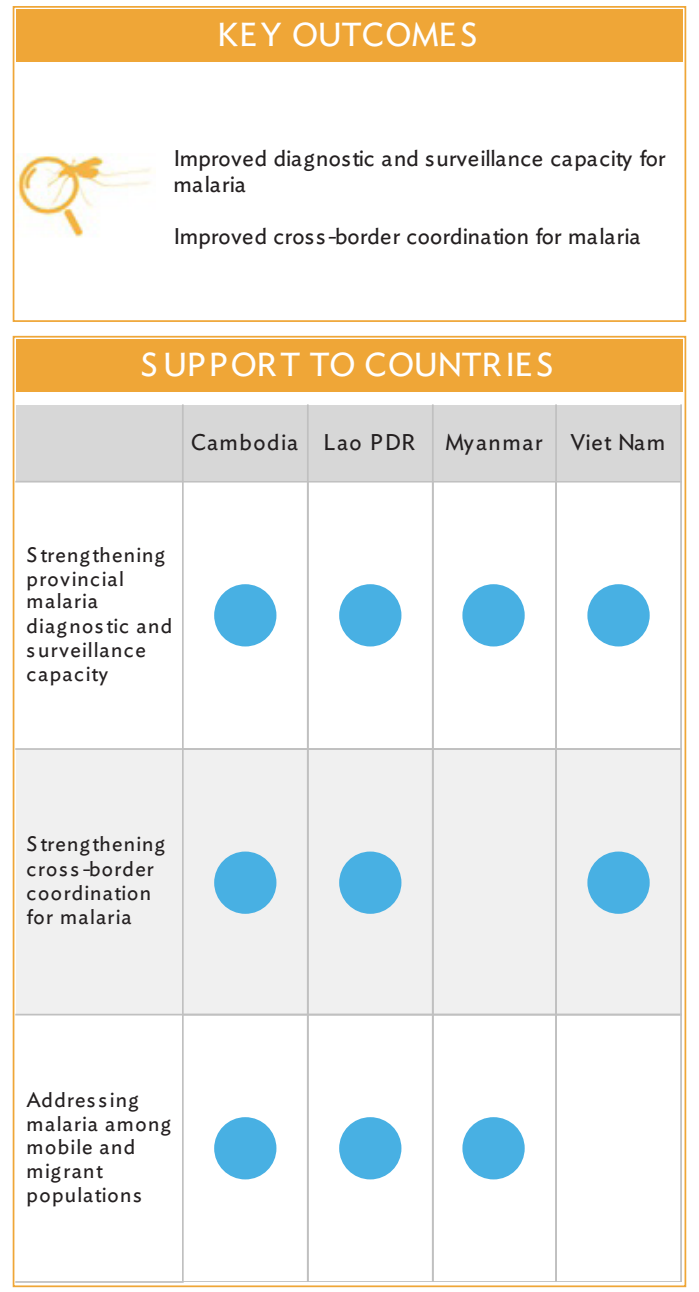

\begin{tabular}{|l|l|l|}
\hline & \multicolumn{2}{|c|}{ TRUS T FUND ALLOCATION } \\
\hline $\begin{array}{l}\text { Total } \\
\text { allocation } \\
\text { in million US } \$\end{array}$ & Share in RMTF \\
\hline
\end{tabular}

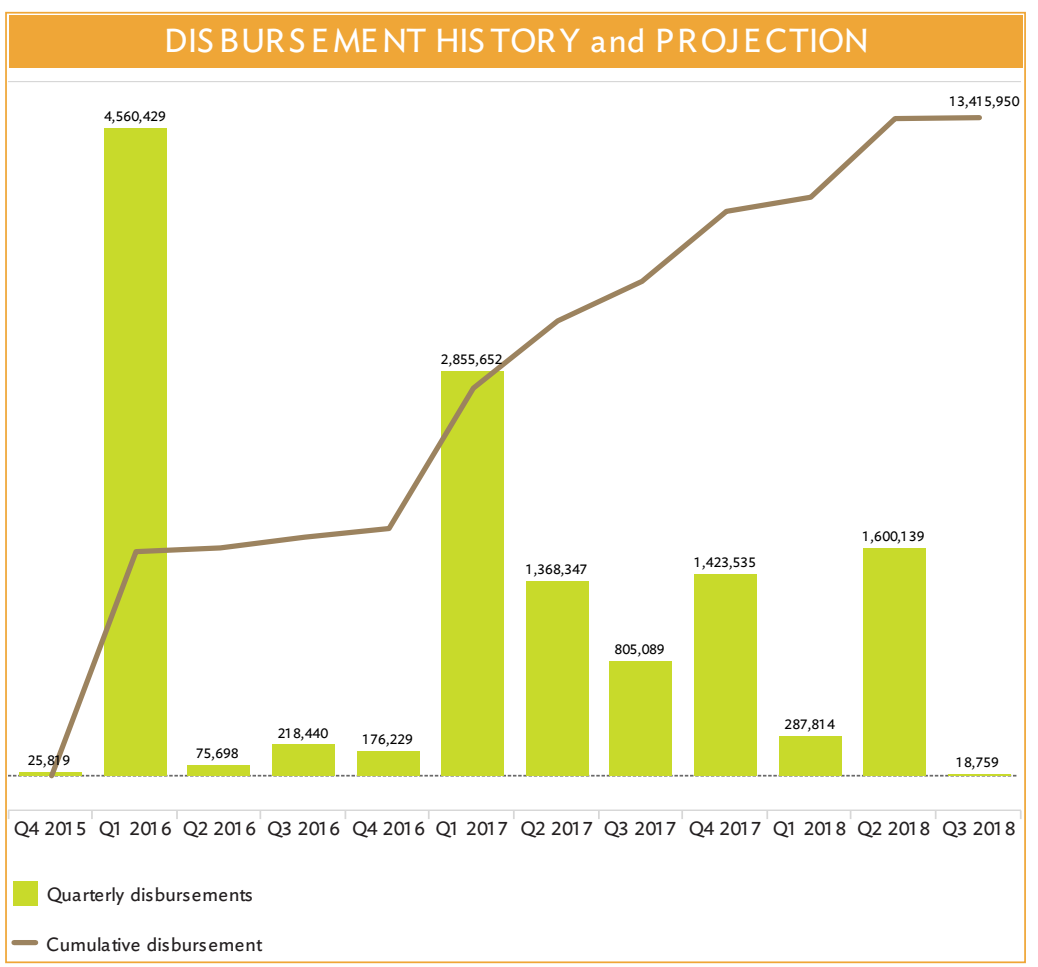




\section{Rationale}

Track, test, and treat is the mantra of malaria elimination, but this chain of events breaks down unless laboratory diagnostics and surveillance systems are strong and well-functioning. The RMTF aimed to leverage ADB's existing projects in communicable disease control that improved diagnostics and surveillance in the GMS, including to remote places and hard-to-reach populations, and strengthened cross-border cooperation.

Table 7: Results of Outcome $\mathbf{5 . 1}$

\begin{tabular}{|c|c|c|c|c|c|c|c|c|c|c|c|c|}
\hline \multirow{2}{*}{ Outcome Indicator } & \multirow{2}{*}{$\begin{array}{c}2014 \\
\text { Baseline }\end{array}$} & \multicolumn{2}{|c|}{ Status in } & \multirow{2}{*}{ Target } & \multirow{2}{*}{ Progress } & \multirow{2}{*}{\multicolumn{2}{|c|}{ Output Indicator }} & \multirow{2}{*}{$\begin{array}{c}2014 \\
\text { Baseline }\end{array}$} & \multicolumn{2}{|c|}{ Status in } & \multirow{2}{*}{ Target } & \multirow{2}{*}{ Progress } \\
\hline & & 2016 & 2017 & & & & & & 2016 & 2017 & & \\
\hline \multirow{3}{*}{$\begin{array}{l}\text { 1. Annual blood } \\
\text { examination per } 100 \\
\text { pop at risk for malaria } \\
\text { in the project areas* }\end{array}$} & & & & & & \multicolumn{7}{|c|}{ Diagnostic capacity for malaria } \\
\hline & & & & & & \multirow{3}{*}{$\begin{array}{l}\text { 1. Proportion of health } \\
\text { facilities in project areas } \\
\text { equipped with malaria } \\
\text { diagnostic equipment }\end{array}$} & CAM & 0 & 0 & 83 & 80 & 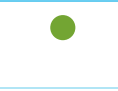 \\
\hline & & & & & & & LAO & 0 & 100 & 100 & 70 & 0 \\
\hline \multirow{4}{*}{$\frac{\text { Cambodia }}{\text { Preah Vihear Province }}$} & \multirow[t]{4}{*}{11.2} & \multirow[t]{4}{*}{6.7} & \multirow[t]{4}{*}{8.4} & \multirow[t]{4}{*}{10.0} & \multirow[t]{4}{*}{0} & & VIE $E^{* *}$ & 78 & 78 & 100 & 100 & 0 \\
\hline & & & & & & \multirow{9}{*}{$\begin{array}{l}\text { 2.Proportion of laboratory } \\
\text { staff in target provinces } \\
\text { trained in malaria } \\
\text { diagnosis }\end{array}$} & CAM & 0 & 0 & 100 & 100 & ○ \\
\hline & & & & & & & LAO & 0 & 0 & 96 & 70 & 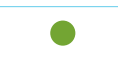 \\
\hline & & & & & & & \multirow[t]{7}{*}{ VIE } & \multirow[t]{7}{*}{0} & \multirow[t]{7}{*}{100} & \multirow[t]{7}{*}{100} & \multirow{7}{*}{100} & \multirow[t]{7}{*}{ ○ } \\
\hline$\frac{\text { Lao PDR }}{\text { Champassack Province }}$ & 12.7 & 7.9 & 9.2 & 10.0 & 0 & & & & & & & \\
\hline Attapeu Province & 25.5 & 13.4 & 18.5 & 10.0 & 0 & & & & & & & \\
\hline Saravane Province & 14.2 & 8.3 & 8.4 & 10.0 & 0 & & & & & & & \\
\hline Sekong Province & 17.4 & 12.1 & 14.6 & 10.0 & 0 & & & & & & & \\
\hline$\frac{\text { Viet Nam }}{\text { Binh Phuoc Province }}$ & 12.5 & 15.6 & 10.5 & 10.0 & 0 & & & & & & & \\
\hline Dak Nong Province & 12.8 & 10.4 & 13.3 & 10.0 & 0 & & & & & & & \\
\hline
\end{tabular}

Progress: Achieved at least $95 \%$ of target Substantial progress achieved

CAM = Cambodia, LAO = Lao People's Democratic Republic, VIE = Viet Nam.

* Data from the Ministry of Health

** Of the 182 commune health stations in the project areas, only 40 required new microscopes for malaria testing Source: Authors.

\section{Table 8: Results of Outcome 5.2}

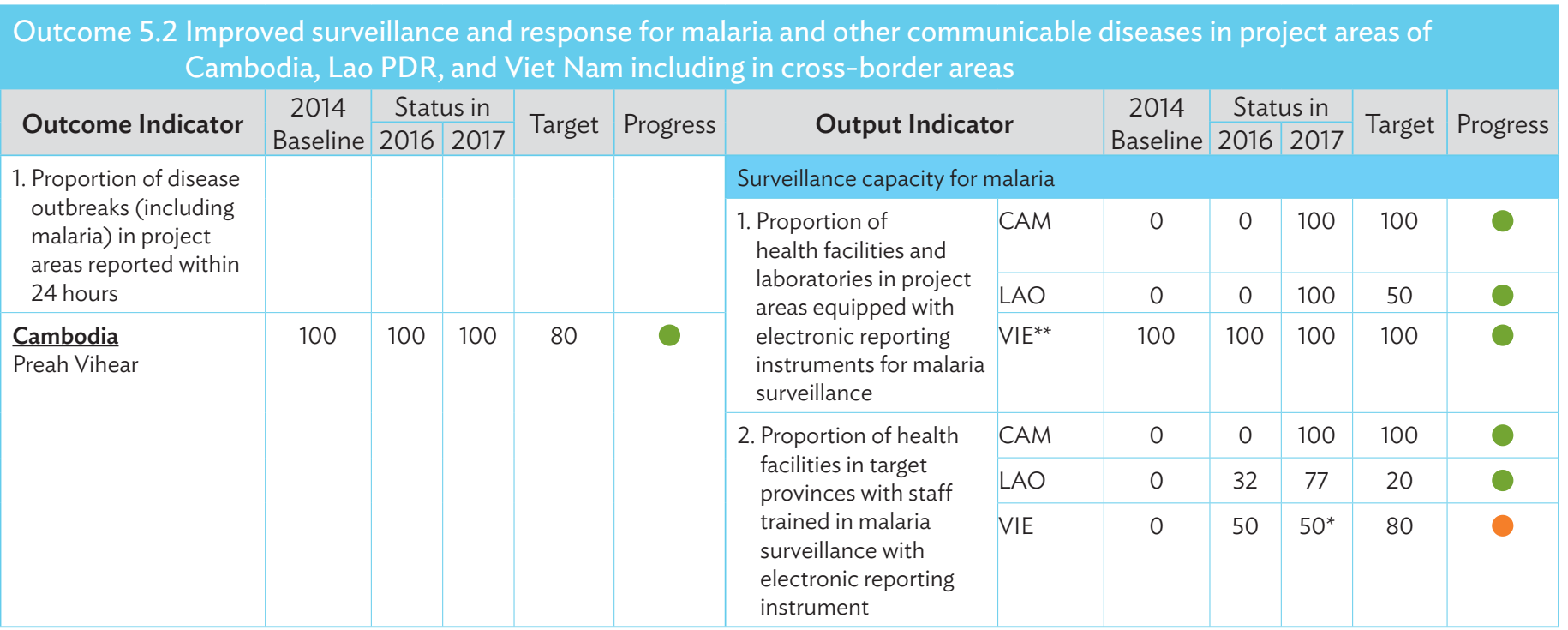


Table 8: continued

\begin{tabular}{|c|c|c|c|c|c|c|c|c|c|c|c|c|}
\hline \multirow{2}{*}{ Outcome Indicator } & \multirow{2}{*}{$\begin{array}{c}2014 \\
\text { Baseline }\end{array}$} & \multicolumn{2}{|c|}{ Status in } & \multirow{2}{*}{ Target } & \multirow{2}{*}{ Progress } & \multirow{2}{*}{\multicolumn{2}{|c|}{ Output Indicator }} & \multirow{2}{*}{$\begin{array}{c}2014 \\
\text { Baseline }\end{array}$} & \multicolumn{2}{|c|}{ Status in } & \multirow{2}{*}{ Target } & \multirow{2}{*}{ Progress } \\
\hline & & 2016 & 2017 & & & & & & 2016 & 2017 & & \\
\hline$\frac{\text { Lao PDR }}{\text { Champassack }}$ & 100 & 100 & 100 & 80 & - & \multicolumn{7}{|c|}{ Cross-border coordination and response for malaria } \\
\hline Attapeu & 50 & 100 & 100 & 80 & 0 & \multirow{3}{*}{$\begin{array}{l}\text { 3. Number of coordinated } \\
\text { cross-border action } \\
\text { plans developed } \\
\text { based on GMS malaria } \\
\text { elimination strategy } \\
\text { in targeted border } \\
\text { provinces }\end{array}$} & dCAM & 0 & 0 & 1 & 1 & 0 \\
\hline Saravane & 100 & 80 & 100 & 80 & 0 & & LAO & 0 & 2 & 2 & 2 & ○ \\
\hline Sekong & 100 & 60 & 83 & 80 & 0 & & VIE & 0 & - & - & 3 & \\
\hline$\frac{\text { Viet Nam }}{\text { Binh Phuoc }}$ & 100 & 100 & $100^{*}$ & 80 & 0 & \multirow{10}{*}{$\begin{array}{l}\text { 4. Number of village } \\
\text { health workers at } \\
\text { border provinces } \\
\text { trained in malaria } \\
\text { control and treatment }\end{array}$} & CAM & 0 & 0 & 331 & 332 & 0 \\
\hline Dak Nong & 100 & 100 & $100^{*}$ & 80 & 0 & & LAO & 0 & 0 & 322 & 60 & 0 \\
\hline $\begin{array}{l}\text { 2. Proportion of border } \\
\text { disease outbreaks } \\
\text { (including malaria) in } \\
\text { project areas reported } \\
\text { across borders within } \\
24 \text { hours }\end{array}$ & & & & & & & \multirow[t]{8}{*}{ VIE } & \multirow[t]{8}{*}{0} & \multirow[t]{8}{*}{236} & \multirow[t]{8}{*}{$236^{*}$} & \multirow[t]{8}{*}{40} & \multirow[t]{8}{*}{0} \\
\hline$\frac{\text { Cambodia }}{\text { Preah Vihear }}$ & NA & NA & NA & 50 & & & & & & & & \\
\hline$\frac{\text { Lao PDR }}{\text { Champassack }}$ & 100 & 100 & 100 & 50 & 0 & & & & & & & \\
\hline Attapeu & 50 & 100 & 100 & 50 & 0 & & & & & & & \\
\hline Saravane & 100 & 80 & 100 & 50 & 0 & & & & & & & \\
\hline Sekong & 100 & 60 & 83 & 50 & 0 & & & & & & & \\
\hline$\frac{\text { Viet Nam }}{\text { Binh Phuoc }}$ & 100 & 100 & $100^{*}$ & 50 & 0 & & & & & & & \\
\hline Dak Nong & 100 & 100 & $100^{*}$ & 50 & 0 & & & & & & & \\
\hline
\end{tabular}

Progress: Achieved at least $95 \%$ of target Substantial progress achieved

CAM $=$ Cambodia, $\mathrm{LAO}=$ Lao People's Democratic Republic, NA - no outbreaks of regional or international relevance, VIE $=$ Viet Nam.

* As of Q1 2017

** Facilities already have the needed equipment

*** No specific cross-border action plans were developed by provinces but six cross-border activities were incorporated into the provincial annual operational plans that were all implemented

Source: Authors.

\section{Table 9: Results of Outcome 5.3}

\begin{tabular}{|c|c|c|c|c|c|c|c|c|c|c|c|}
\hline \multirow{2}{*}{ Outcome Indicator } & \multirow{2}{*}{$\begin{array}{c}2014 \\
\text { Baseline }\end{array}$} & \multicolumn{2}{|c|}{ Status in } & \multirow{2}{*}{ Target } & \multirow{2}{*}{ Progress } & \multirow{2}{*}{ Output Indicator } & \multirow{2}{*}{$\begin{array}{c}2014 \\
\text { Baseline }\end{array}$} & \multicolumn{2}{|c|}{ Status in } & \multirow{2}{*}{ Target } & \multirow{2}{*}{ Progress } \\
\hline & & 2016 & Q2 2018 & & & & & 2016 & Q2 2018 & & \\
\hline $\begin{array}{l}\text { 1. National malaria } \\
\text { diagnostic quality } \\
\text { assurance guidelines } \\
\text { endorsed by the } \\
\text { National Malaria } \\
\text { Control Program }\end{array}$ & & & & & & $\begin{array}{l}\text { 1. Proportion of health } \\
\text { facilities in project areas } \\
\text { equipped with malaria } \\
\text { diagnostic equipment }\end{array}$ & 44 & 0 & 100 & 100 & - \\
\hline Mon State & No & No & Yes & Yes & ○ & $\begin{array}{l}\text { 2. Proportion of } \\
\text { laboratory staff in } \\
\text { target provinces trained } \\
\text { in malaria diagnosis }\end{array}$ & 24 & 0 & 96 & 100 & - \\
\hline Sagaing Region & No & No & Yes & Yes & ○ & $\begin{array}{l}\text { 3. National malaria } \\
\text { diagnostic quality } \\
\text { assurance guidelines } \\
\text { developed }\end{array}$ & No & No & Yes & Yes & ○ \\
\hline
\end{tabular}


Table 9: continued

\begin{tabular}{|c|c|c|c|c|c|c|c|c|c|c|c|}
\hline \multirow{2}{*}{ Outcome Indicator } & \multirow{2}{*}{$\begin{array}{c}2014 \\
\text { Baseline }\end{array}$} & \multicolumn{2}{|c|}{ Status in } & \multirow{2}{*}{ Target } & \multirow{2}{*}{ Progress } & \multirow{2}{*}{ Output Indicator } & \multirow{2}{*}{$\begin{array}{c}2014 \\
\text { Baseline }\end{array}$} & \multicolumn{2}{|c|}{ Status in } & \multirow{2}{*}{ Target } & \multirow{2}{*}{ Progress } \\
\hline & & 2016 & Q2 2018 & & & & & 2016 & Q2 2018 & & \\
\hline \multicolumn{6}{|l|}{$\begin{array}{l}\text { 2. Annual blood } \\
\text { examination per } 100 \\
\text { pop at risk for malaria } \\
\text { in the project areas }\end{array}$} & & & & & & \\
\hline $\begin{array}{l}\text { Mon State (Project } \\
\text { townships average) } \\
\text { (Mawlamyaing, Belin, } \\
\text { Paung, Kyaikhto) }\end{array}$ & 4.2 & - & $13.5^{*}$ & $8.0^{* * * *}$ & - & & & & & & \\
\hline $\begin{array}{l}\text { Sagaing Region (Project } \\
\text { townships average) } \\
\text { (Hkamti, Homalin, } \\
\text { Paungbyin, Taze, } \\
\text { Monywa, Pale) }\end{array}$ & 3.1 & - & $24.1^{*}$ & $8.0^{* * * *}$ & O & & & & & & \\
\hline
\end{tabular}

Progress: Achieved at least $95 \%$ of target

$\mathrm{Q}=$ quarter

* Data for 2017

** Total number of 43 health facilities

***Total number of 83 staff

**** ABER target for 2020 in Myanmar, WHO-Malaria NSP 2016-30

Note: 2016 data was not collected because the project interventions started only in 2017.

a This outcome indicator is used only for Myanmar. RCDTA8959 supports the development of national guidelines on laboratory diagnostic and surveillance and is consistent with the Monitoring and Result Framework of the ADB Technical Assistance Document for RCDTA8959 developed with concurrence from the Government of Myanmar. For Myanmar, the output indicator on cross border coordination is not included since the project has a limited scope on it while focusing on internal migrant and mobile populations. RCDTA8959 also supports MMP-related activities in Cambodia and the Lao PDR.

${ }^{\mathrm{b}}$ Estimated total number of beneficiaries (1,984,915 under laboratory diagnostics: and 969,585 under surveillance).

c RCDTA8959 supports the Government of Myanmar in developing of a model to strengthen its laboratory diagnostic and surveillance system at local level in two project areas (Mon State and Sagaing Region), which is expected to roll out in the entire country, while simultaneously supporting the government capacity at the central level.

Source: Authors.

Table 10: Results of Outcome 5.4

\begin{tabular}{|c|c|c|c|c|c|c|c|c|c|c|c|}
\hline Outcome Indicator & $\begin{array}{c}2014 \\
\text { Baseline }\end{array}$ & \multicolumn{2}{|c|}{ Status in } & Target & Progress & Output Indicator & $\begin{array}{c}2014 \\
\text { Baseline }\end{array}$ & \multicolumn{2}{|c|}{ Status in } & Target & Progress \\
\hline $\begin{array}{l}\text { 1. National malaria } \\
\text { surveillance guidelines } \\
\text { endorsed by the } \\
\text { National Malaria } \\
\text { Control Program }\end{array}$ & & & & & & $\begin{array}{l}\text { 1. Proportion of health } \\
\text { staff in project areas } \\
\text { equipped with electronic } \\
\text { reporting instruments } \\
\text { for malaria surveillance* }\end{array}$ & 0 & 0 & 97 & 100 & 0 \\
\hline Mon State & No & No & Yes & Yes & 0 & $\begin{array}{l}\text { 2. Proportion of health } \\
\text { staff in target provinces } \\
\text { trained in malaria } \\
\text { surveillance with } \\
\text { electronic reporting } \\
\text { instrument }\end{array}$ & 0 & 0 & 97 & 100 & O \\
\hline Sagaing Region & No & No & Yes & Yes & O & \multirow{3}{*}{$\begin{array}{l}\text { 3. National malaria } \\
\text { surveillance guidelines } \\
\text { developed }\end{array}$} & \multirow[t]{3}{*}{ No } & \multirow[t]{3}{*}{ No } & \multirow[t]{3}{*}{ Yes } & \multirow[t]{3}{*}{ Yes } & \multirow[t]{3}{*}{ - } \\
\hline Mon State & NA & NA & $* *$ & 80 & 0 & & & & & & \\
\hline Sagaing Region & NA & NA & ** & 80 & 0 & & & & & & \\
\hline
\end{tabular}

Progress: Achieved at least $95 \%$ of target

$\mathrm{NA}=\mathrm{NA}-$ no outbreaks of regional or international relevance, $\mathrm{Q}=$ quarter.

${ }^{*}$ Total number of health staff and village health volunteers

** All malaria cases were reported real-time within 24 hours by mDMS (mobile database malaria surveillance)

$\mathrm{NA}$ - no outbreaks of regional or international relevance

Source: Authors. 


\section{Communicable Disease Control 2- Additional Financing}

The additional financing for malaria-related activities directed efforts toward controlling and eliminating malaria elimination through regional and country structures and processes already established under the ADB Communicable Disease Project 2 (CDC2). By allocating investments to the continuation of an existing ADB project, the RMTF was able to take previous gains, elevate them, and include malaria-specific interventions. Malaria activities funded under the RMTF complemented and augmented the national malaria programs in Cambodia, the Lao PDR, and Viet Nam and were synchronized with donor partners' ongoing involvements in malaria and in addressing the spread of artemisinin resistance in the region.

In all three countries, the project's activities strengthened and sustained vector control, promoted behavioral change, and strengthened malaria diagnosis, treatment, and surveillance capabilities. Through this project the RMTF was able to work at the grassroots level in cross-border areas, an otherwise extremely challenging environment in which to make an impact. The project brought about cooperation between the national malaria program and the communicable disease control (CDC) program at the central, provincial, and district levels. The two programs selected intervention sites together and jointly defined their priorities and resources needs for those sites.

In the areas identified for coverage by the RMTF project, support included provision of computer hardware, microscopes and other lab equipment; diagnostic supplies; and updating of lab standard operating procedures (SOPs) and quality assurance manuals and guidelines. The national malaria programs noted improvement in the quality of clinical diagnostic and case management through training conducted on malaria case management and treatment, surveillance for provincial and district health staff, and village health workers. Cross-border activities included disease information exchange, which included malaria and joint outbreak response simulation exercises.

\section{Laboratory Quality Assurance and Malaria Surveillance in Myanmar}

The RMTF-funded TA8959 project developed manuals, SOPs, and algorithms for malaria laboratory quality assurance for Myanmar. By bringing together the National Health Laboratory (NHL) and the NMCP, the project changed the way the two agencies worked together, which in turn also helped the NHL work with other disease agencies.

Data management systems for malaria surveillance in the project areas was strengthened, including the use of mobile data management system (mDMS) for case reporting, and analytical tools for decisionmaking. It worked with grassroots volunteer malaria workers to improve routine, and real-time case reporting through a mobile data management system piloted in the three townships. The mDMS, a smartphone-based app, was developed by Save the Children with the NMCP, but RMTF funding enabled widespread piloting of the app for volunteer malaria workers and the initial results helped improve the app to make it more efficient and more user-friendly. The NMCP and other development partners are reviewing the mDMS together with another mobile app developed by WHO for facilitybased health workers.

\section{Migrant and Mobile Populations}

In Cambodia, the Lao PDR, and Myanmar, the RMTF extended the reach of the health system by training and equipping village health volunteers and migrant workers for malaria diagnosis and treatment, and mobile traders as volunteer peer educators to conduct health education and prevention. These volunteers formed the first line of defense against communicable diseases. The International Organization for Migration (IOM) worked with the national malaria programs in the three countries to develop innovative approaches to address malaria needs of migrant and mobile populations in work settings such as gold and jade mines, rubber plantations, and dam construction sites. 
One of the key successes of the project is the engagement of the private sector by tapping and mobilizing camp site and construction managers as malaria volunteers. The managers were granted permission by the corporation heads to implement malaria control and prevention programs in their respective worksites. A final review mission in March 2018 found that mobile traders from the Lao PDR and Viet Nam, who ply around the district and who were trained as malaria peer educators, were found to effectively reach mobile and migrant populations (MMPs) with systematic malaria monitoring and have good coordination with the village volunteers.

\section{Enabling Factors}

Overall, building on existing project management units and the regional cooperation mechanisms established under the CDC2 project in Cambodia, the Lao PDR, and Viet Nam accelerated the achievements of the CDC2 AF in the provinces and districts and institutionalized malaria-specific SOPs.

In Myanmar, bringing together two different actors - the national health laboratories and the national malaria control program-under a common framework was transformational. With common SOPs and manuals on laboratory quality assurance, they were able for the first time to synchronize their reporting. Recruiting the right partners was also key: University Research Co. LLC (URC), and the IOM were chosen for their existing strong and deep presence in Myanmar and the Lao PDR. They brought with them an understanding of the local landscape, and existing relationships that could not be quickly achieved by a new player, smoothing the way for a good consultation process with country counterparts.

\section{Next Steps and Sustainability Pathway}

\section{Case Detection and Laboratory Testing} In the Lao PDR, the reduction in malaria incidence can also be attributed to government efforts, including discouraging illegal logging and people going into forests, and increased army patrols. Malaria cases may start to rise if these efforts are not sustained, through cooperation with the private sector and

the military.

There is need to sustain and expand ICT infrastructure for better case reporting, as well as staff competencies on facility management, infection control, disease management through more health-care worker training. There is also a need to strengthen subnational financial management, so that funds reach the districts where they are required, to properly implement the 1-3-7 malaria elimination strategy. ${ }^{16}$

In Cambodia, as for the other GMS countries, mechanisms for microscopy skills retention and laboratory quality assurance should be in place, as fewer malaria cases will be seen during the elimination phase. While laboratory staff in Cambodia, for example, have stated a preference to use rapid diagnostic tests rather than microscopy, since this is easier, health-care workers should actually perform microscopy for malaria diagnosis. This is in line with the country's malaria elimination strategy, which states that each case must be confirmed by microscopy before treatment can be provided, as recommended by WHO. The technical support under CDC2-AF was able to provide microscopes, training on microscopy, and updated guidelines. The microscopes provided can digitally capture and share digital image of the blood smears. This cuts down diagnosis time and should facilitate timely treatment.

The country's medicine stocking and redistribution policy and processes should be adjusted. Cambodia experienced stockouts of malaria testing kits and medicines in 2018. The malaria program claims that this was due to the unexpected increase in the malaria cases, and there were difficulties restocking. Extra supplies from other provinces could not be directly channeled to the facilities where they were needed, as these commodities had to be first be channeled back to the central level.

16 The 1-3-7 malaria elimination strategy entails reporting of malaria cases within 1 day, confirmation and investigation within 3 days, and response to prevent further transmission within 7 days. 
Malaria $P$. vivax cases are increasing and this requires glucose-6-phosphate dehydrogenase (G6PD) testing and close supervision during treatment, patient counseling and access to blood transfusion services for G6PD-deficient individuals. This will require health facilities and service providers in malaria endemic areas to have the right laboratory equipment and commodities, training, and mechanisms for medical supervision of G6PDdeficient cases.

\section{Cross-Border Information Exchange}

Cambodia, the Lao PDR, and Viet Nam have started to exchange data on an agreed list of communicable diseases of public health significance. However, the frequency and timeliness of information exchange can still be improved, and data standards, such as for case definition, need to be aligned.

\section{Migrant and Mobile Populations}

In discussions with the members of the Cambodia malaria program, it is clear that MMPs are still one of the main sources of malaria transmission and drug resistance. It also appears that the government does not have the capacity to address MMP issues, which include a general lack of access to health services, especially for foreign MMPs and undocumented workers. Some tend to self-medicate and travel to home countries to access health services. The issue of malaria elimination among MMPs must be integrated into the national health strategy, and addressing the issue of how to reach MMPs will also require stronger collaboration with the private sector.
Another challenge is sustaining the motivation, skills, and work of malaria health volunteers and peer educators as malaria incidence goes down and when Global Fund grant support for GMS countries ends and financing switches to their governments instead. In Cambodia, the government cannot pay for activities that are conducted beyond 20 kilometers from the health facilities, and most MMPs are forest goers. The government therefore relies on NGOs, which also have flexible systems that allow them to pay for volunteer health workers people outside the public health system. Treatment compliance among MMPs is also challenging. The first dose of malaria treatment is usually administered at the health facility, but problems remain with ensuring completion of treatment doses.

In Myanmar, the project with URC started under the RMTF will continue through Defeat Malaria Activity funded by the United States Agency for International Development. The Global Fund is working on funding support for IOM-Myanmar to continue its work on malaria and migrant and mobile population in the RMTF project sites. Central and provincial health offices in Cambodia and the Lao PDR have committed to sustain mobilization of village volunteers, particularly training of mobile traders as outreach and peer educators. This model was piloted under CDC2-AF has been expanded to the other provinces using Global Fund grants. 


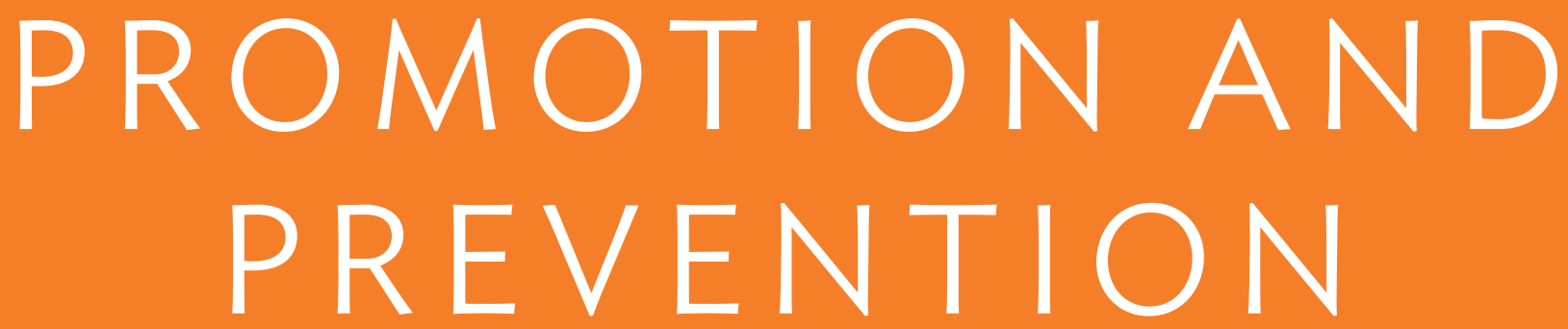

Increased capacity to apply heath impact assessment to consider determinants of health and communicable diseases in infrastructure projects

\section{R-CDTA 8763:}

Results for Malaria Elimination and Control of Communicable

Diseases Threats in Asia and the Pacific (RECAP)

Output 6 communicable diseases addressed in infrastructure projects

\section{OUTCOME 6: Increased capacity to address communicable diseases in infrastructure projects}

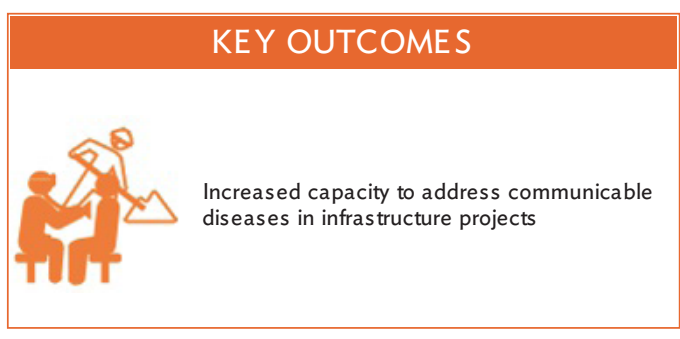

\begin{tabular}{|l|l|l|l|l|}
\hline \multicolumn{3}{|c|}{ HEALTH IMPACT AS S S S MENT } \\
DEMONS TRATION PR OJECT \\
\hline & Cambodia Lao PDR & Myanmar & Thailand & Viet Nam \\
\hline Energy & & & \\
\hline Transport & & & \\
\hline $\begin{array}{l}\text { Urban } \\
\text { development }\end{array}$ & & & \\
\hline Water supply & & & \\
\hline $\begin{array}{l}\text { Water and } \\
\text { sanitation }\end{array}$ & & & \\
\hline $\begin{array}{l}\text { Special } \\
\text { economic } \\
\text { zones }\end{array}$ & & & \\
\hline
\end{tabular}
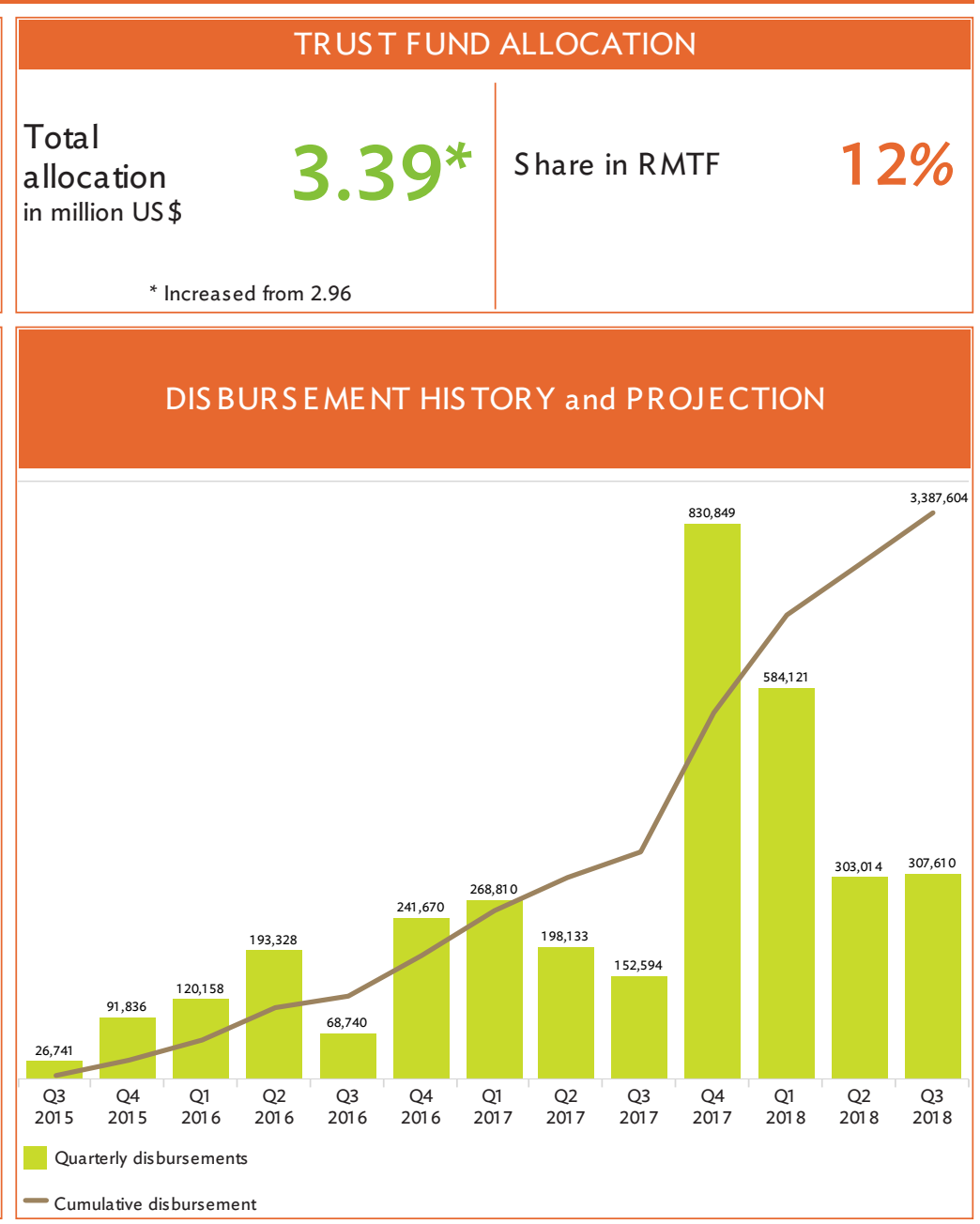


\section{Rationale}

Infrastructure projects have a health dimension that can be assessed, the impact ameliorated, and the benefits magnified to prevent malaria and other communicable diseases, and promote healthy development. The current public health challenges that stem from the interface of development and environmental and social change include the impacts of developing economic corridors and special economic zones (SEZs), issues of air quality, water and food security, and growing mobility. Antimicrobial resistance and poor coverage of informal often mobile and migrant population groups working in infrastructure development projects also justify the need for HIA.

\section{Malaria Prevention in Infrastructure Development}

The promotion and prevention component of the RMTF promoted HIA as a means to mitigate vectorborne diseases risks in large-scale infrastructure projects and improve community health outcomes. Large infrastructure projects attract mobile and migrant populations - those most at risk of malaria. The RMTF created an opportunity to advance HIA, particularly in the GMS, as a good practice to ensure project designs can safeguard and promote human health. The promotion of HIA was timely given the current public health challenges that stem from the interface of development and environmental and social change.

In the GMS countries, HIA policies and practice and efforts to include HIA as a formal part of infrastructure development planning and investment practice have been at different stages of development. Under the RMTF, HIA was promoted as an intersectoral approach to protecting and promoting community health and safety. Capacity for HIA practice expanded in the GMS in the past 2 years with RMTF support. The project became a catalyst for renewed interest for $\mathrm{HIA}$ as a development planning tool drawing attention to health risks and health co-benefits and facilitating healthy design and management of infrastructure projects.
An interrelated package of support was provided, to GMS countries and at regional level, for capacity development. To demonstrate HIA good practice, case studies were conducted in various sectors, i.e., energy, SEZs and border development, transport, urban development, and water and sanitation. These case studies, considering both community and occupational health and safety, offered recommendations to manage risks and benefits as part of the project planning, design and implementation.

\section{Case Study in Urban Development Project}

An HIA was developed for Mandalay Urban Services Improvement Project 1, which included a Public Health Management Plan (PHMP) with health indicators for monitoring of community health impacts. Stakeholder consultations promoted collaboration between project stakeholders and public health authorities for the implementation of the PHMP and discussion of institutional arrangements for the monitoring and management of vector-related diseases such as malaria and their environmental determinants.

The meetings also enabled discussions on strengthening the capacity of local public health and environmental conservation teams to support public awareness and education campaigns. Project stakeholders, including government local health and environment staff, were trained on HIA.

\section{Case Studies in Special Economic Zones and Border Development}

HIAs were initiated in three SEZs-Savannakhet (Savan-SENO), the Lao PDR; Mukdahan, Thailand; Thilawa, Myanmar and in a border economic zoneYunnan Lincang Border Economic Cooperation Zone Development, People's Republic of China (PRC). In the PRC, HIA involved rapid scoping and an analysis of health risks such as vector-borne diseases and impacts and recommendations for mitigation. The recommendations, developed in partnership with local health officials, were required to protect both workers and community members, include malaria services and supplemental to the 
Table 11: Results of Outcome 6.1

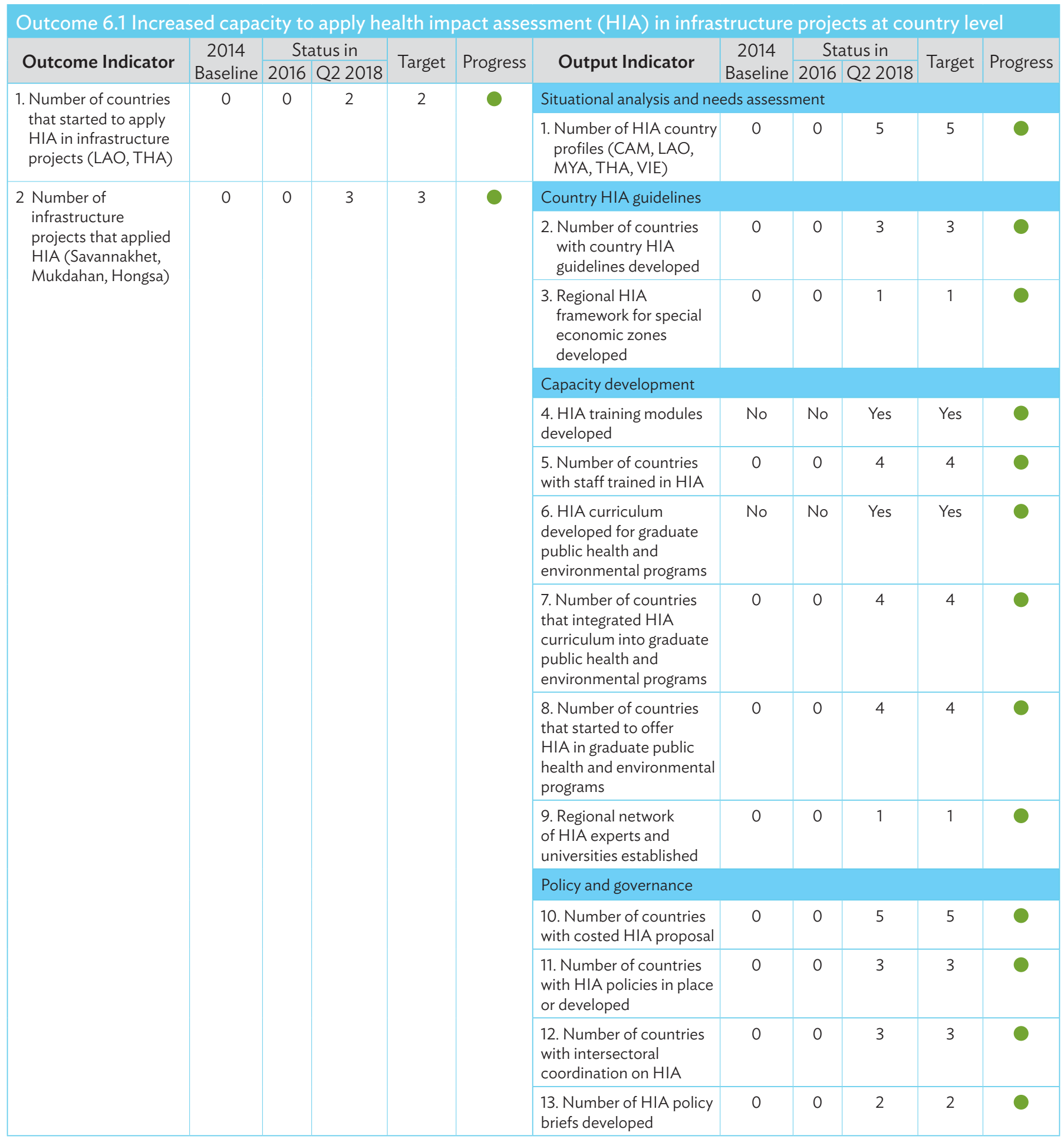

Progress: Achieved at least $95 \%$ of target

CAM = Cambodia, HIA = health impact assessment, Lao PDR = Lao People's Democratic Republic, MYA = Myanmar, THA = Thailand, VIE = Viet Nam . Source: Authors. 
Table 12: Results of Outcome 6.2

\begin{tabular}{|c|c|c|c|c|c|c|c|c|c|c|c|}
\hline \multirow{2}{*}{ Outcome Indicator } & \multirow{2}{*}{$\begin{array}{c}2014 \\
\text { Baseline }\end{array}$} & \multicolumn{2}{|c|}{ Status in } & \multirow{2}{*}{ Target } & \multirow{2}{*}{ Progress } & \multirow{2}{*}{ Output Indicator } & \multirow{2}{*}{$\begin{array}{c}2014 \\
\text { Baseline }\end{array}$} & \multicolumn{2}{|c|}{ Status in } & \multirow{2}{*}{ Target } & \multirow{2}{*}{ Progress } \\
\hline & & 2016 & Q2 2018 & & & & & 2016 & Q2 2018 & & \\
\hline \multirow{3}{*}{$\begin{array}{l}\text { 1. Number of } \\
\text { ADB-supported } \\
\text { infrastructure projects } \\
\text { in malaria-endemic } \\
\text { areas that applied } \\
\mathrm{HIA}^{*} \text { (CAM, MYA, } \\
\text { VIE) }\end{array}$} & \multirow[t]{3}{*}{0} & \multirow[t]{3}{*}{0} & \multirow[t]{3}{*}{4} & \multirow[t]{3}{*}{4} & \multirow[t]{3}{*}{ - } & $\begin{array}{l}\text { 1. ADB HIA tools } \\
\text { developed (sourcebook } \\
\text { and checklists) }\end{array}$ & No & Yes & Yes & Yes & 0 \\
\hline & & & & & & $\begin{array}{l}\text { 2. ADB HIA training } \\
\text { modules developed }\end{array}$ & No & Yes & Yes & Yes & O \\
\hline & & & & & & $\begin{array}{l}\text { 4. ADB HIA tools } \\
\text { integrated into ADB } \\
\text { processes }\end{array}$ & No & No & Yes & Yes & - \\
\hline
\end{tabular}

Progress: Achieved at least $95 \%$ of target ${ }^{*}$ Desktop review $\mathrm{ADB}=$ Asian Development Bank, CAM = Cambodia, $\mathrm{HIA}=$ health impact assessment, $\mathrm{MYA}=$ Myanmar, VIE = Viet Nam. Source: Authors.

existing environment impact assessment and management plan.

HIA in the three SEZs enabled the development of an HIA framework for SEZs in the GMS, which can serve as a management tool for the continued development of healthy economic zones in the subregion. ${ }^{17}$ Country-specific guidelines were also produced for the Lao PDR, Myanmar, and Thailand reflecting their local context and specific requirements. Cross-border cooperation has also been promoted, with the Lao PDR and Thailand bilateral cooperation agreement for joint health surveillance and reporting, particularly in the affected border areas between Savannakhet and Mukdahan SEZs.

\section{Curriculum Development and Training}

To increase HIA capacity in the region key government agencies and universities should cooperate to improve the skills and knowledge of those currently involved in HIA, and build a new generation of HIA experts. In partnership with the WHO Collaborating Center for Impact Assessment at Curtin University (WHO CC-Curtin University) three curricula were developed-a standalone HIA course; HIA in environmental impact assessment; and HIA in planning, environment, or health courses. Using adapted curricula, certificate courses were subsequently offered by six GMS universities and parallel training workshops were led by health ministries. Over $600 \mathrm{HIA}$ practitioners from key government agencies and staff from the private sector have been trained on basic principles and practice of HIA, application of tools, exploring decision-making criteria and options for institutional arrangements between the health and environment sectors to support a coordinated approach to HIA. Within ADB, ADB staff have been trained on HIA as part of staff development training program, using the bank's own funding.

\section{Regulation and Guidelines}

To ensure infrastructure projects do not inadvertently increase the risk of malaria and undermine efforts to eliminate the disease, national legislation for HIA implementation is essential. In the GMS, both the Lao PDR and Thailand have an HIA policy as part of their healthy public policy since 2006 and 2000 , respectively. Technical assistance through RMTF made possible a review of HIA policy and implementation and the development of sector-specific guidelines for these countries. In Cambodia, Myanmar, and 
Viet Nam, the RMTF has enabled discussion between ministries of health and ministries of environment on the integration of health into the well-functioning environment impact assessment processes. Moreover, HIA guidelines have been prepared for these countries for further intergovernmental review led by each country's ministry of health. Country and sector-specific guidelines allow for more explicit community health and workers' health and safety components in infrastructure development, which can be used as part of the malaria elimination effort in these countries.

Within ADB, an HIA sourcebook has been developed, providing clear procedures to ensure commitment for community and occupational health and safety are met in the development and implementation of projects. Following this new guideline, advocacy for HIA in large projects continues, including consultation with safeguards staff on stronger monitoring of health impacts from projects to mitigate risks of malaria. Further, an addendum on health has been proposed for inclusion in the ADB Handbook on Poverty and Social Analysis. This could support the assessment of community health attributes of a project.

\section{Enabling Factors}

At the country level, the key to success of every project was the presence of a local champion within the country counterpart agencies, and also engagement of local consultants who could carry the work of the international consultants forward in the local language. Keeping HIA highly visible within ADB over a protracted period of time paid off, both in terms of creating demand for HIA training, and for advocacy for resources to continue the work started under the RMTF. The project came at a time when a tipping point could be reached within $A D B$, and the bank has become the only multilateral financing institutions with so much experience in
HIA to share with development partners. Engaging with the WHO CC-Curtin University on HIA to develop curricula and then disseminating them through local universities was a very successful strategy to mainstream $\mathrm{HIA}$ and make local training in it sustainable.

\section{Next Steps and Sustainability Pathway}

Countries still have unexploited opportunities to formally adopt national HIA guidelines and other HIA tools, particularly in the provinces. Within the health sector, institutional arrangements must govern HIA with clear and functional links to other $\mathrm{MOH}$ departments and health programs. There is a need to further strengthen intersectoral cooperation to apply HIAs and implement PHMP to mitigate risks of malaria and other communicable disease threats as it relates to development projects. This requires clear institutional arrangements between public health, environment, and planning authorities, including at provincial level.

Governments still need to agree on the nature of HIA, not only in terms of health risk assessment with a view to mitigation, but also in identification of health opportunities to promote health co-benefits from development projects., such as through provision of health services to MMPs who often work in large development projects, integrated border development projects or SEZs. To encourage and sustain improvements in the practice of HIA, a network was established jointly with the WHO CC-Curtin University. It is envisaged that the HIA Network Asia Pacific will facilitate collaboration between countries and HIA practitioners, including research and sharing of good practices. ${ }^{18}$ The GMS Health Cooperation Strategy and Action Plan for 2018-2022 will guide forward programming and mobilizing resources for health cooperation, and includes HIA as one of the strategic and operational priorities. This provides additional opportunities to expand HIA work in the GMS.

18 About the HIA Network Asia Pacific. http://www.hianetworkasiapac.com/about/ 


\section{KNOWLEDGE PRODUCTS AND PUBLICATIONS}

Regional Malaria and Other Communicable Disease Threats Trust Fund ADB. 2015. Malaria Elimination: An entry point for strengthening heath systems and regional security, and a public health best buy. Manila. https://www.adb. org/sites/default/files/publication/178203/malariaelimination.pdf

\section{Leadership}

M. Counahan et al. 2018. Investing in Regional Health Security for Sustainable Development in Asia and the Pacific. ADB Sustainable Development Working Paper Series No. 56. Manila: Asian Development Bank. https://www.adb.org/ publications/regional-health-security-asia-pacific

\section{Medicines}

S. Roth et al. 2018. Strong Regulation of Medical Products: Cornerstone of Public Health and Regional Health Security. ADB Briefs. No. 99. Manila: Asian Development Bank. https://www.adb.org/ sites/default/files/publication/456866/adb-brief099-strong-regulation-medical-products.pdf

S. Roth et al. 2018. Portable Screening Devices for Medicines Quality: Putting Power into the Hands of Regulators in Low-Resource Settings. ADB Briefs. NO.101. Manila: Asian Development Bank. https:// www.adb.org/sites/default/files/publication/461051/ adb-brief-101-screening-devices-medicine-quality.pdf
S. Roth et al. 2016. Strong Supply Chains Transform Public Health. ADB Briefs. No. 72. Manila: Asian Development Bank. https://www.adb.org/sites/ default/files/publication/214036/strong-supplychains.pdf

S. Roth et al. 2016. Better Regulation of Medicines Means Stronger Regional Health Security. ADB Briefs. No. 54. ADB Briefs No. 54, Manila: Asian Development Bank. https://www.adb.org/sites/ default/files/publication/184392/better-regulationmedicine.pdf

\section{Information Technology}

ADB. Forthcoming. Digital Health Convergence Meeting Toolkit.

P. Drurry et al. 2018. Guidance for Investing in Digital Health. ADB Sustainable Development Working Paper Series. No.52. Manila: Asian Development Bank. https://www.adb.org/sites/ default/files/publication/424311/sdwp-052guidance-investing-digital-health.pdf

ADB. 2018. Unique Health Identifier Assessment Tool Kit. Manila https://www.adb.org/documents/ unique-health-identifier-assessment-toolkit

A. Marclo et al. 2018. Transforming Health Systems Through Good Digital Health Governance. ADB Sustainable Development Working Paper Series. No. 
51. Manila: Asian Development Bank. https://www. adb.org/publications/transforming-health-systemsgood-digital-health-governance.

S. Ebener et al. 2018. Building Capacity for GeoEnabling Health Information Systems: Supporting Equitable Health Services and Well-Being for All. ADB Briefs. No. 88. Manila: Asian Development Bank. https://www.adb.org/publications/buildingcapacity-geo-enabling-health-informationsystems.

S. Mellor et al. 2016. Digital Health Infrastructure: The Backbone of Surveillance for Malaria Elimination. ADB Briefs. No. 69. Manila: Asian Development Bank. https://www.adb.org/sites/ default/files/publication/210856/digital-healthinfrastructure.pdf.

M. Stahl et al. 2018. On the Road to Universal Health Coverage Every Person Matters. ADB Briefs. No. 56. Manila: Asian Development Bank. https:// www.adb.org/sites/default/files/publication/183512/ uhc-every-person-matters.pdf

S. Roth et al. 2016. The Geography of Universal Health Coverage. ADB Briefs. No. 55. Manila: Asian Development Bank. https://www.adb.org/sites/ default/files/publication/183422/geography-uhc.pdf
S. Roth et al. 2015. Universal Health Coverage By Design. ADB Briefs. No. 36. Manila: Asian Development Bank. https://www.adb.org/sites/ default/files/publication/160117/universal-healthcoverage-design-ict.pdf

\section{Promotion and Prevention}

ADB. 2018. A Health Impact Assessment Framework for Special Economic Zones in the Greater Mekong Subregion. Manila. https://www. adb.org/publications/health-impact-assessmentframework-economic-zones-gms.

ADB. 2016. Greater Mekong Subregion Health Impact Assessment Project: Project Brief. Manila. https:// www.adb.org/publications/gms-health-impactassessment-project-brief.

\section{Others}

ADB and World Health Organization. 2016. Monitoring Universal Health Coverage in the Western Pacific. Framework, indicators and dashboard. Manila. https://www.adb.org/sites/default/files/ publication/203926/uhc-western-pacific.pdf. 


\section{GENDER DIMENSIONS}

ADB's Strategy 2020 identifies gender equity as one of the five drivers of change that are emphasized in all of its operations. ADB's commitment to gender equality is integral to the management of the RMTF. ADB loans and grants meeting specific requirements include a gender action plan (GAP), with a clear monitoring and evaluation framework.

There are several specific gender issues related to malaria and other communicable diseases, which are considered under the RMTF implementation. Men are more at risk to contract malaria through occupational exposure during night time in rubber plantations, forests and mines, for example. On the other hand, women shoulder the main burden of taking care of sick family members, and pregnant women are more vulnerable to develop severe malaria. However, typically there is a lack of sexdisaggregated data in national malaria information systems. In terms of malaria project staffing, although there are more female than male villagelevel malaria workers, at the management level in national malaria programs, there are more men than women. In some settings, such as plantations deep in forested areas where it was difficult or dangerous for women to work, it was more appropriate to work with male volunteers rather than females.

Gender activities were integrated into the implementation of the main activities of the project, notably the additional financing to Second GMS Regional Communicable Diseases Control Project, which specifically included gender action plans for each country to address some of the issues raised above.

Some key achievements for Cambodia, the Lao PDR, and Viet Nam are detailed in the following tables, according to three dimensions: (i) enhancement of opportunities for female staff in Center for Disease Control systems and improved gender analysis in regional CDC systems; (ii) improved responsiveness of CDC to gender/ethnic issues in targeted districts and/or province and increased participation and awareness of women in CDC prevention in project location; and (iii) enhanced gender-awareness and responsiveness of CDC project management.

Highlights include the fact that $100 \%$ of surveillance and response data in the Lao PDR is sexdisaggregated. In Viet Nam, data collected since 2016 is disaggregated and in Cambodia, malaria and other key communicable disease data has been sexdisaggregated. This data is widely used in project plans across the three countries. All three have also shown marked increased in hiring of new female staff, increasing the overall proportion of female staff from 44\% in 2012 to $54 \%$ in 2016 Cambodia, and from $45 \%$ in 2014 to $61.7 \%$ in 2016 in the Lao PDR. Women are equally represented in the ranks of volunteer health workers (VHW) in the Lao PDR, account for 44\% of VHWs trained since 2012 in Cambodia, and accounted for the majority trained in Viet Nam. 


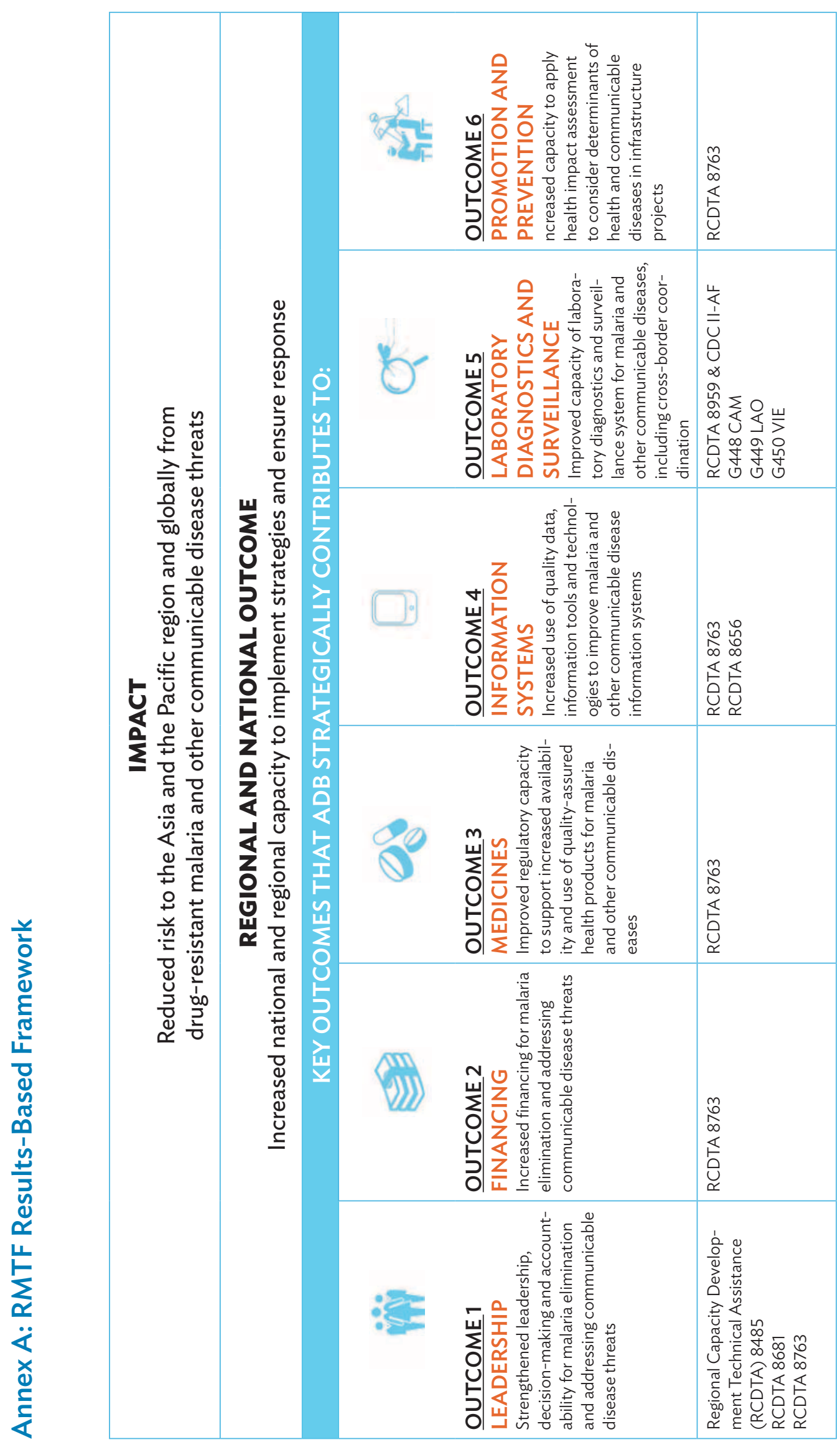




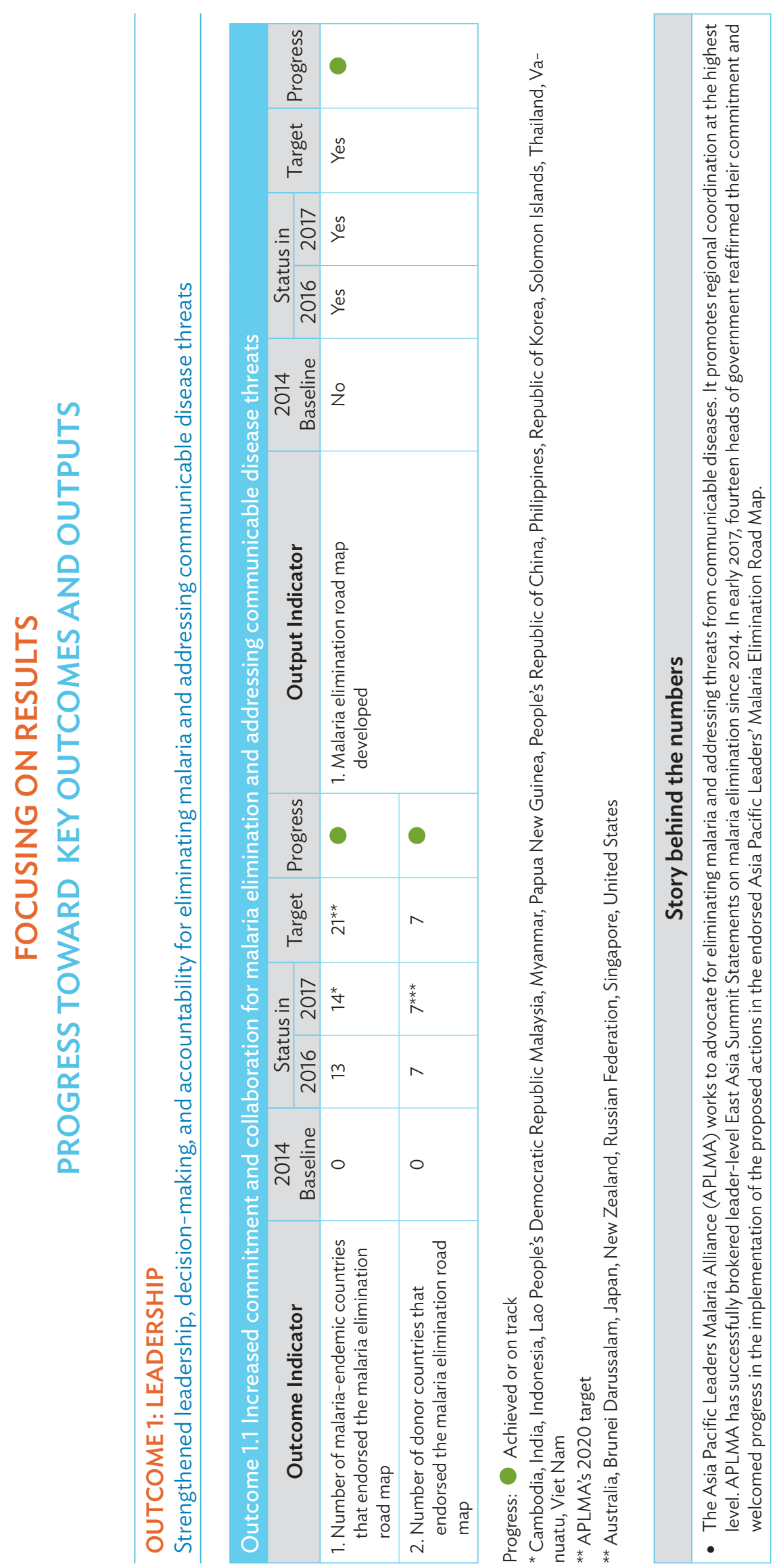



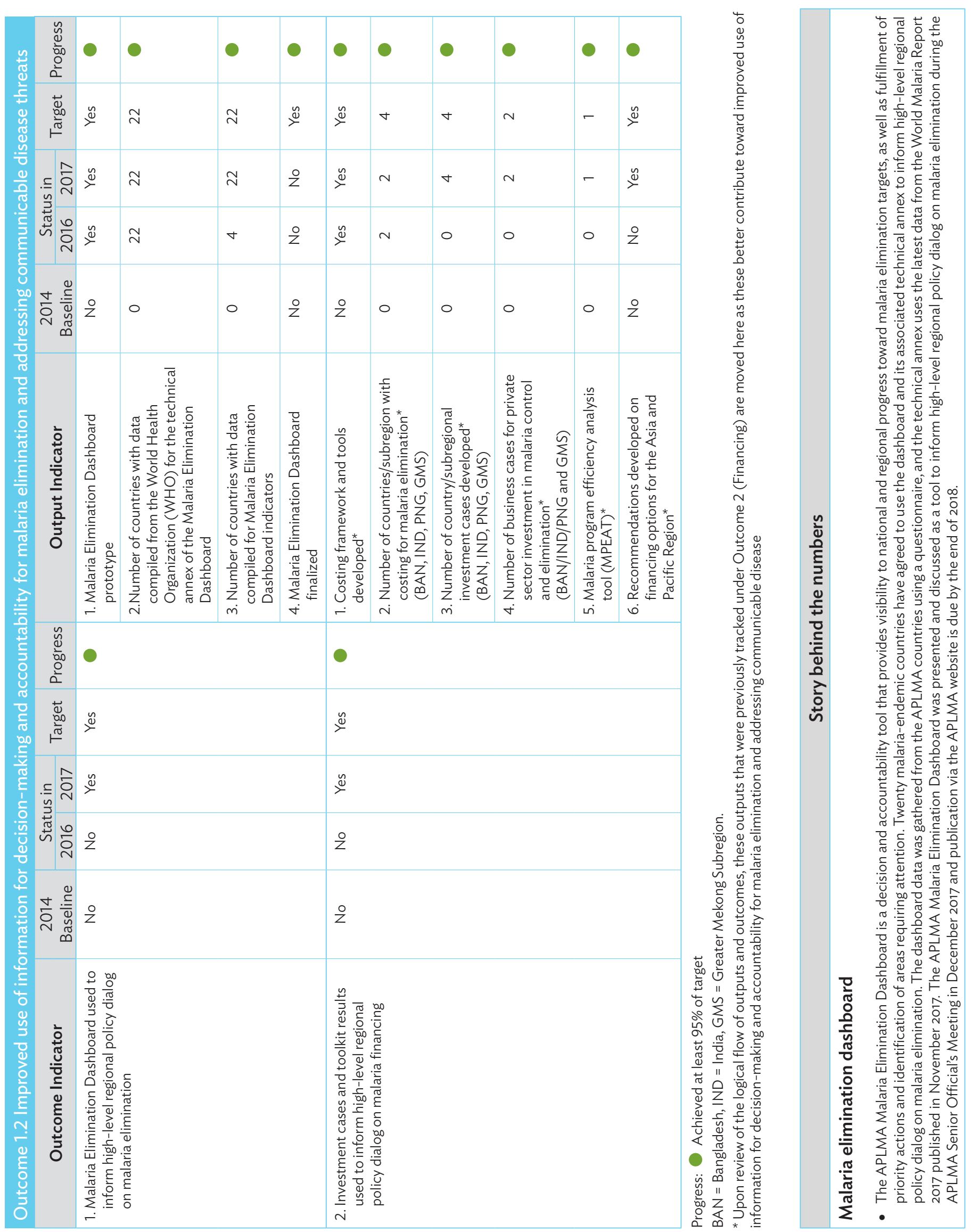


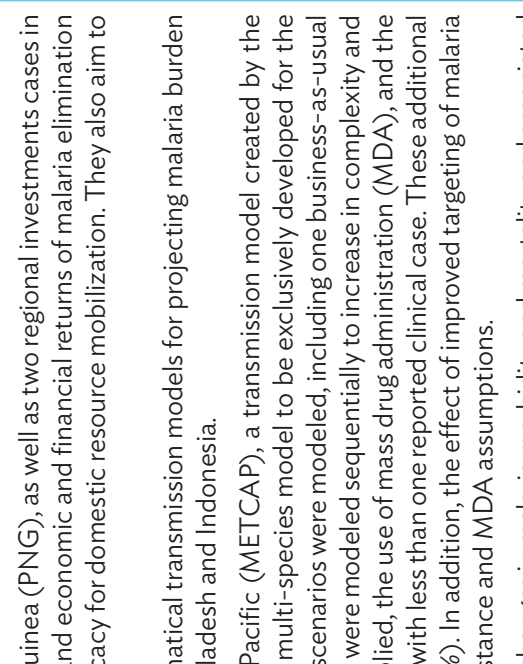

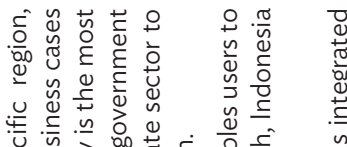

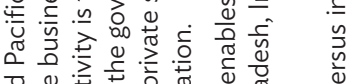

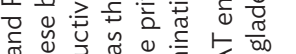

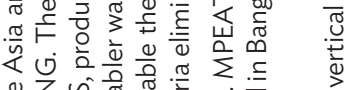

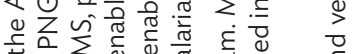

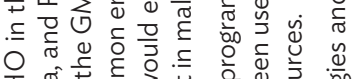

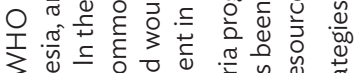

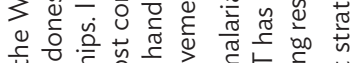

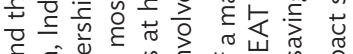

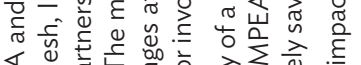

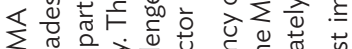

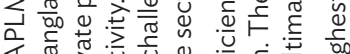

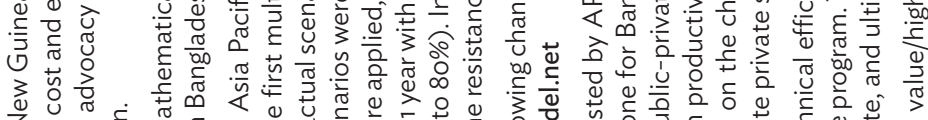

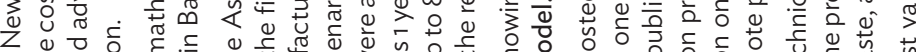

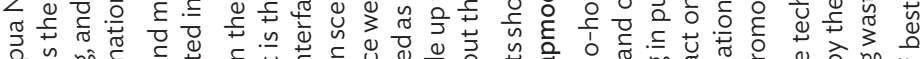

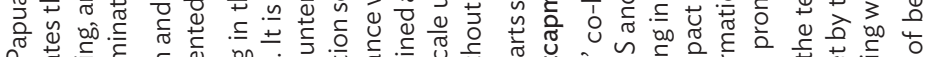

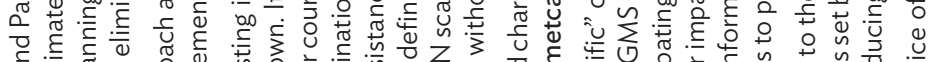

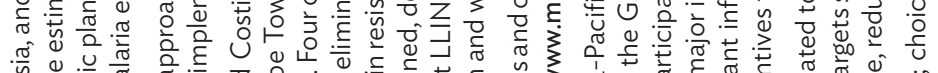

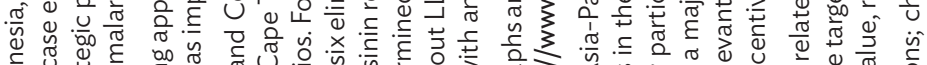

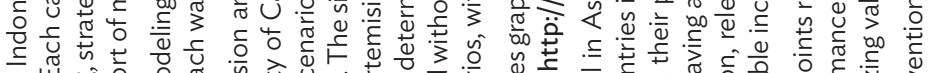

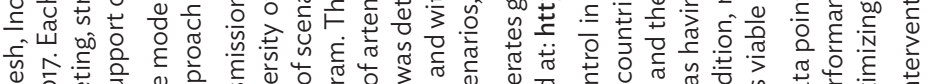

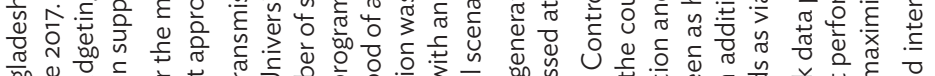

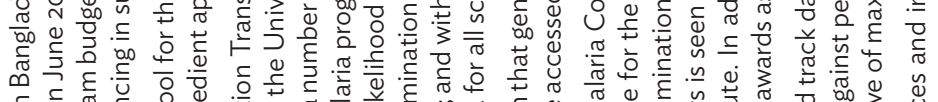

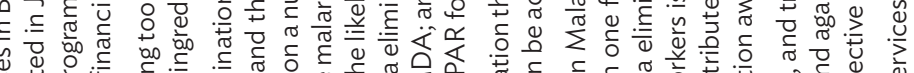

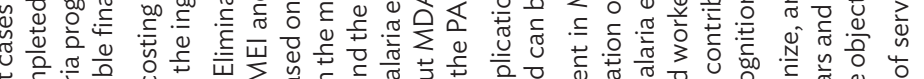

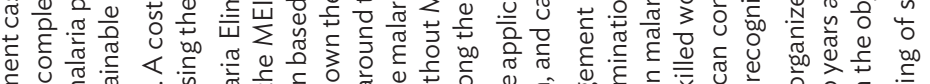

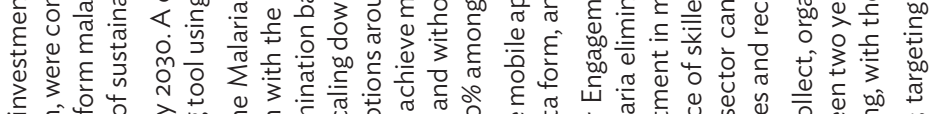

б.

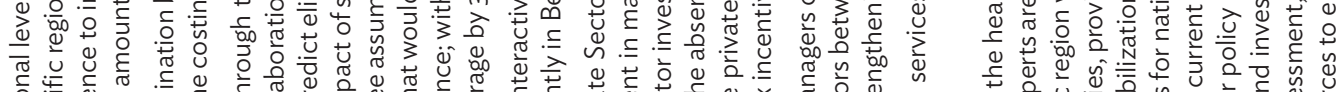

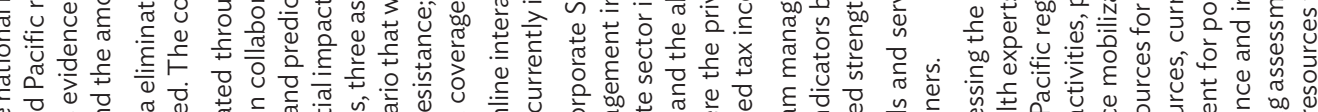

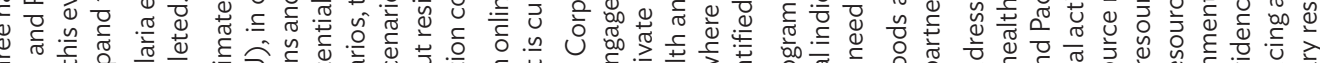

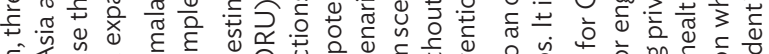

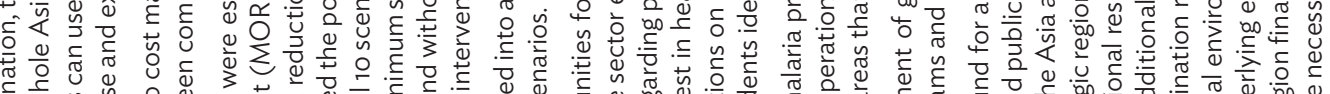

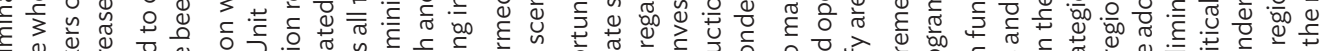

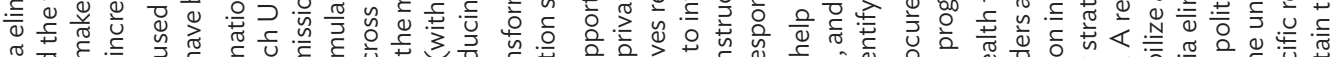

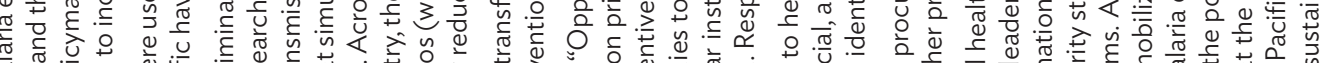

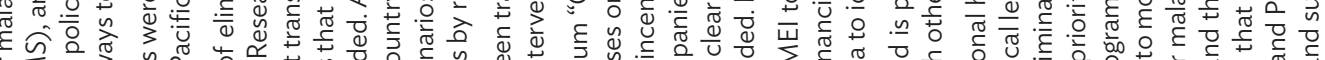

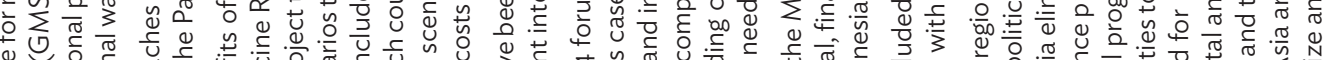

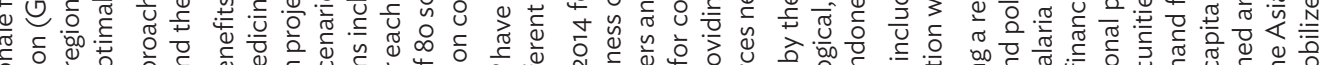

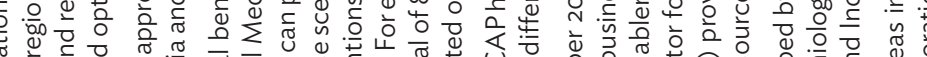

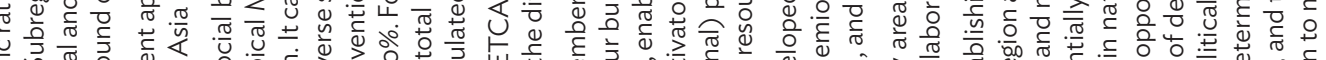

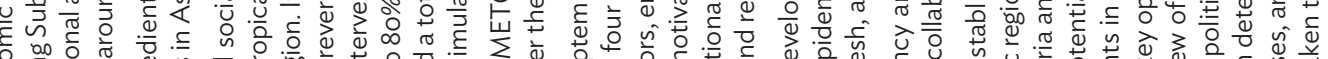

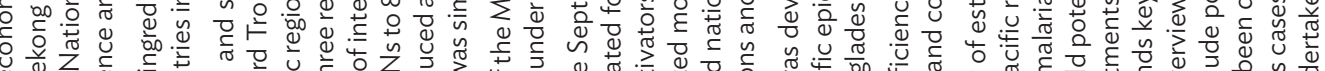

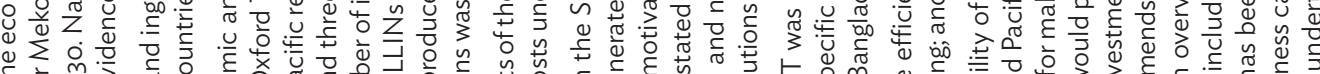

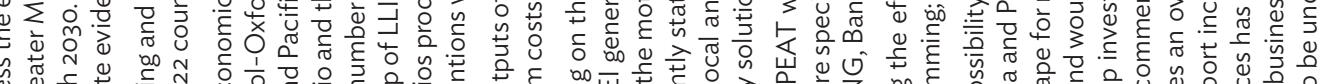

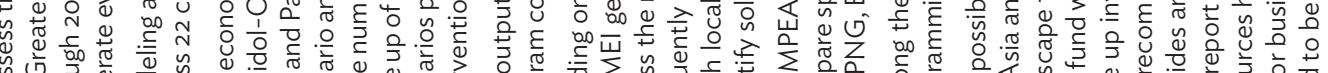

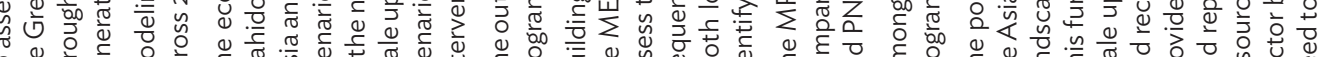

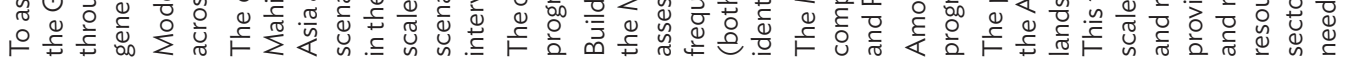




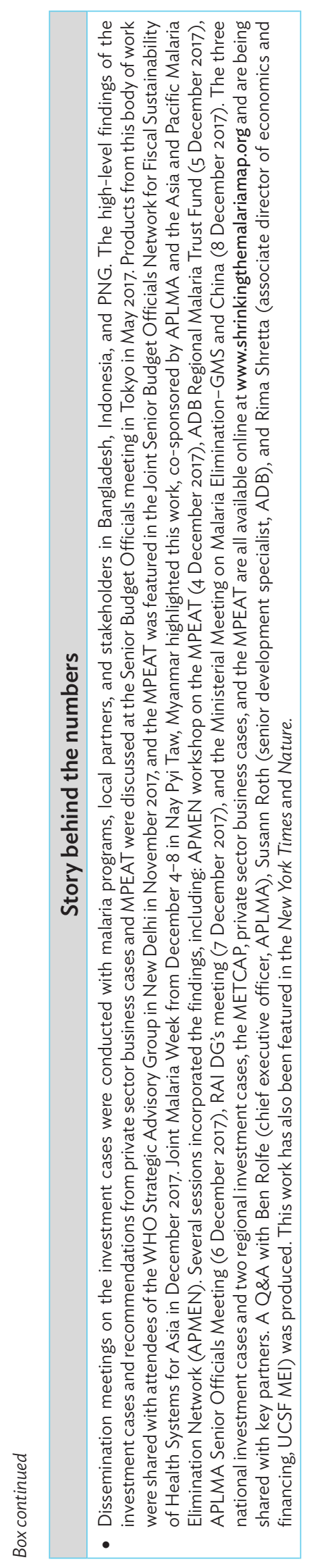



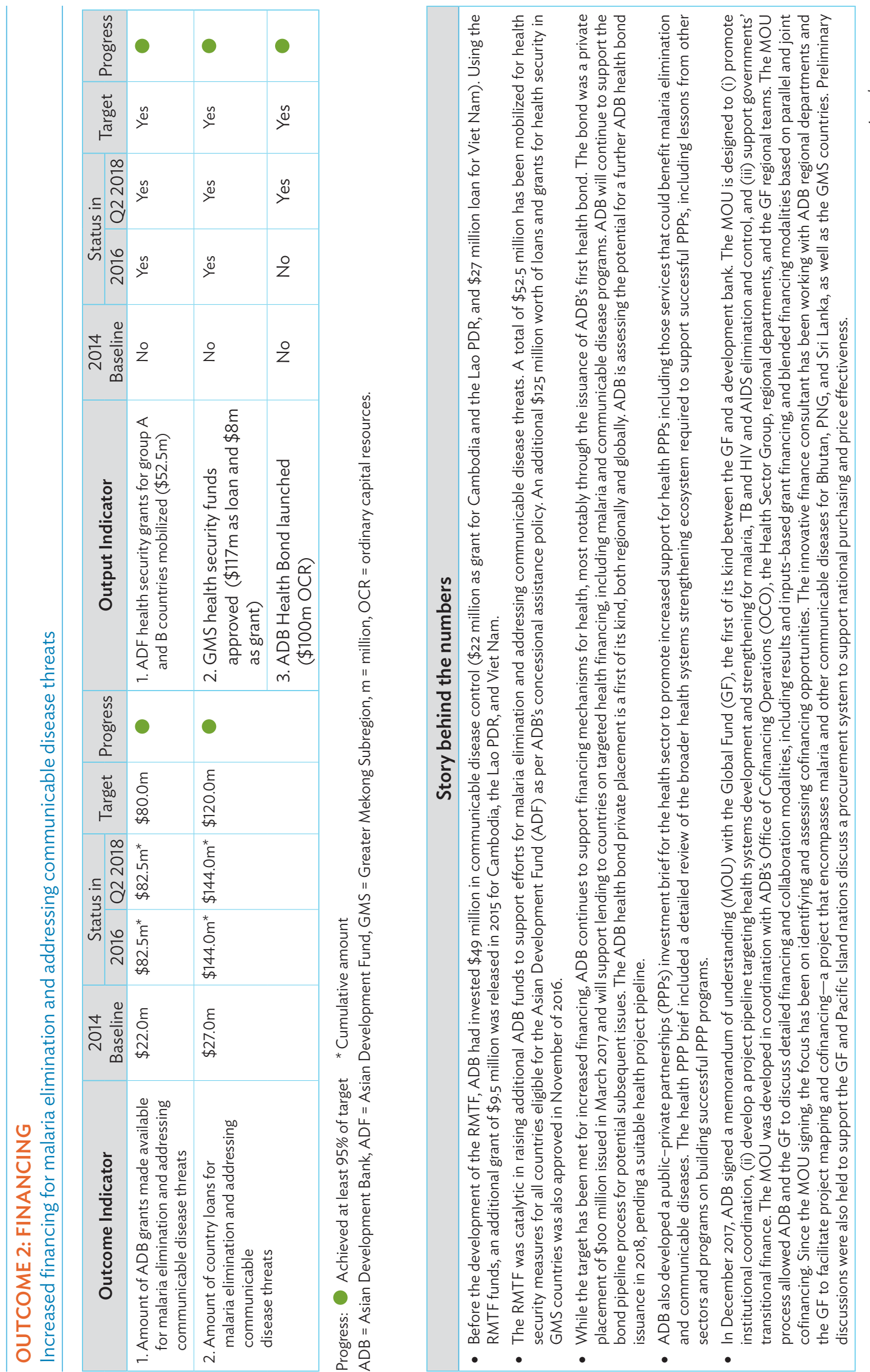


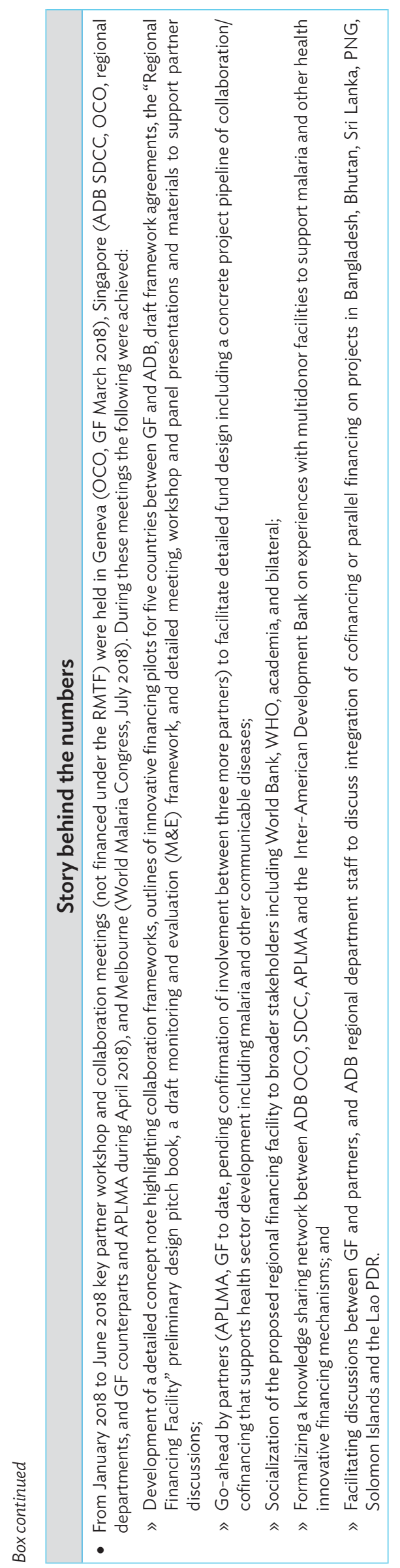




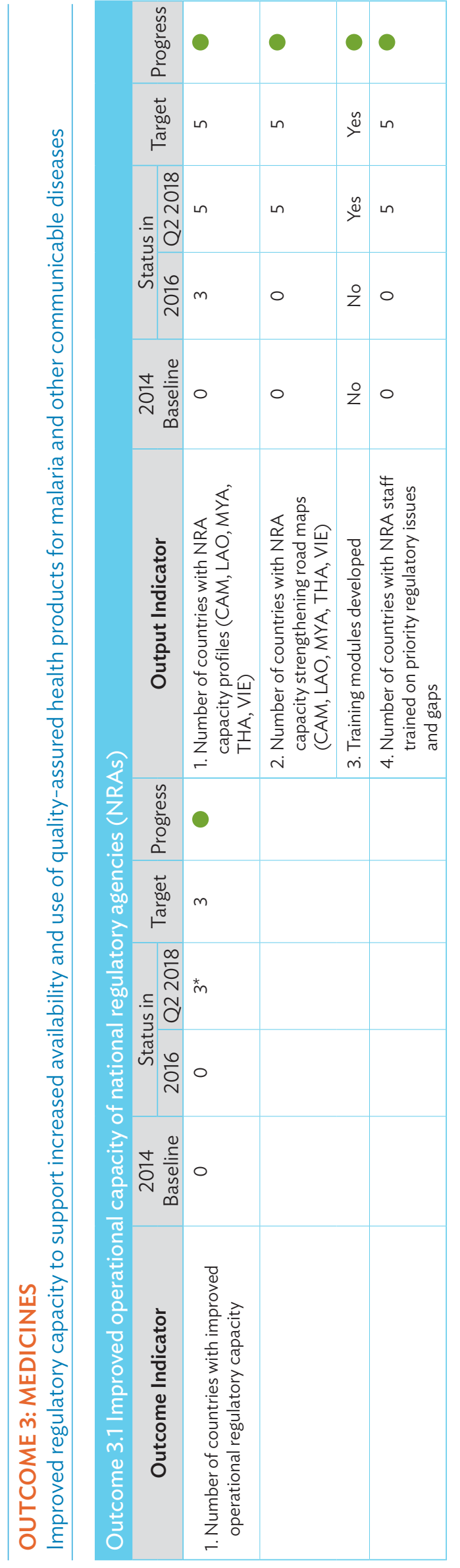

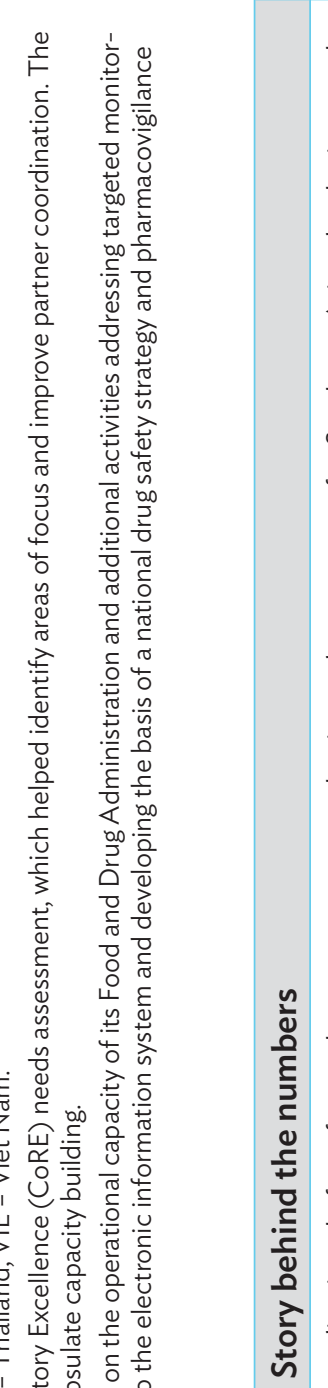

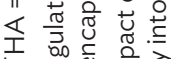

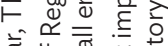

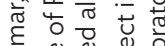

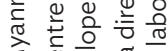

$\sum \cup \stackrel{0}{0} \frac{\pi}{D}$

4

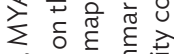

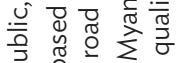

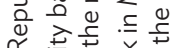

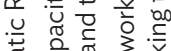

엉

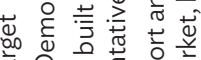

屯

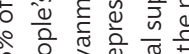

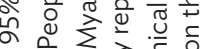

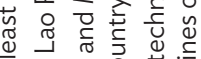

范

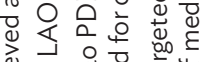

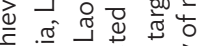

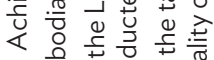

- है है

i. U

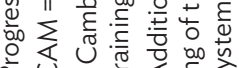

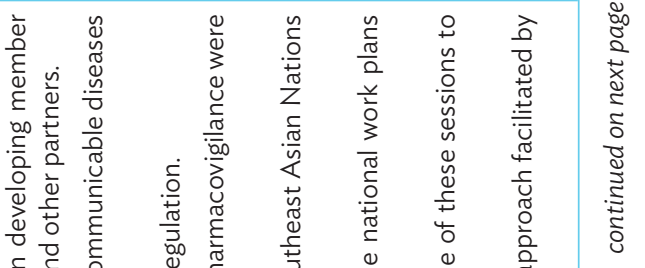

ᄃ듀

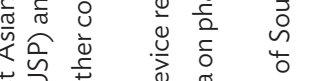

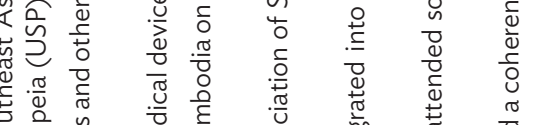

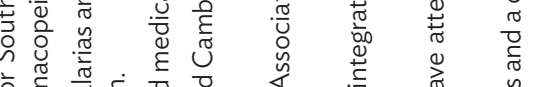

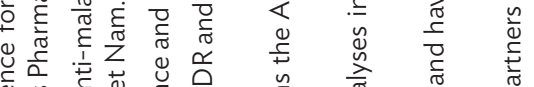

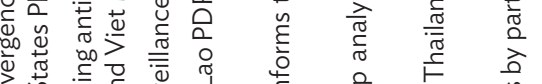

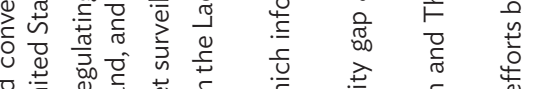

完它

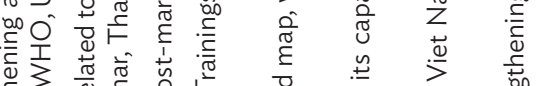

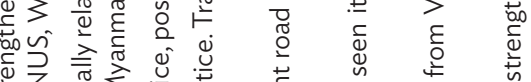

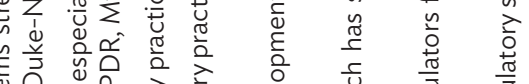

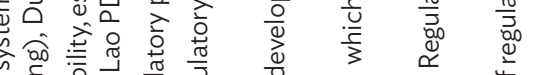

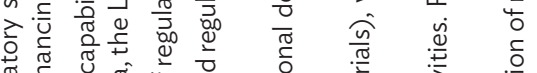

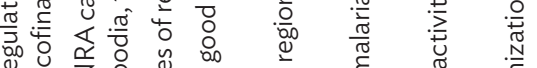

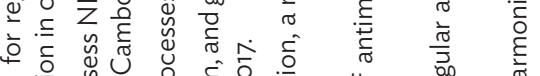

है

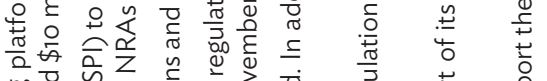

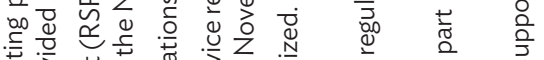

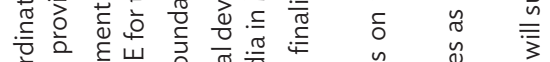

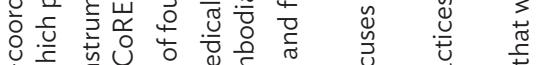

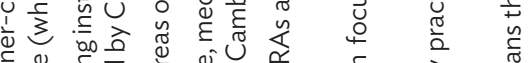

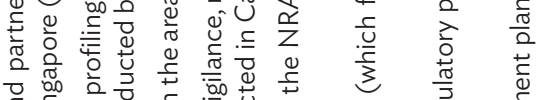

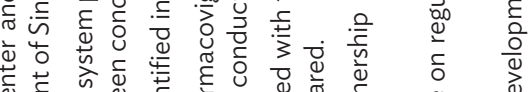

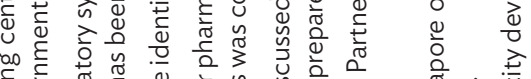

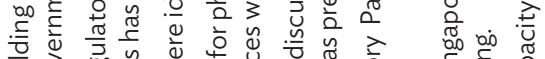

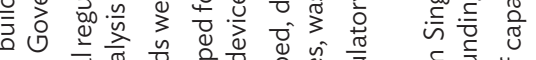
不

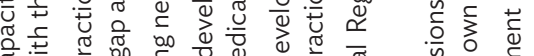

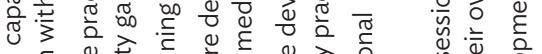

ฮั

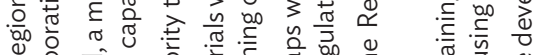

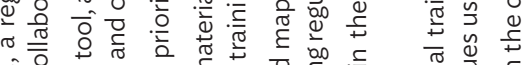

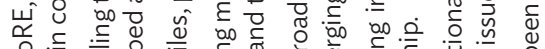

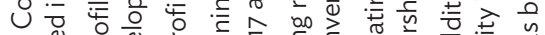

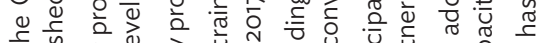

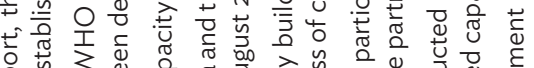

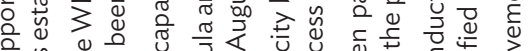

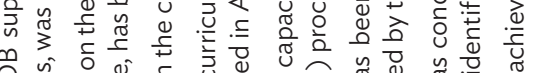

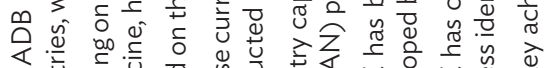

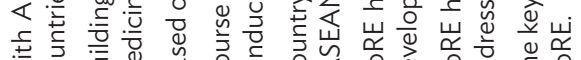

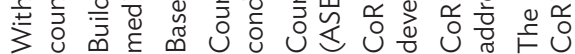


50 Annex

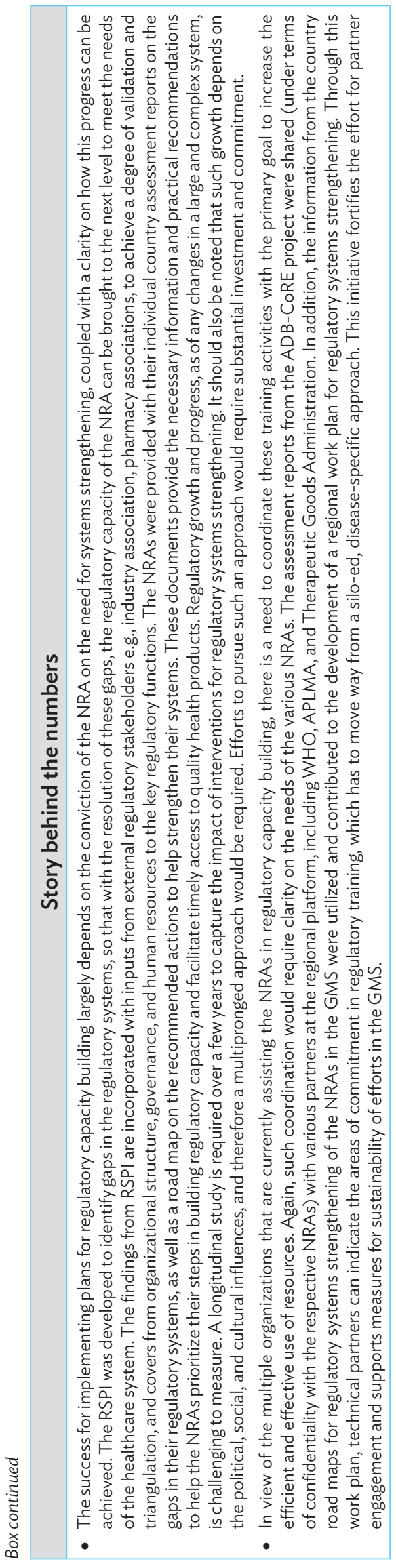



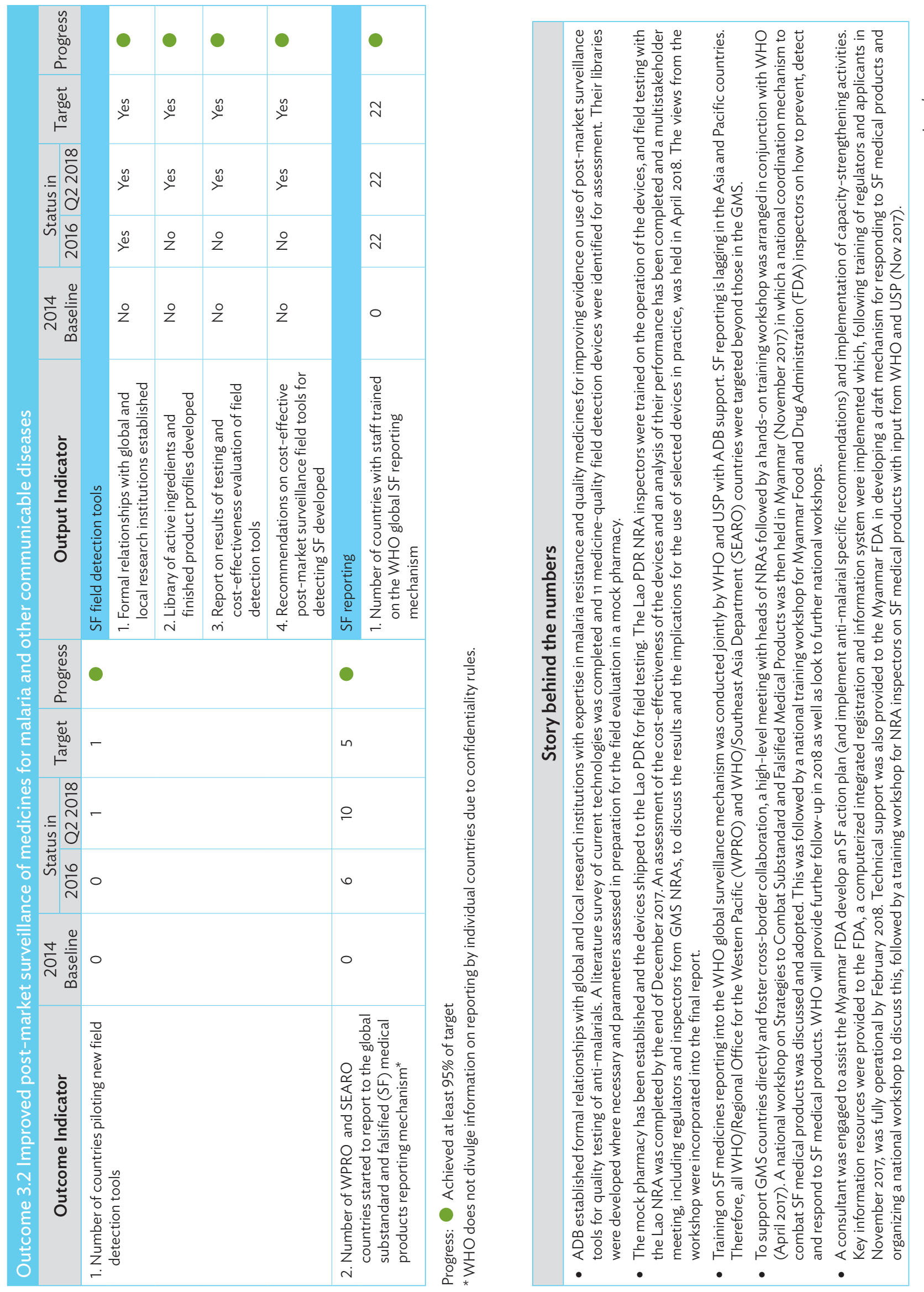


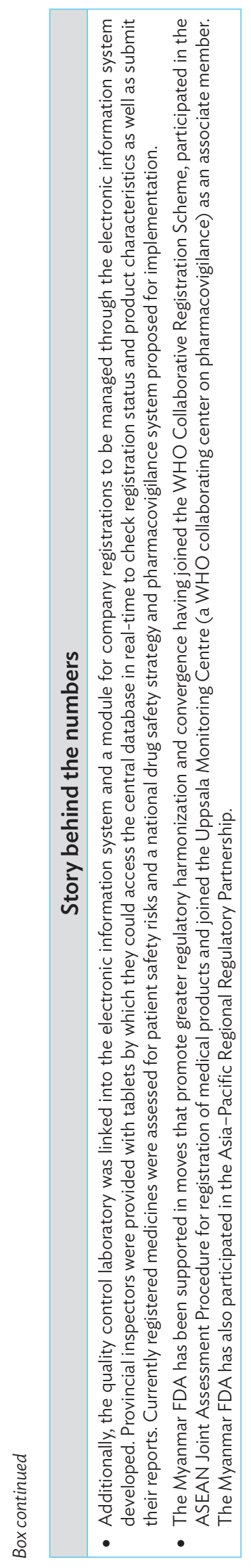



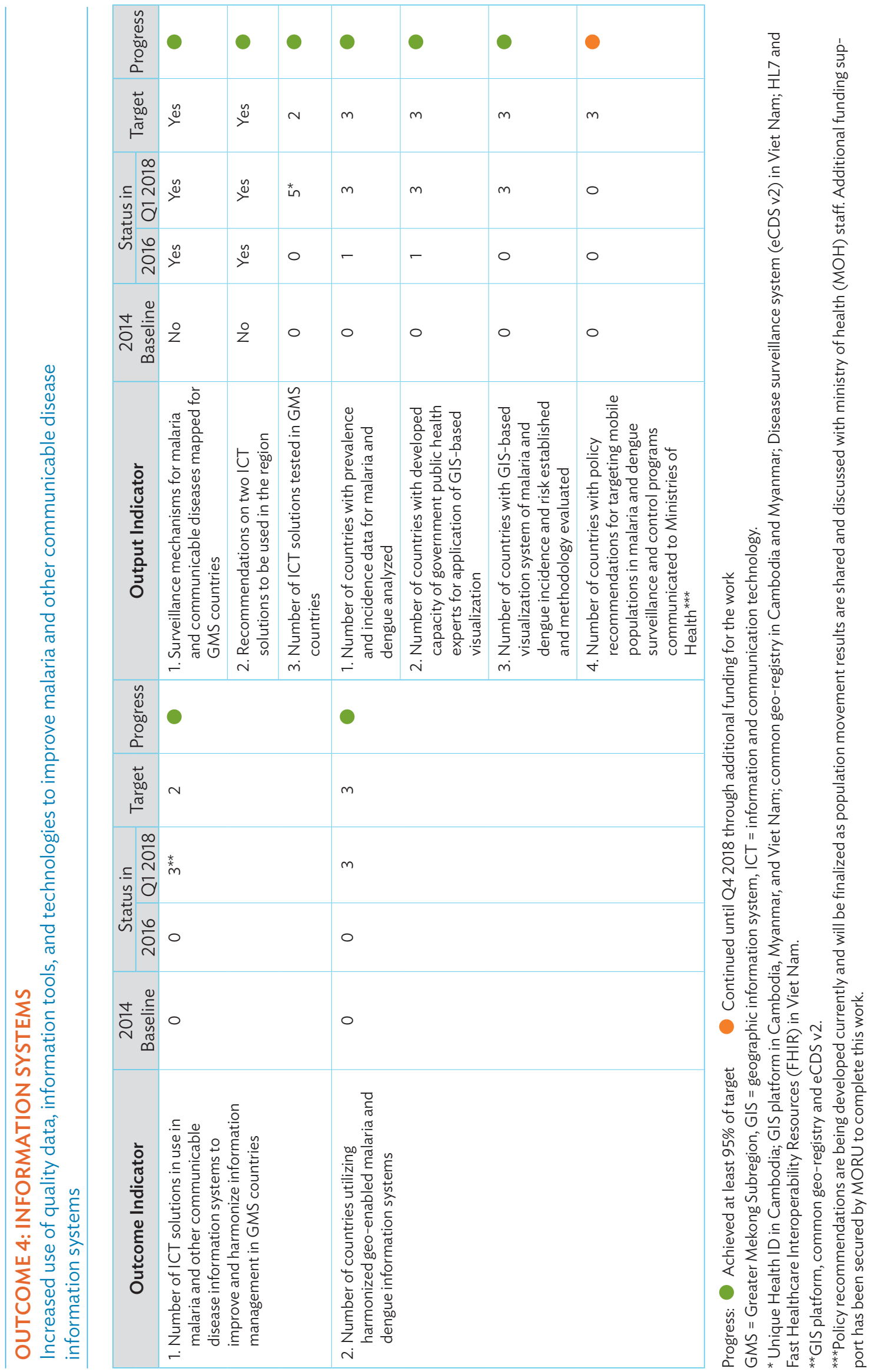


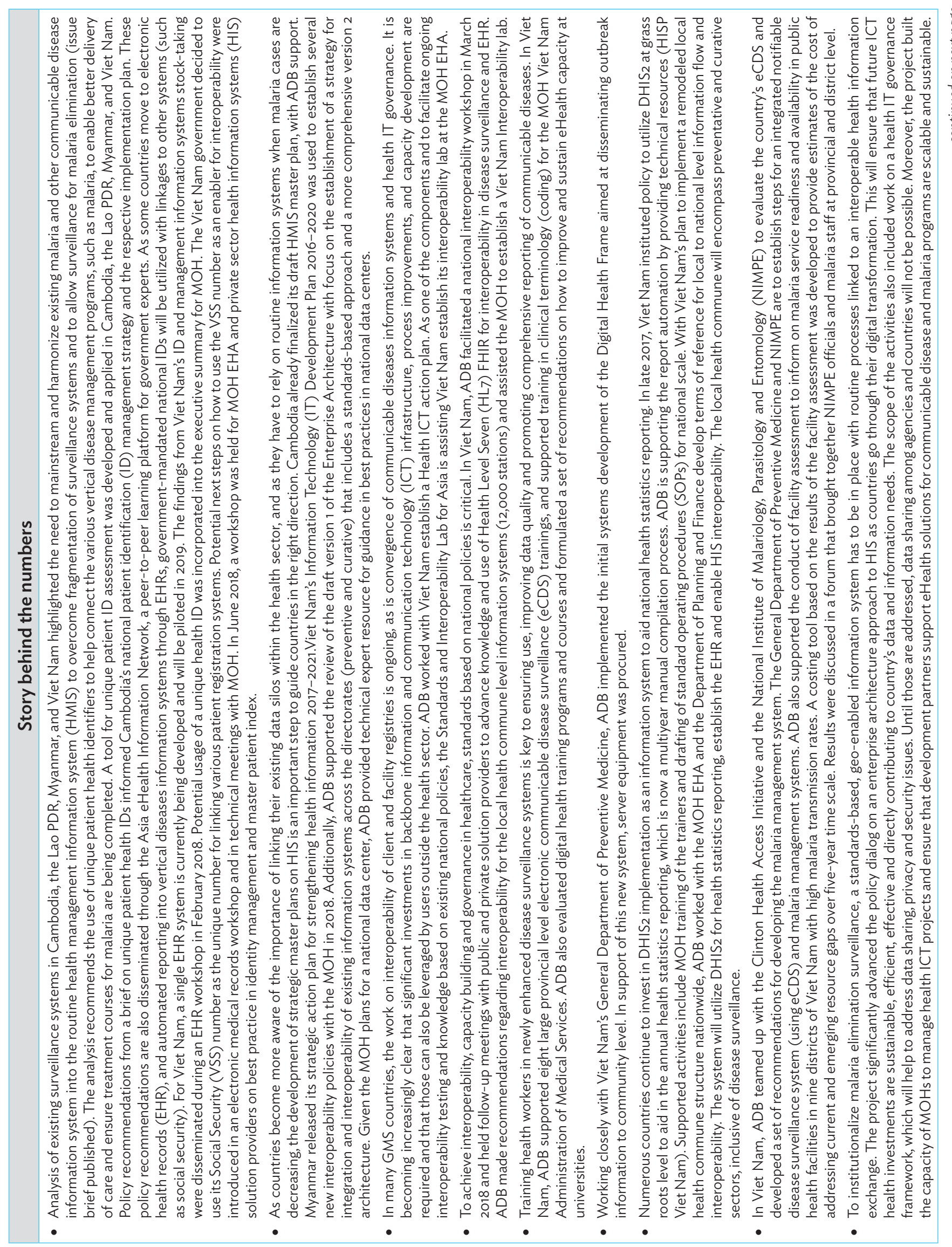




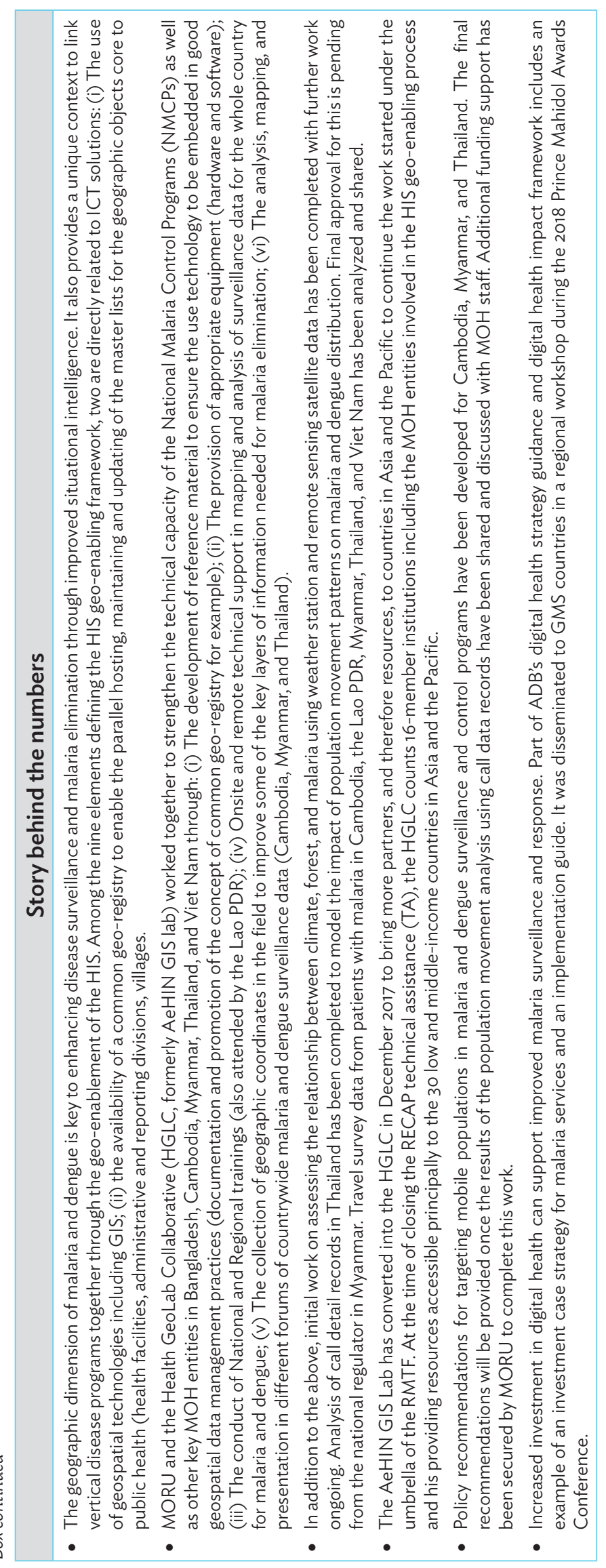




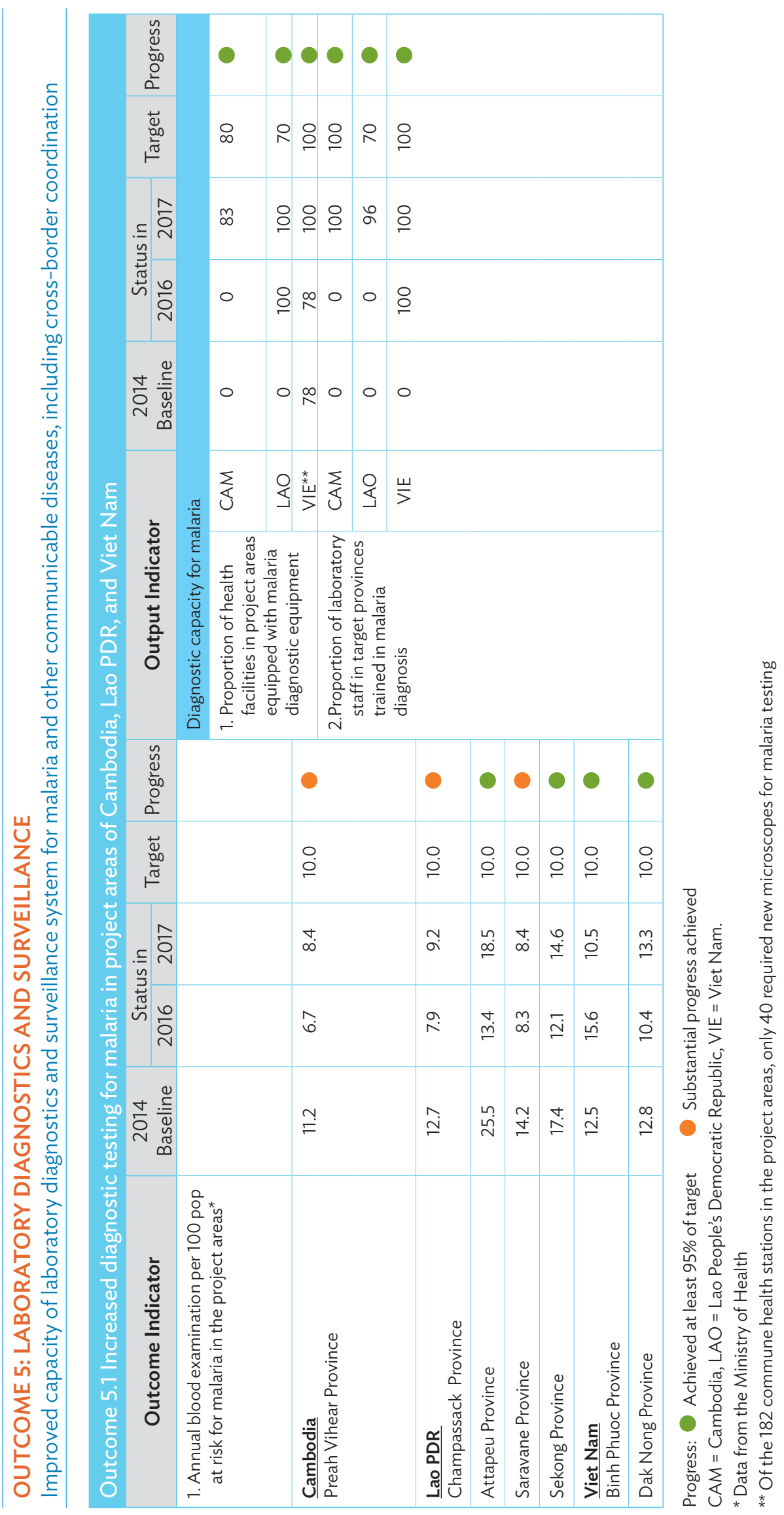




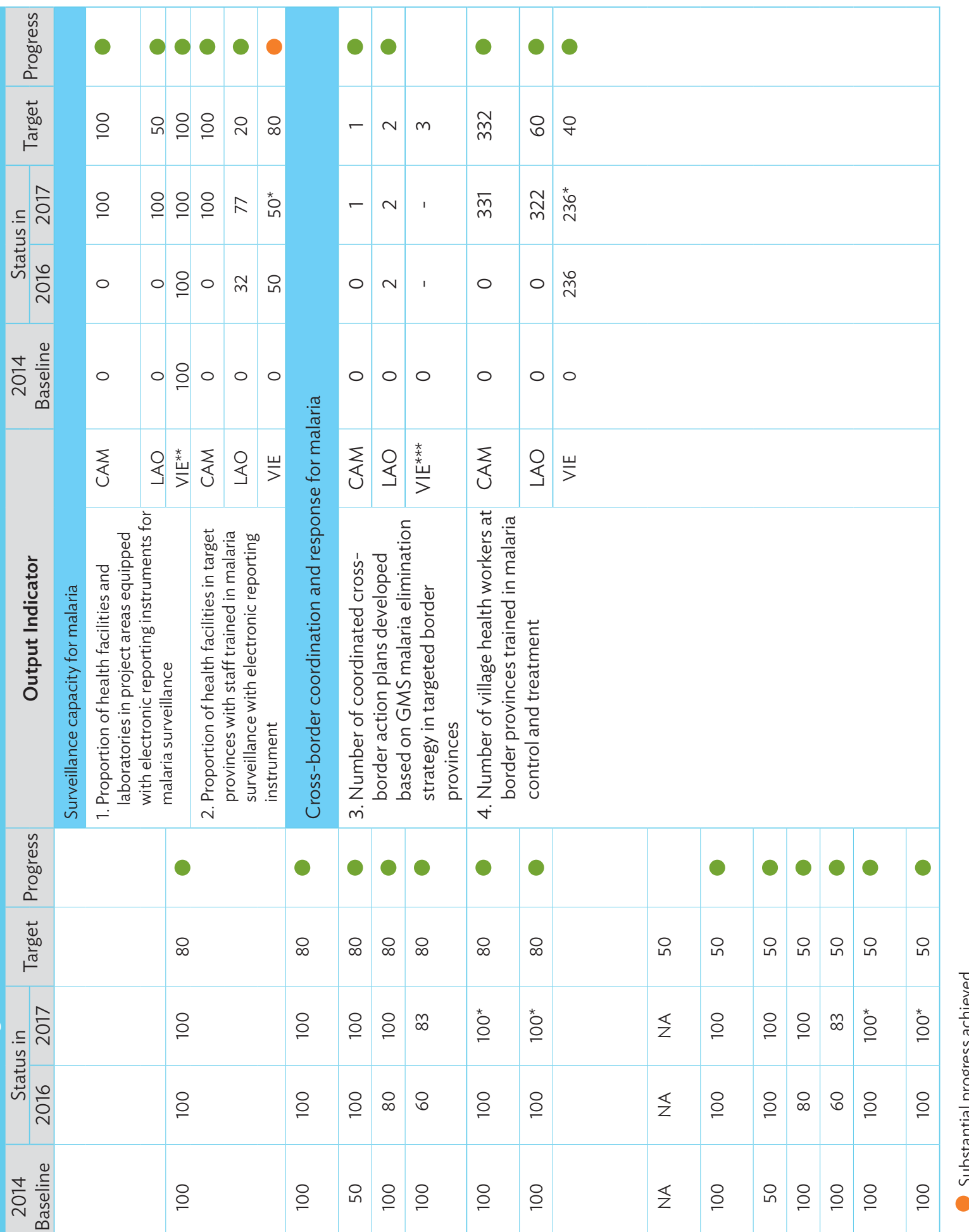




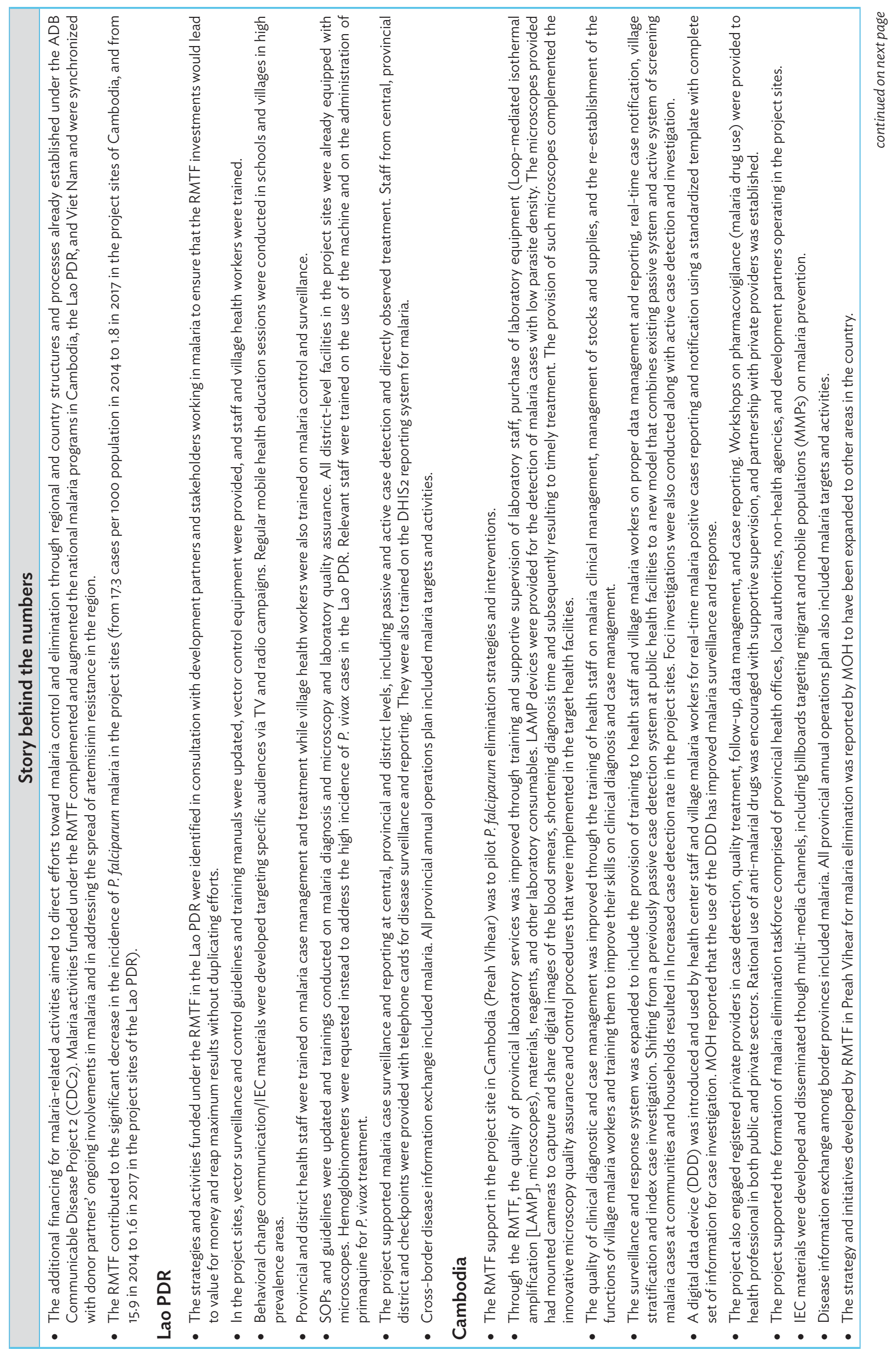




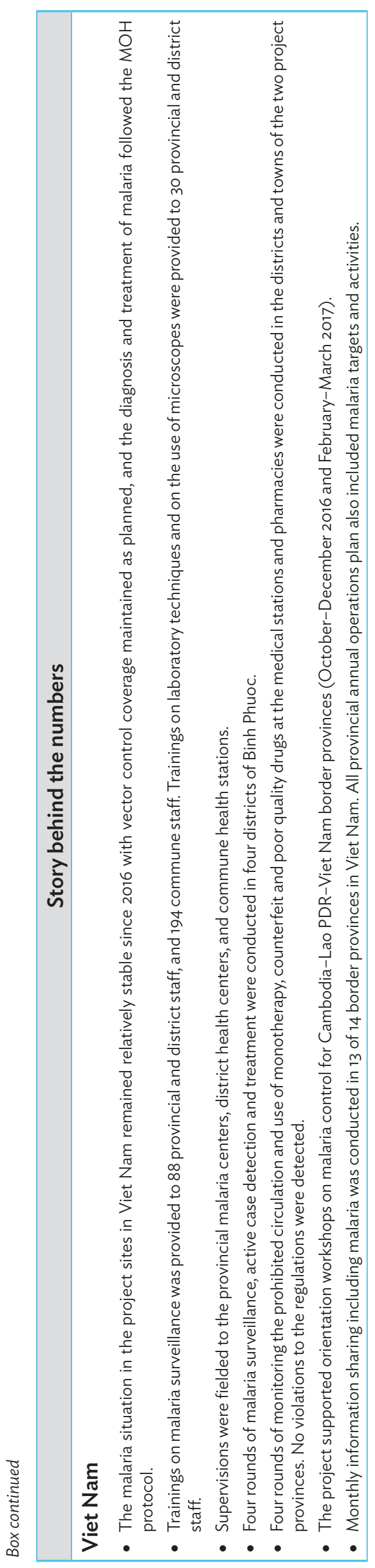



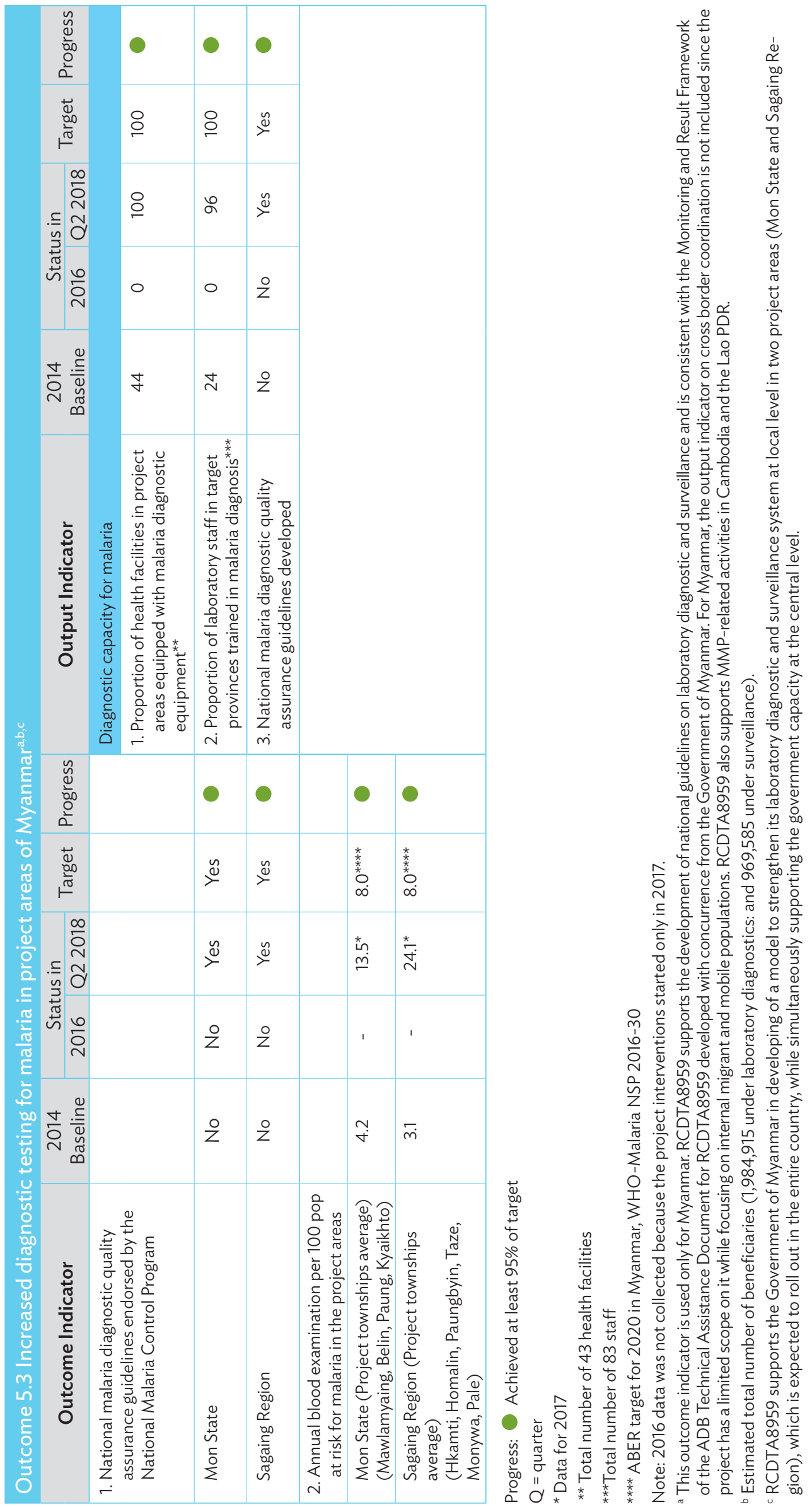


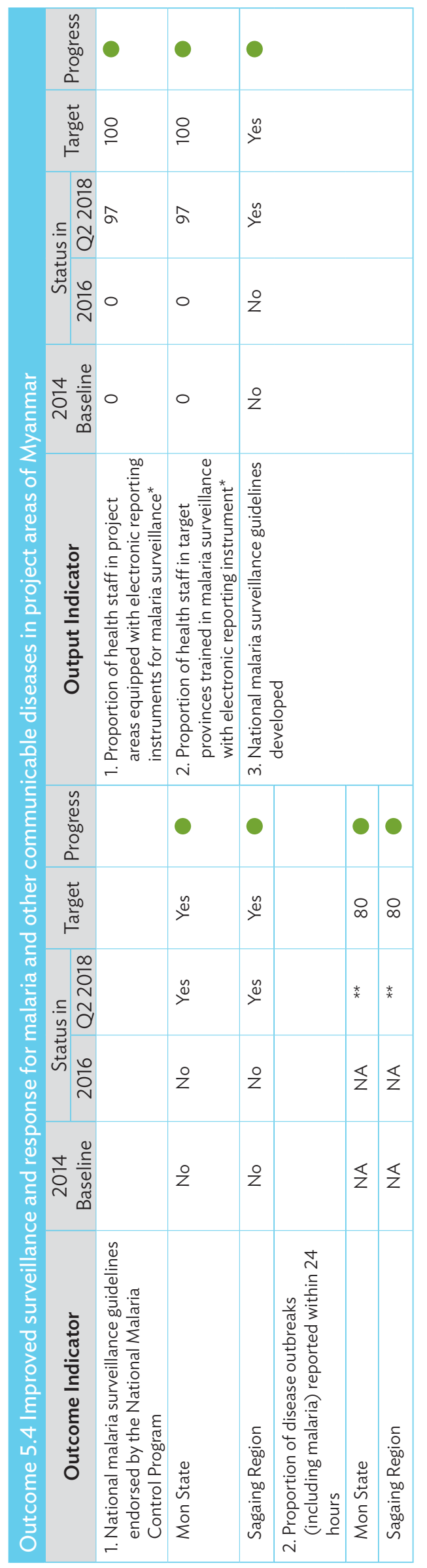

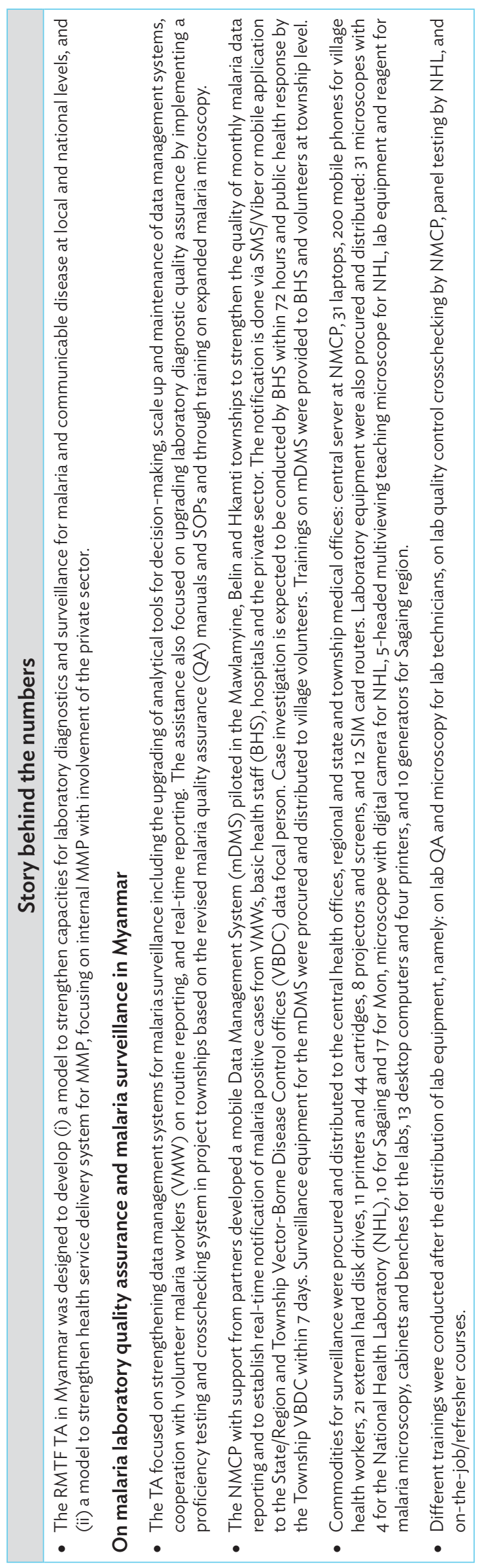




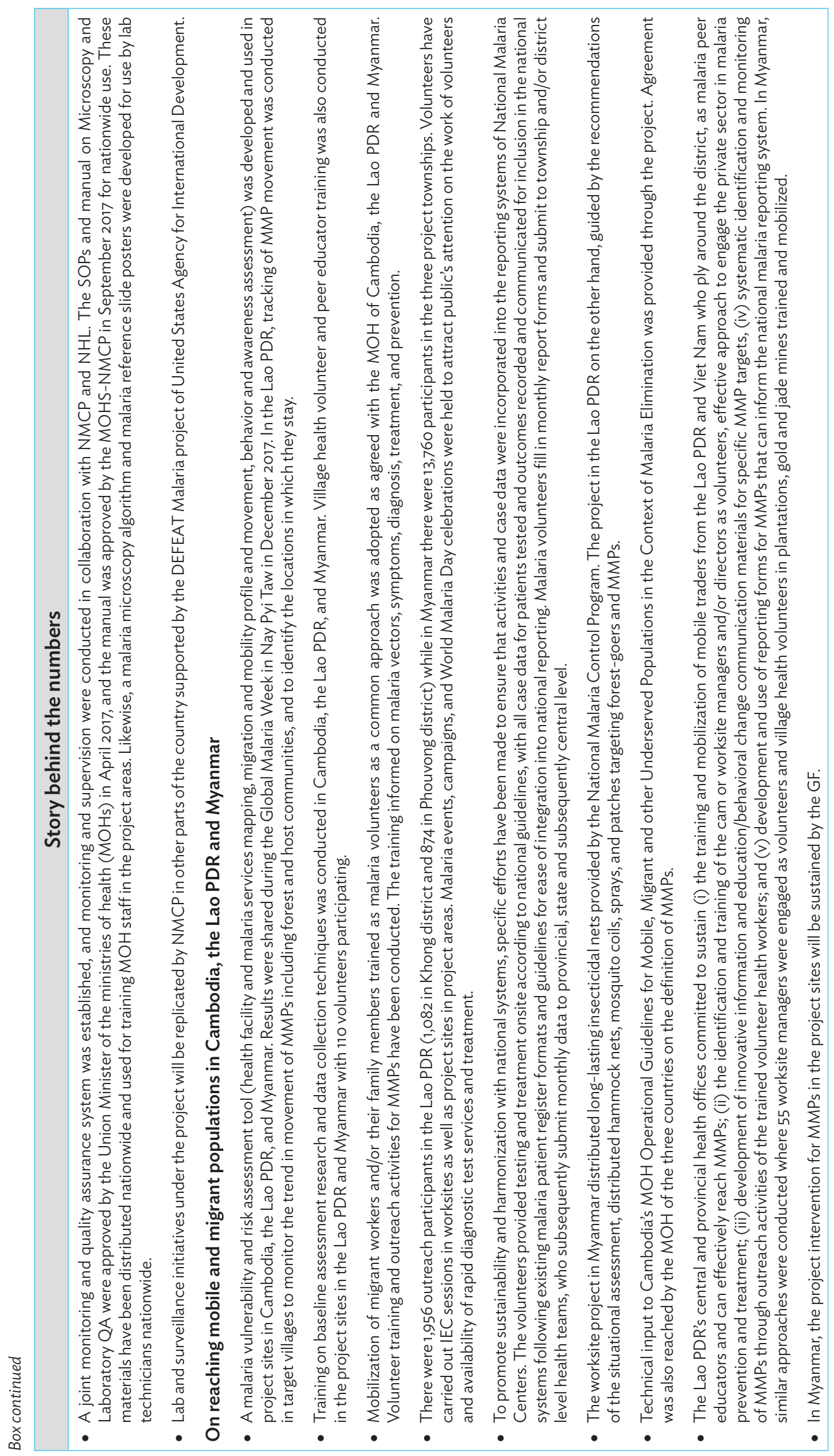




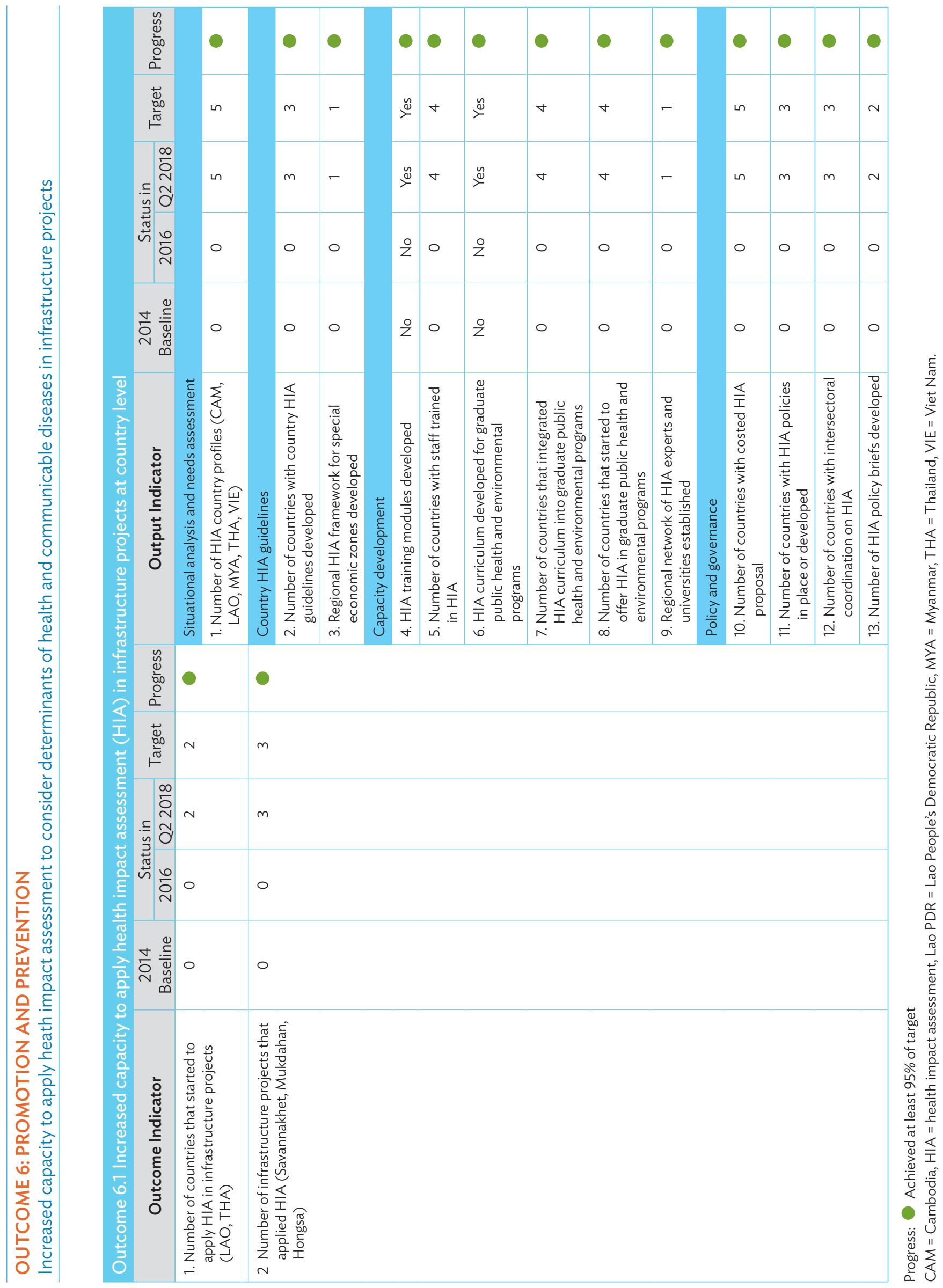




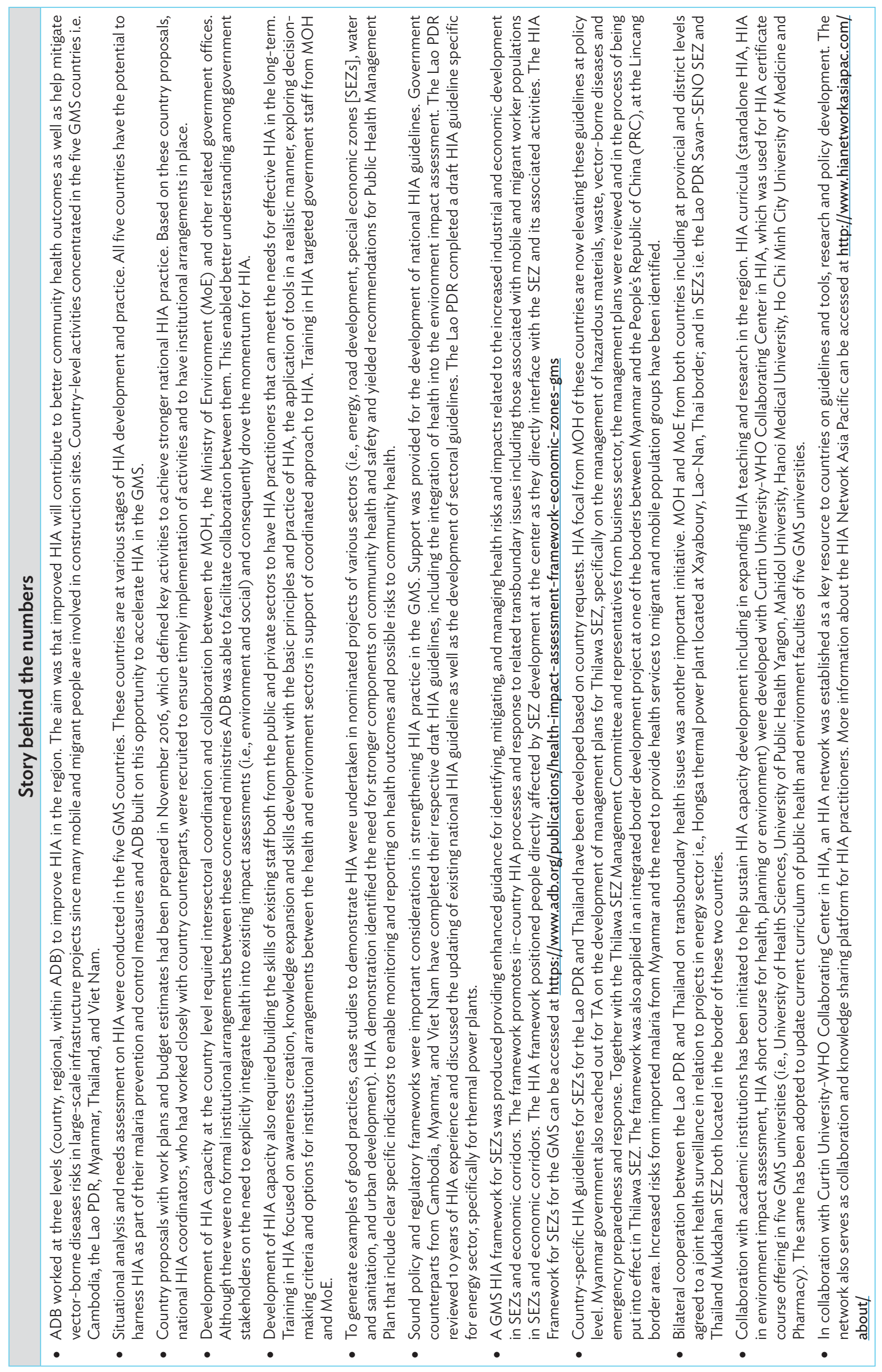



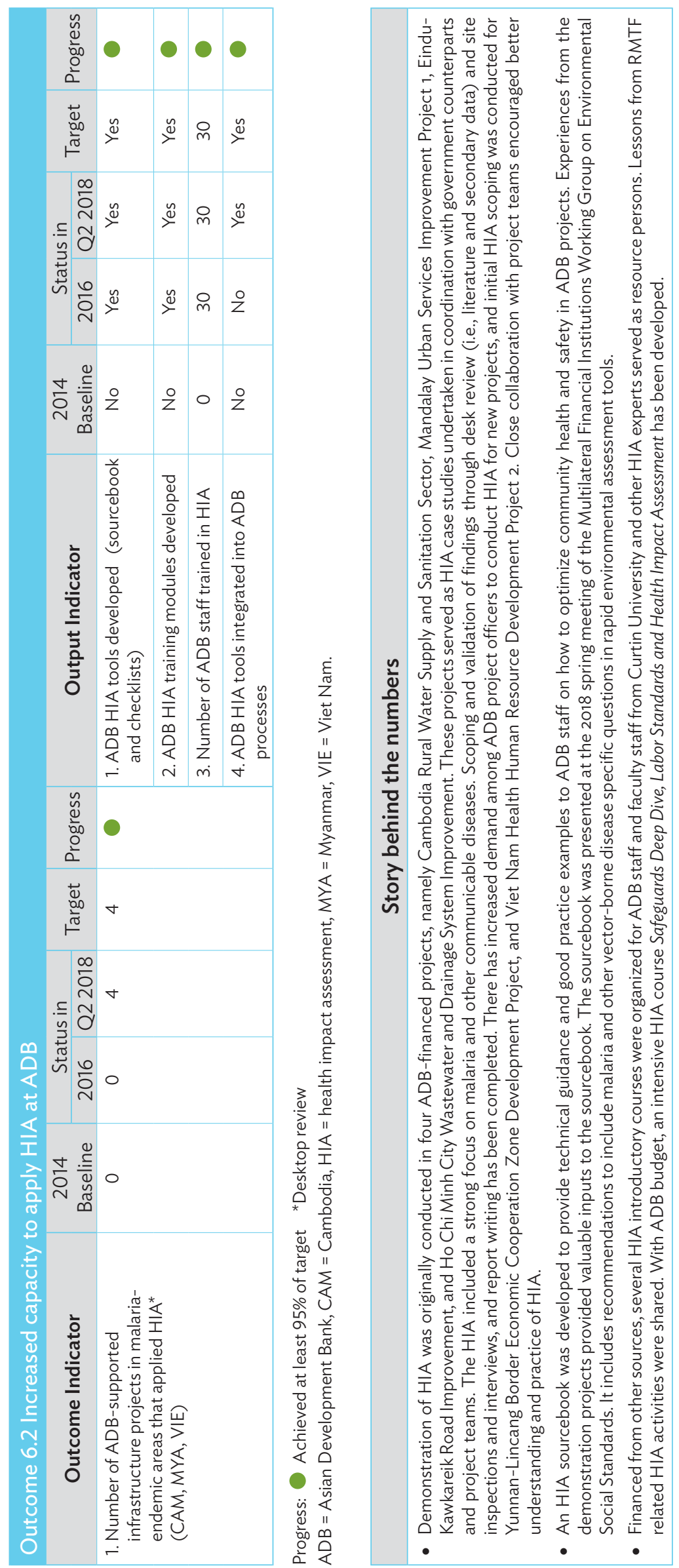

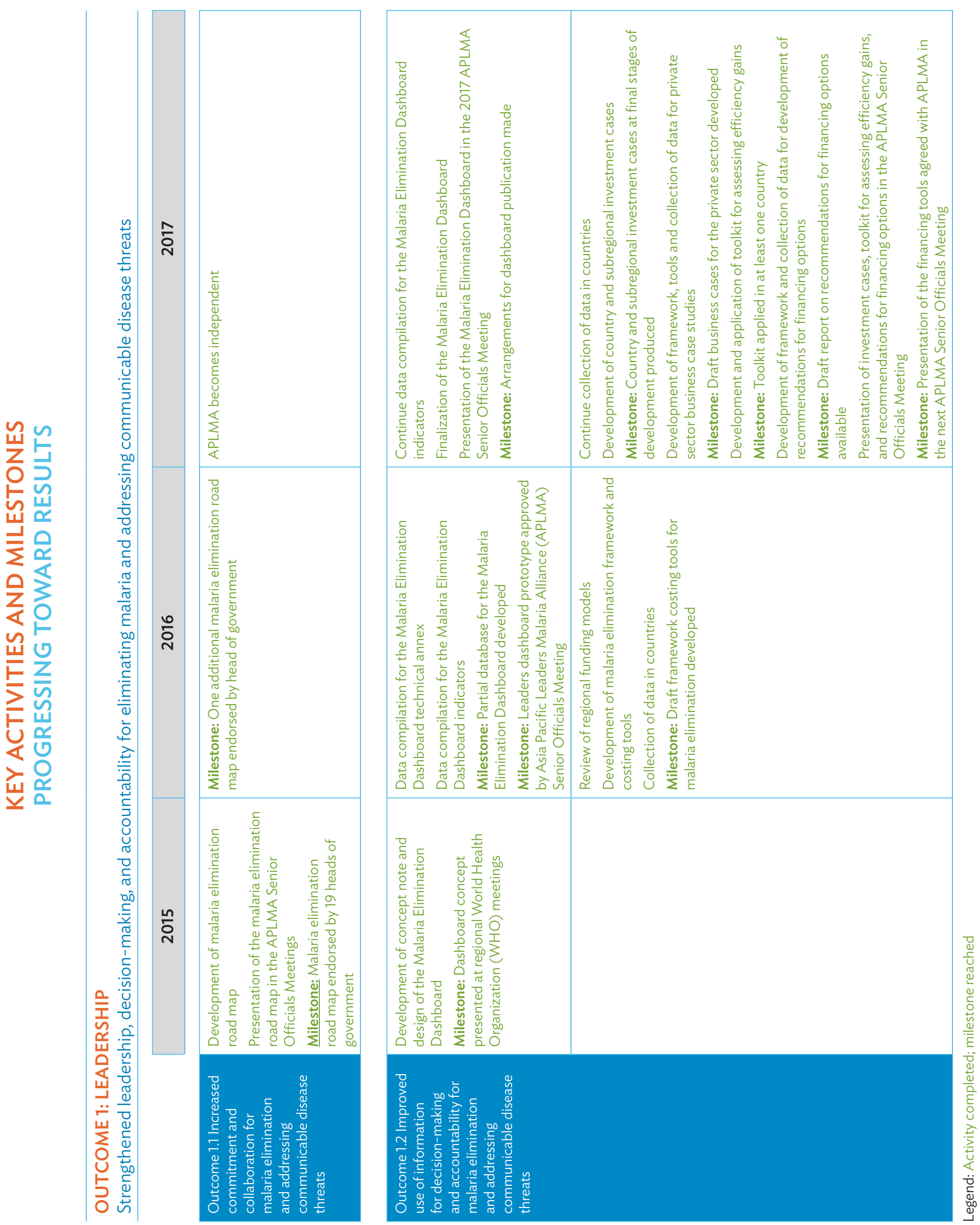


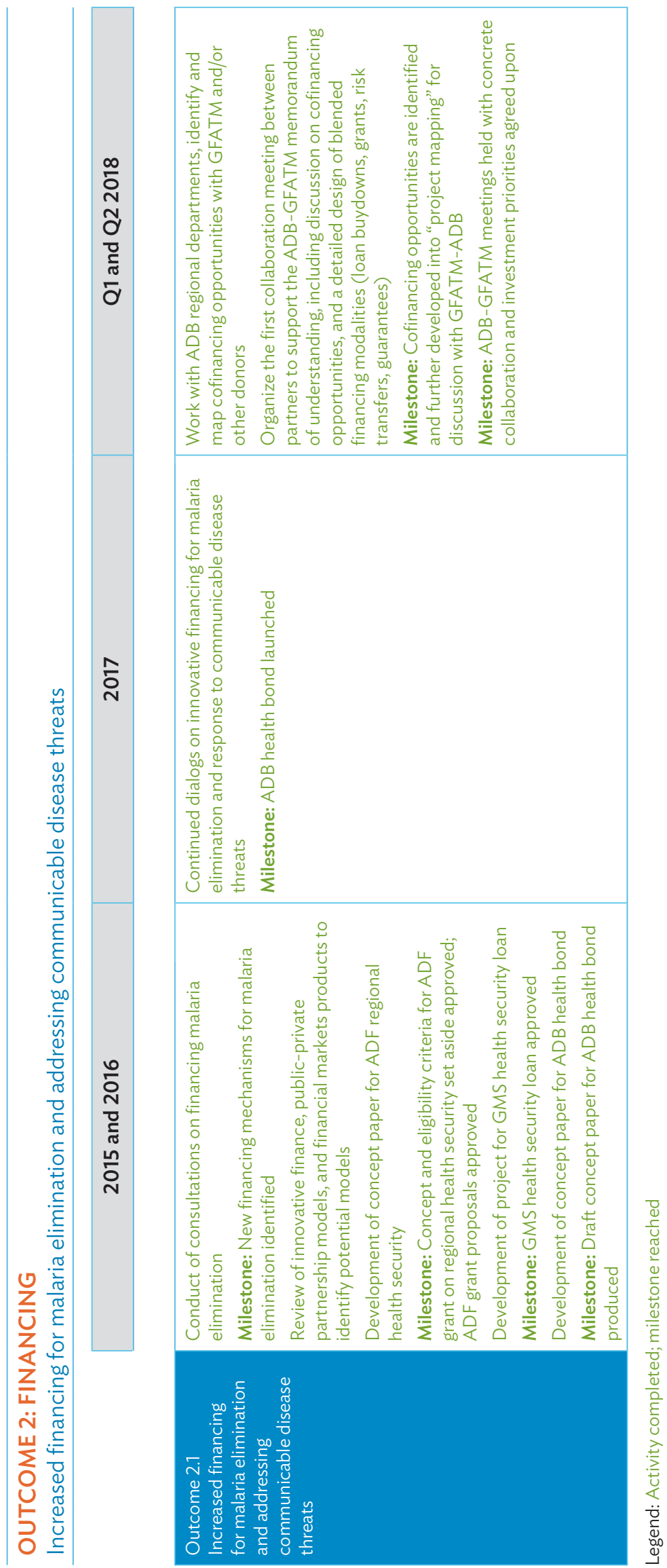




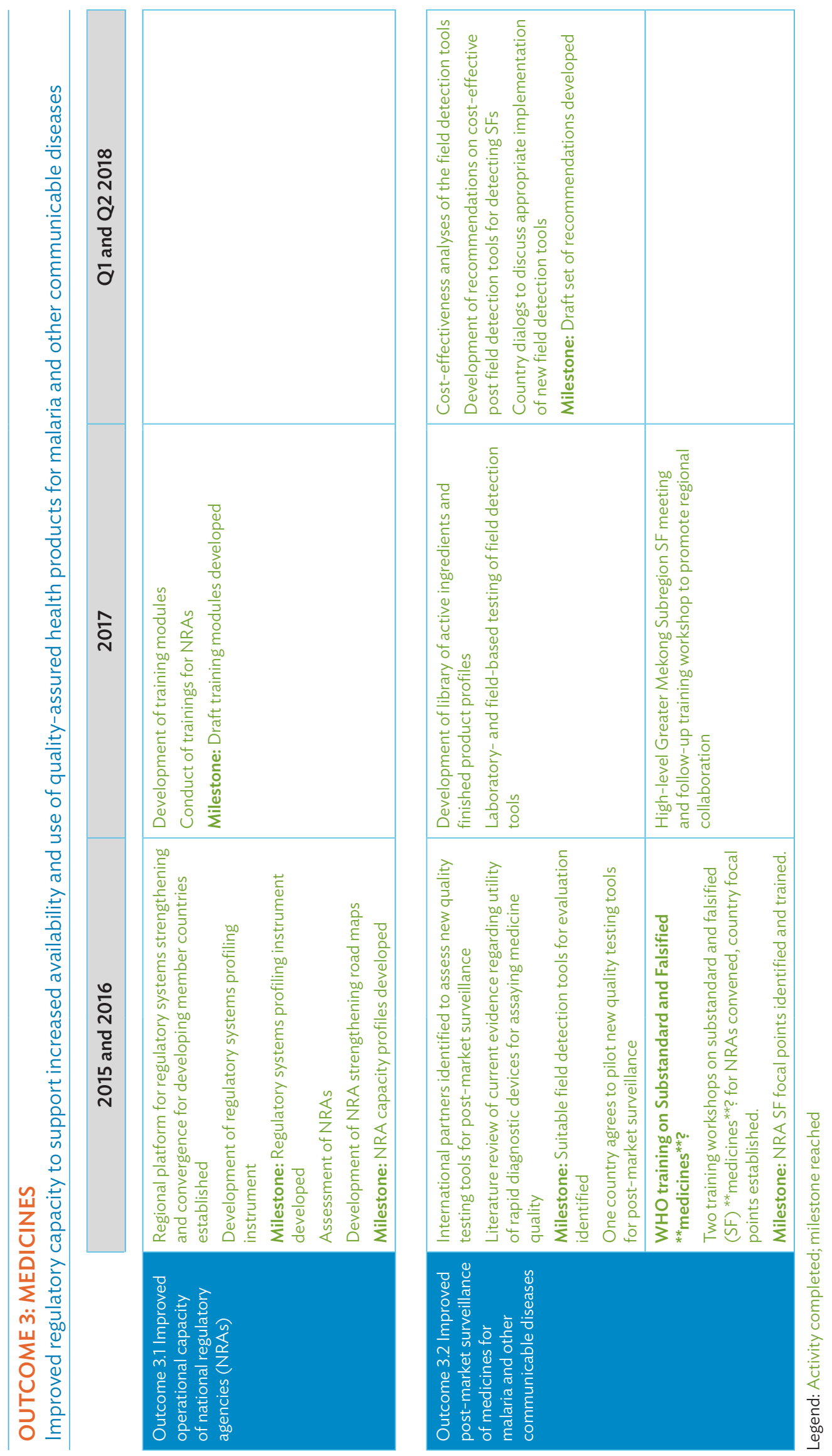




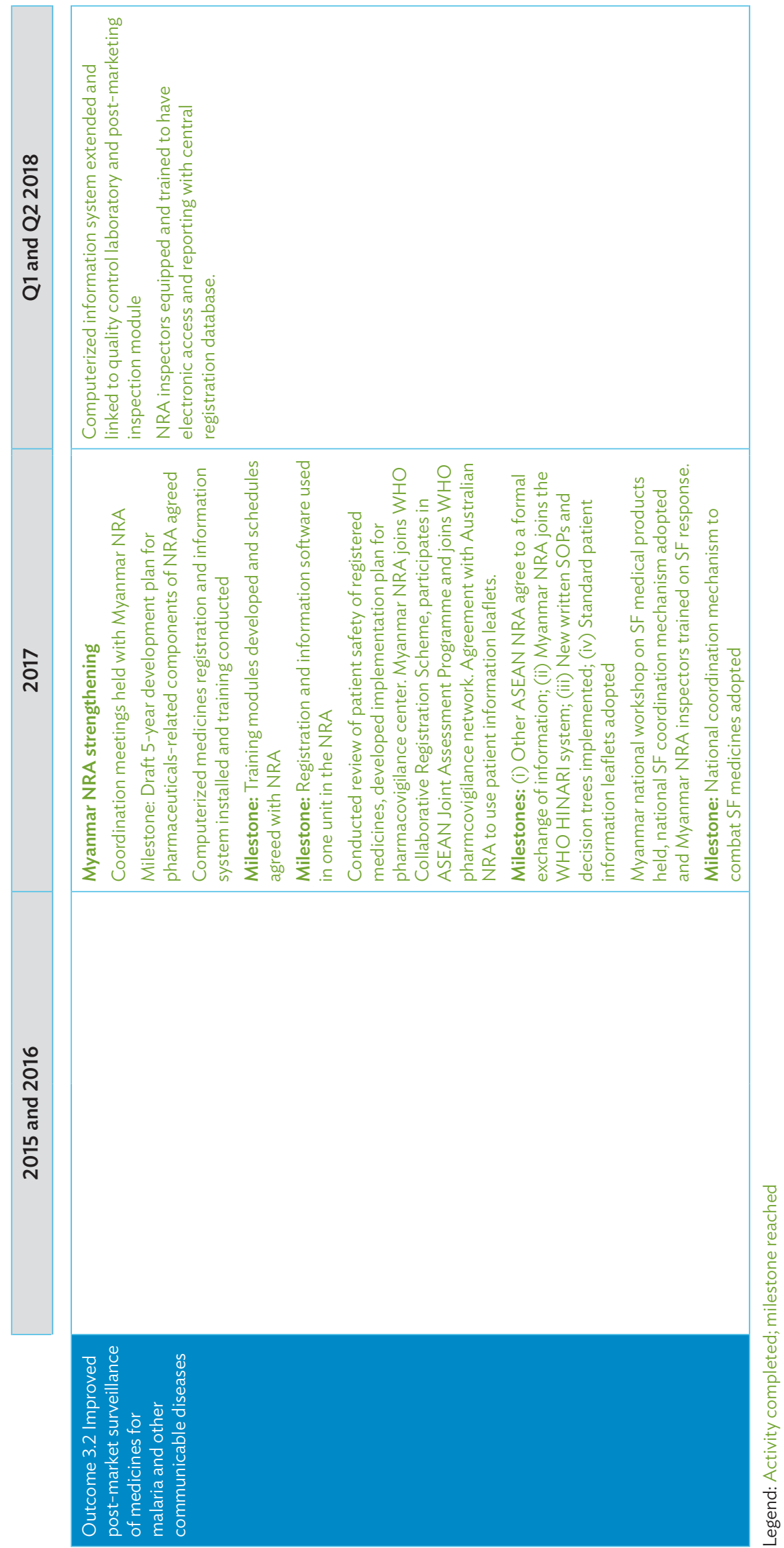




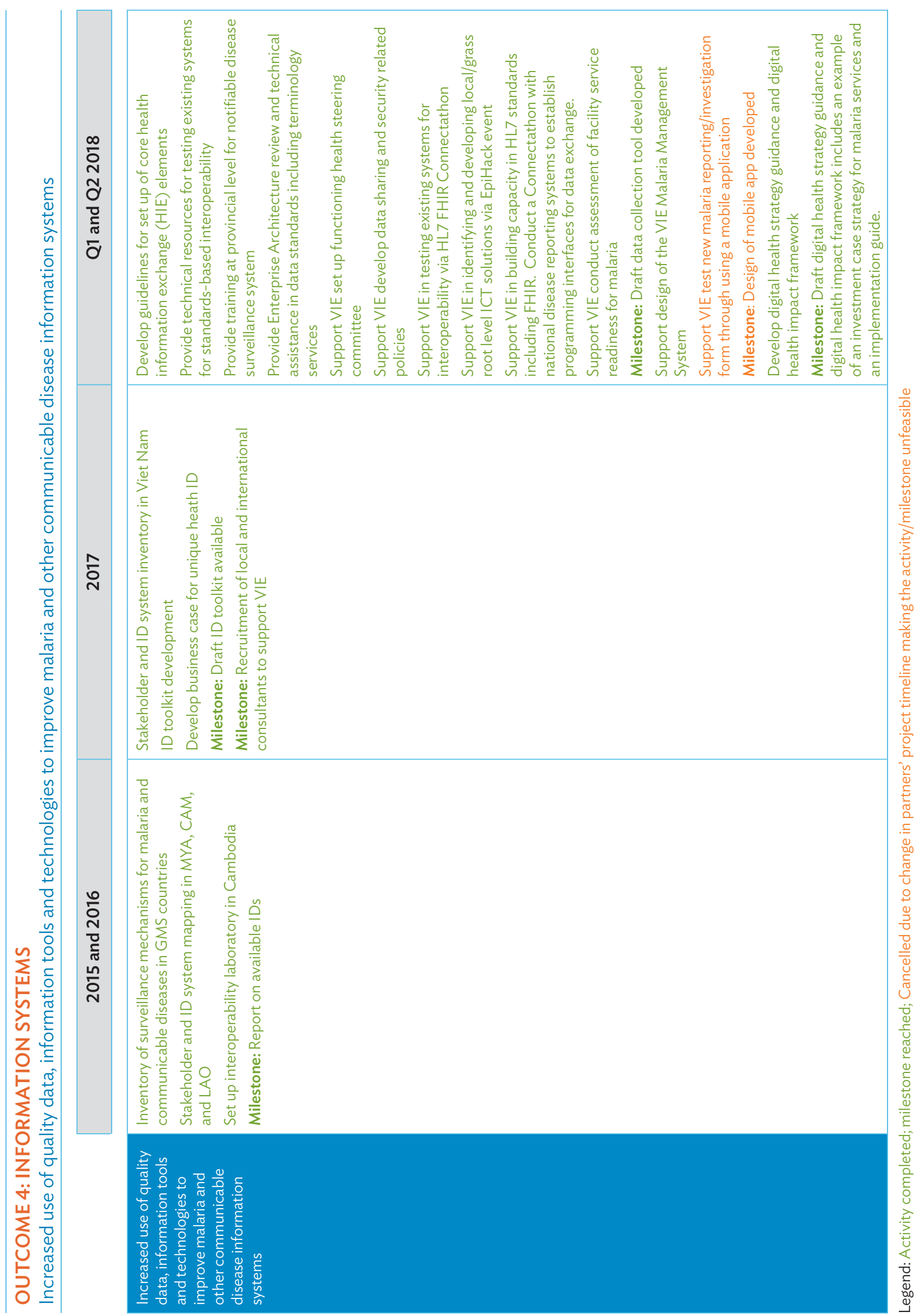



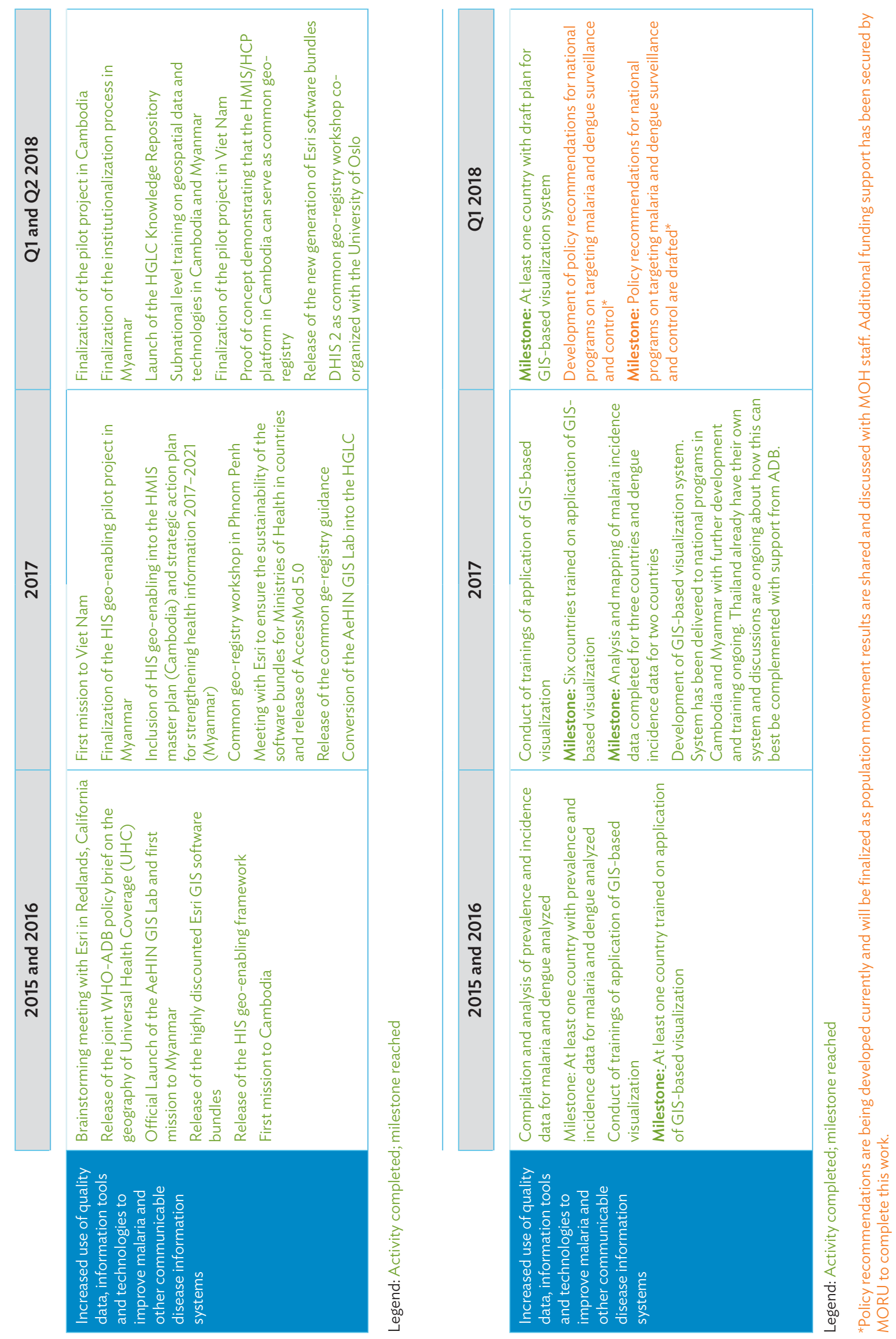


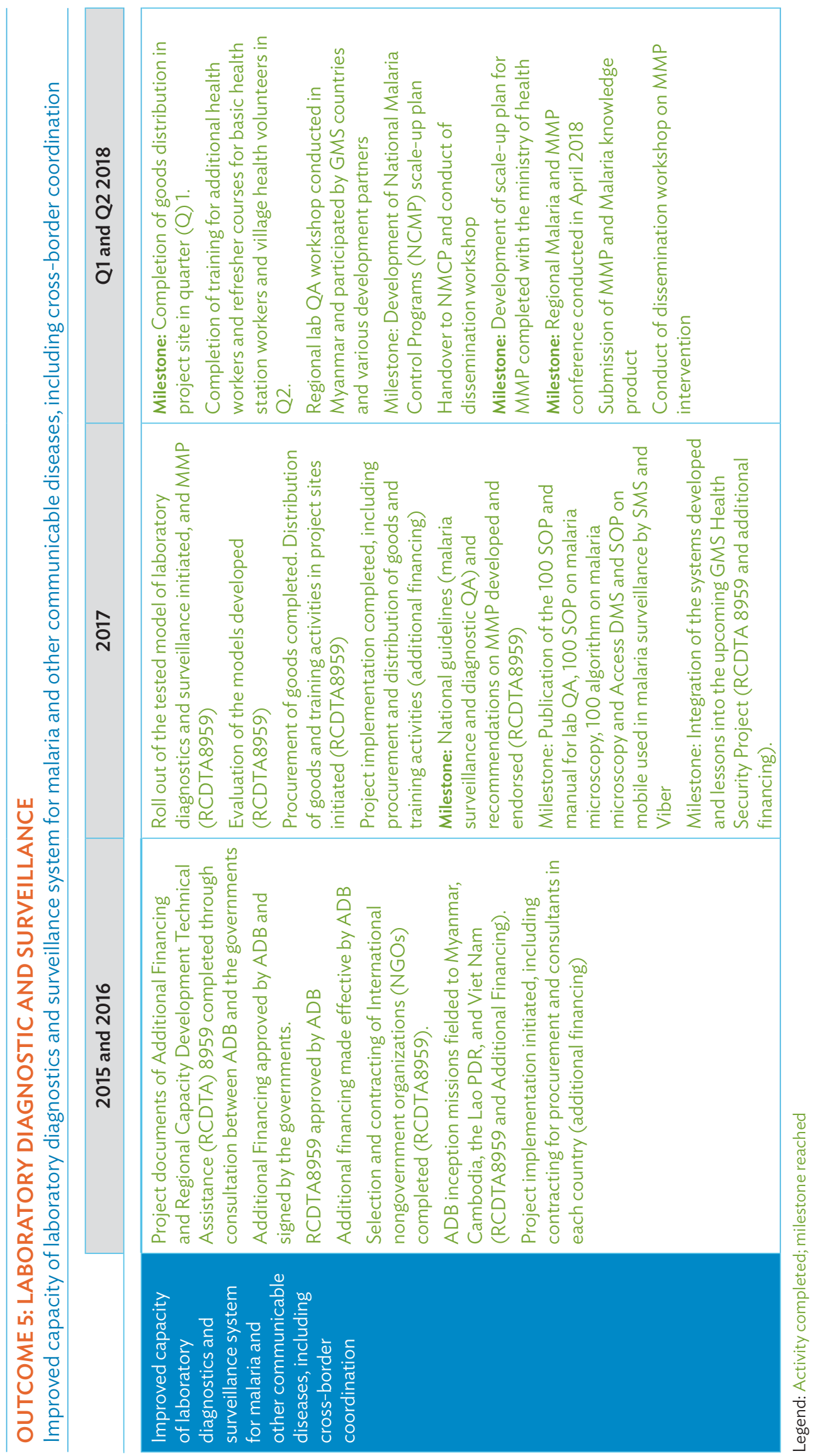




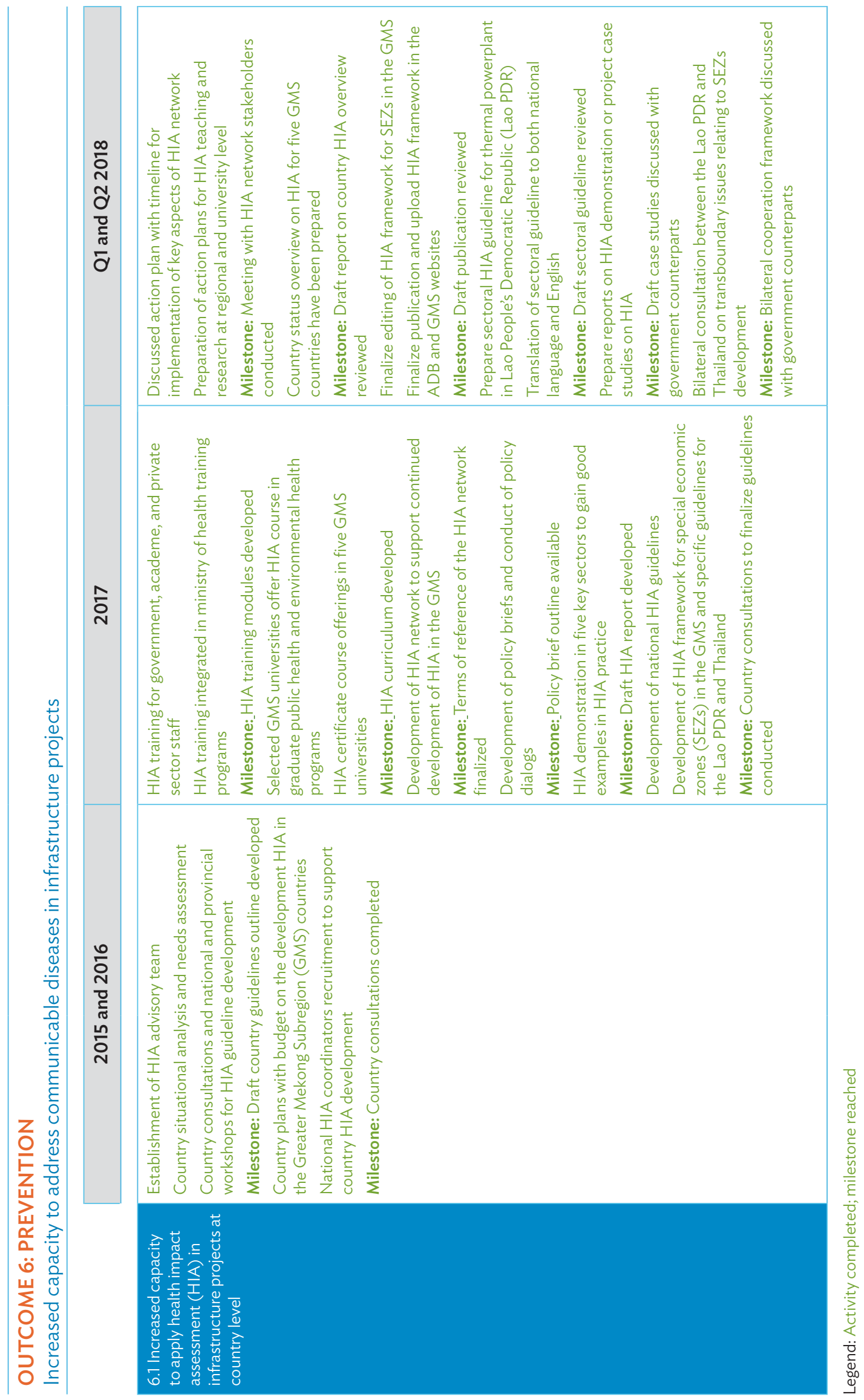




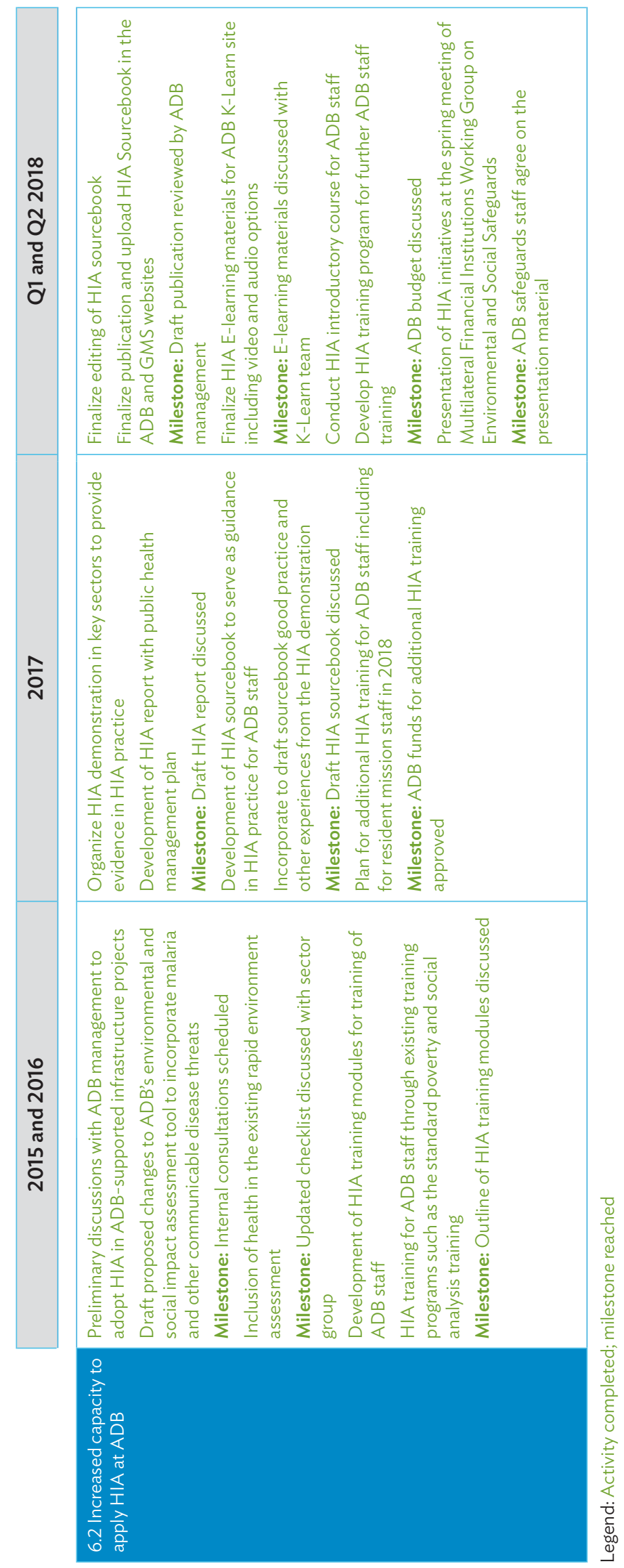




\section{Annex B: Glossary of Results-Based Framework Terms}

\begin{tabular}{|c|c|}
\hline \multirow[t]{2}{*}{ Impact } & $\begin{array}{l}\text { Changes in conditions } \\
\text { Millennium Development Goals (MDGs), health, social, economic, cultural, civil society, environmental, political. }\end{array}$ \\
\hline & $\begin{array}{l}\text { Positive and negative long-term effects on identifiable population groups produced by a development intervention, directly } \\
\text { or indirectly, intended or unintended. }\end{array}$ \\
\hline \multirow[t]{2}{*}{ Outcome } & $\begin{array}{l}\text { Changes in capacity and performance of the primary duty-bearers } \\
\text { Changes in behaviors and attitudes, social action, viability, institutional, policy formulation, decision-making, norms, } \\
\text { knowledge, efficiency, competencies, opinions, standards. Achieved though the combination of RMTF investments. }\end{array}$ \\
\hline & $\begin{array}{l}\text { The changes in institutional performance or behavior among individuals or groups that occur between the completion of } \\
\text { outputs and the achievement of goals. }\end{array}$ \\
\hline \multirow[t]{2}{*}{ Output } & $\begin{array}{l}\text { What implementers produce } \\
\text { Goods and services, change in skills and capabilities, systems, evaluations, new products, reports, publications produced. } \\
\text { Outputs are linked to project outputs. }\end{array}$ \\
\hline & $\begin{array}{l}\text { The changes in skills or abilities, or the availability of new products and services that result from the completion of activities } \\
\text { within a development intervention. }\end{array}$ \\
\hline \multirow[t]{2}{*}{ Activities } & $\begin{array}{l}\text { What implementers do } \\
\text { Develop curriculum, train, evaluate, recruit, procure, facilitate, develop action plans, work with media, etc. }\end{array}$ \\
\hline & $\begin{array}{l}\text { Actions taken or work performed through which inputs, such as funds, technical assistance and other types of resources are } \\
\text { mobilized to produce specific outputs. }\end{array}$ \\
\hline Inputs & $\begin{array}{l}\text { What stakeholders invest in } \\
\text { Human or financial resources, personnel, equipment, technology, time. }\end{array}$ \\
\hline Milestone & Sets out how much of a target or what specific steps toward that target will be complete by specific dates. \\
\hline
\end{tabular}

\section{References:}

International Labour Office. 2011. Applying Results-Based Management in the International Labour Organization, A Guidebook, Version 2. Geneva.

United Nations Development Group. 2011. Results-based Management Handbook. New York. 


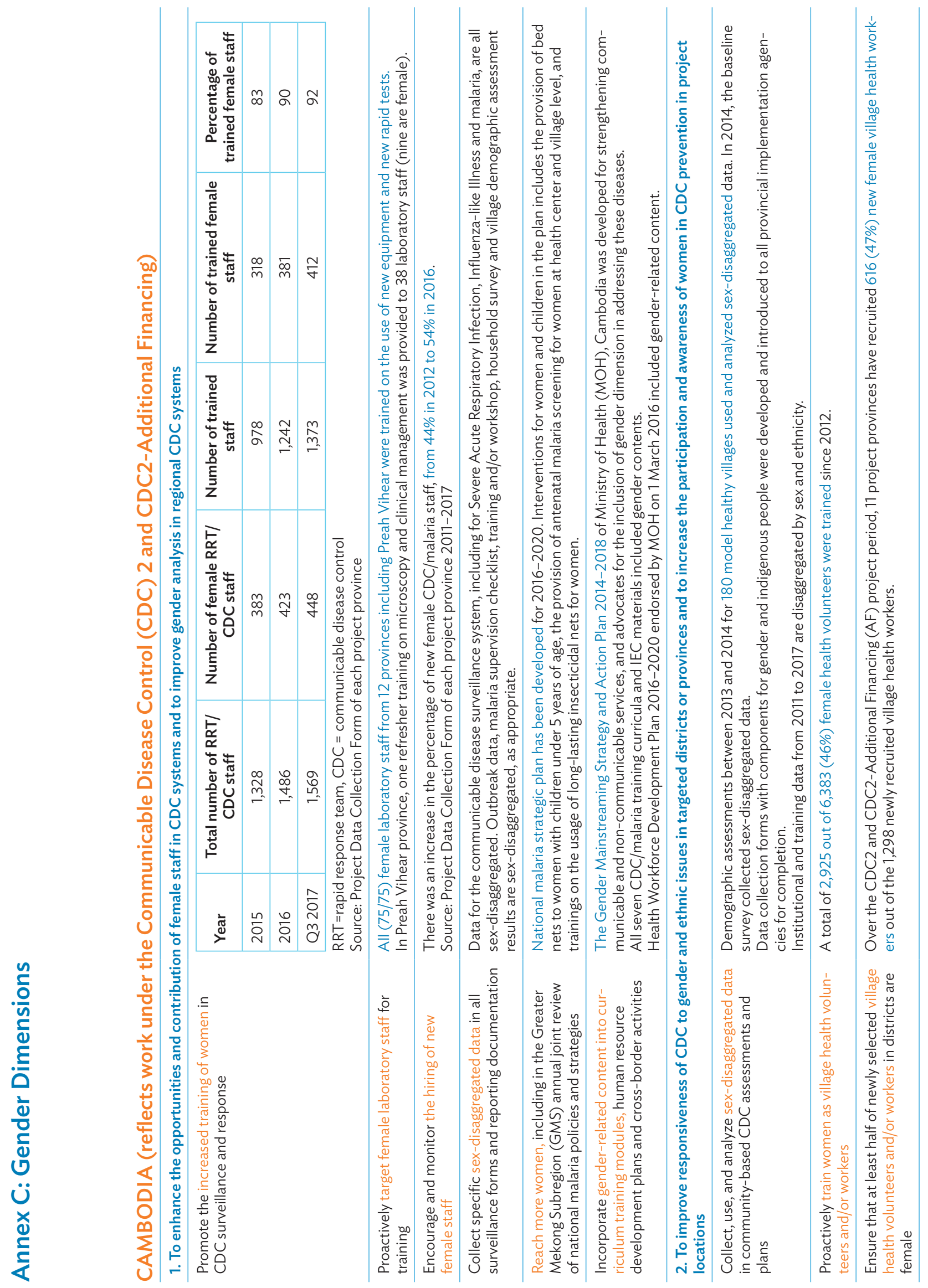




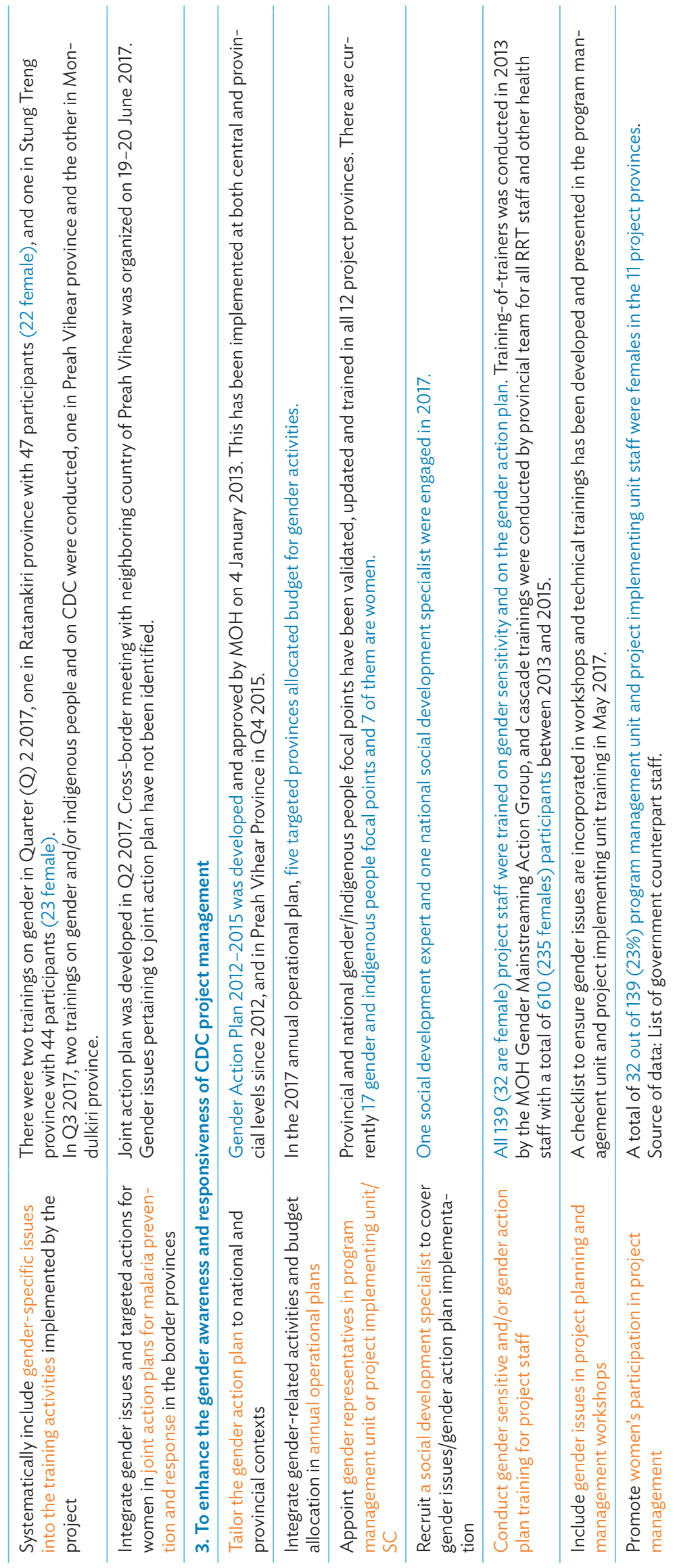




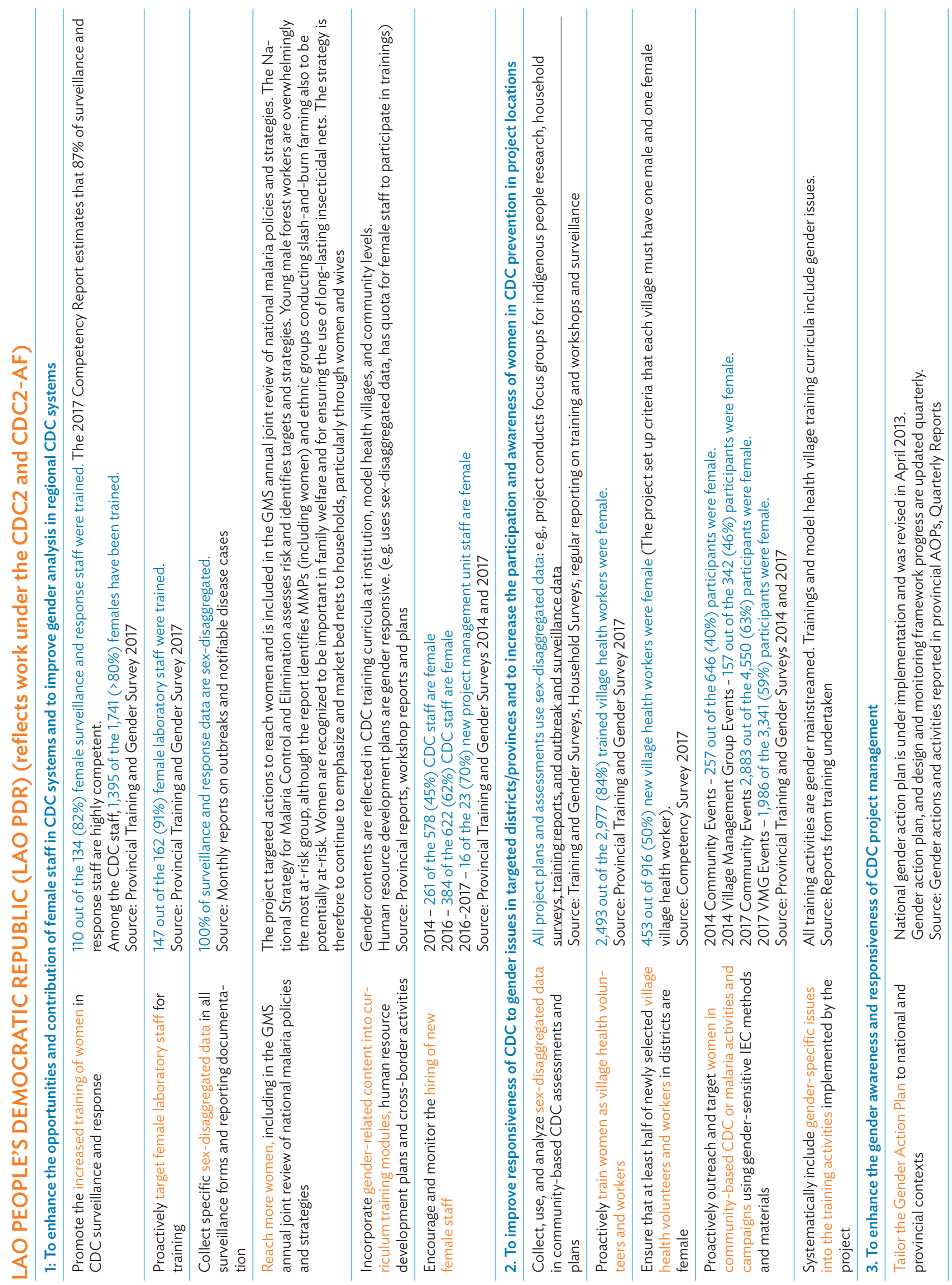




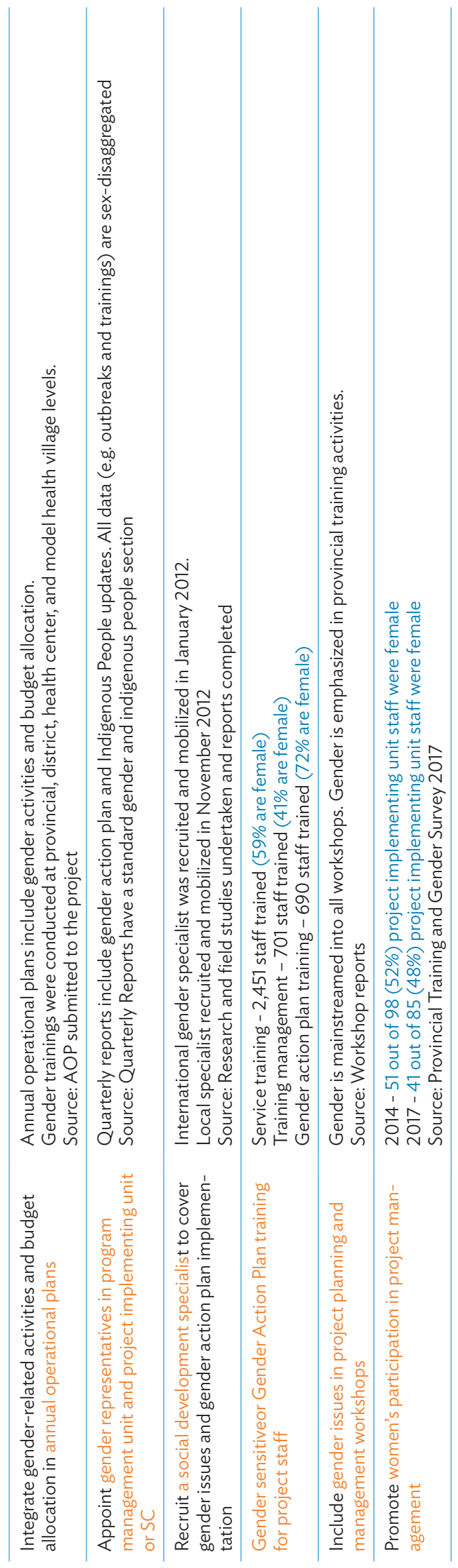




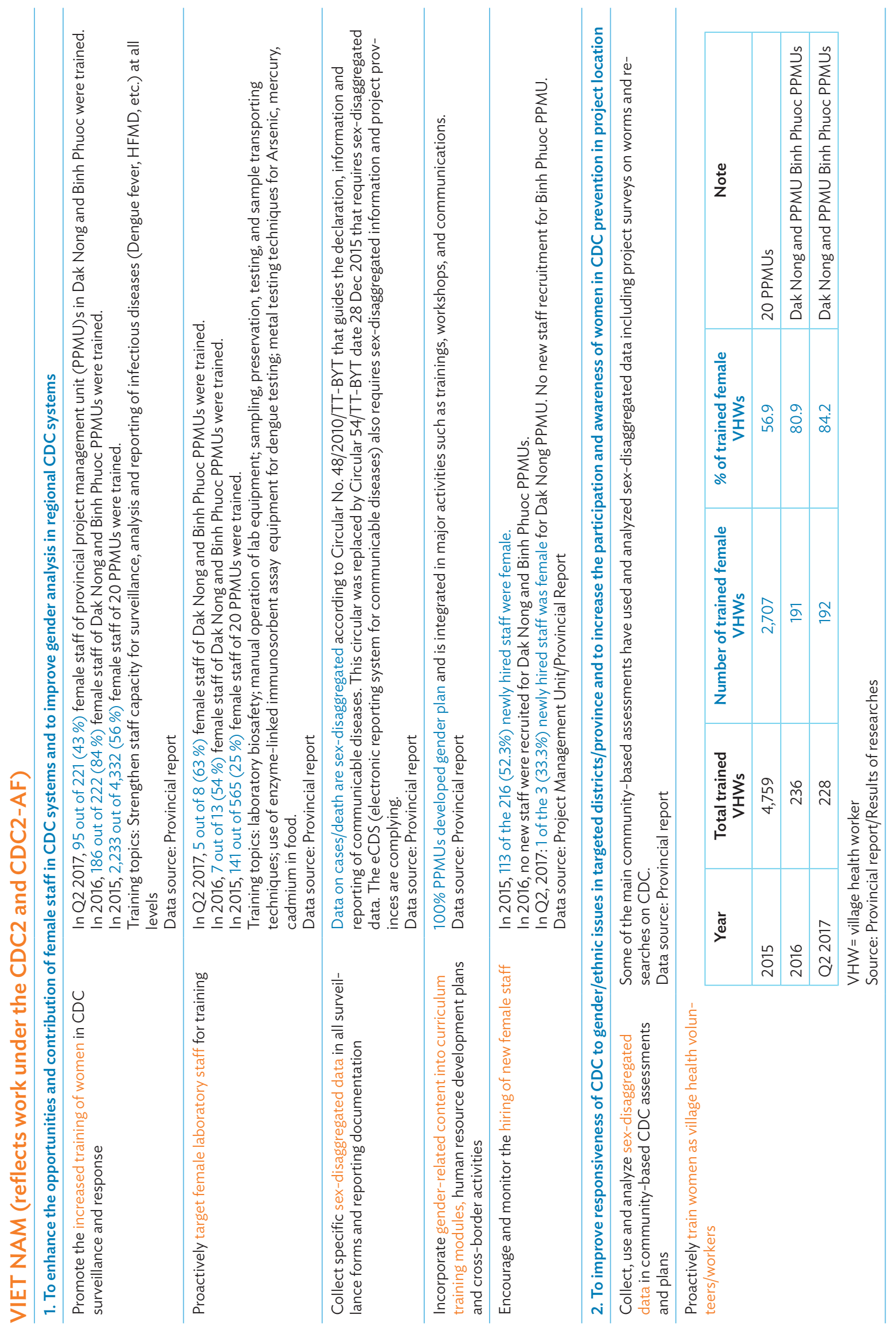




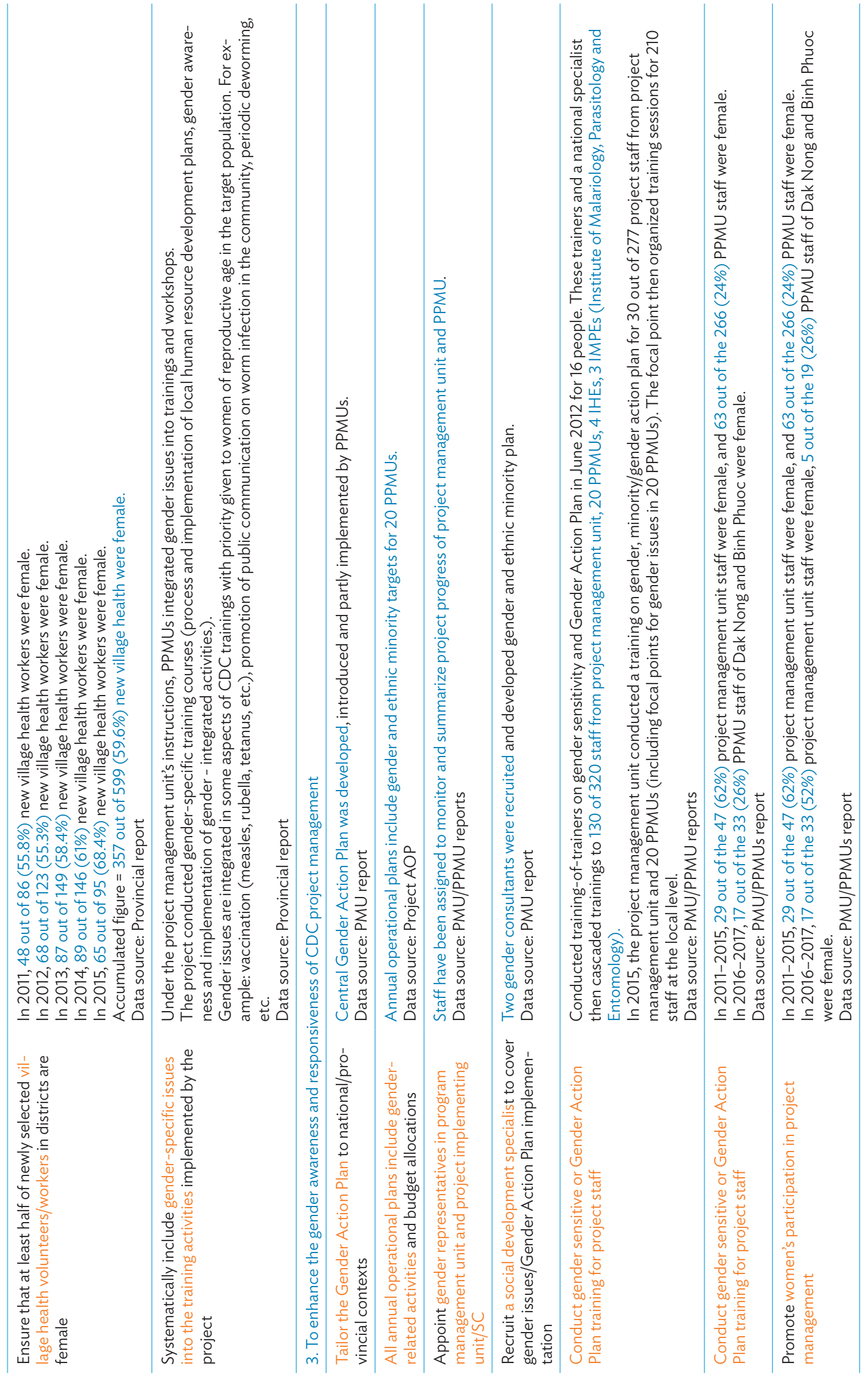




\title{
Annex D: Finance
}

\author{
ASIAN DEVELOPMENT BANK \\ ADMINISTRATOR FOR \\ REGIONAL MALARIA AND OTHER COMMUNICABLE DISEASE THREATS TRUST FUND
}

\author{
STATUS OF GRANT \\ AS OF 31 AUGUST 2018 \\ (EXPRESSED IN US DOLLARS)
}

\section{CONTRIBUTION RECEIVED:}

Government of Australia (DFAT)

$15,756,300$

Government of UKNI (DFID)

$12,414,880$

Government of Canada (DFATD)

531,916

NET CONTRIBUTION AVAILABLE

$28,703,096$

Investment Income

316,764

TOTAL AMOUNT AVAILABLE

$29,019,860$

\section{AMOUNT UTILIZED FOR:}

Outcome 1: Leadership

$(2,345,103)$

Outcome 2: Financing

Outcome 3: Medicines

$(3,116,152)$

Outcome 4: Information Systems

Outcome 5: Laboratory Dianostic and Surveillance

$(13,415,950)$

Outcome 6: Promotion and Prevention

$(3,387,604)$

Direct Charges

$(858,464)$

Administrative Costs, Audit, Financial Costs

$(1,445,695)$

$(28,334,157)$

UNUTILIZED BALANCE $685,703^{1 /}$

1/ Unutilized Balance

685,703

Less: DFATD/Canada Contribution

$(531,916)$

DFATD/Canada Investment Income

$(5,870)$

DFID/DFAT Unutilized Balance

147,917 


\section{Annex E: RMTF Recommendations for Management of Future Trust Funds}

- Background research is essential to ensure efforts are aligned with government needs and that they take into account the prevailing environment in terms of private sector and other agency involvement.

- Meeting donor reporting requirements is a key part of successful fund management, and it is useful to have donor involvement at the beginning, preferably at the country factfinding mission stage, so that data collection can be organized in a way that meets donor requirements. For the same reason, it is also important to involve an evaluation and monitoring expert from the outset.

- Delays due to constraints on counterparts should be anticipated and built into project design so that projects can evolve as circumstances change.

- Local counterpart and government champions can expedite projects and greatly increase their chance of success.
- International and locally based consultants have complementary skills and both are needed to achieve sustainable results.

- When working at the grassroots level, people and civil society organizations can be trusted to know the needs of local community, and are often the best placed to get results from interventions if they are genuinely involved from the planning stage onwards and empowered to take charge of projects.

- Innovation entails risk, and it should be expected that a proportion of projects will fail. Lessons should be shared.

- Close collaboration with development partners is important to avoid duplication, silos, and unsustainable results.

- It is common for some of the funds to be returned when a project ends, and this does not necessarily signal project failure. Sometimes activities are less expensive than anticipated. 


\section{Regional Malaria and Other Communicable Disease Threats Trust Fund}

\section{Final Report}

This report details the key achievements of the Regional Malaria and Other Communicable Disease Threats Trust Fund from its creation in 2013 to the first half of 2018. It provides detailed analysis of the results by outcome, profiles specific projects that serve as exemplars of the fund's impact, and offers insights into how similar trust funds can be managed for success in future.

\section{About the Asian Development Bank}

ADB is committed to achieving a prosperous, inclusive, resilient, and sustainable Asia and the Pacific, while sustaining its efforts to eradicate extreme poverty. Established in 1966, it is owned by 67 members -48 from the region. Its main instruments for helping its developing member countries are policy dialogue, loans, equity investments, guarantees, grants, and technical assistance. 